University of Tennessee Health Science Center

UTHSC Digital Commons

$12-2013$

\title{
Tetraspanin CD9: Contributions to Cancer Cell and Vascular Cell Phenotypes from the Sixth Man
}

\author{
Michael James Herr II \\ University of Tennessee Health Science Center
}

Follow this and additional works at: https://dc.uthsc.edu/dissertations

Part of the Neoplasms Commons

\section{Recommended Citation}

Herr, Michael James II , "Tetraspanin CD9: Contributions to Cancer Cell and Vascular Cell Phenotypes from the Sixth Man" (2013). Theses and Dissertations (ETD). Paper 126. http://dx.doi.org/10.21007/ etd.cghs.2013.0135.

This Dissertation is brought to you for free and open access by the College of Graduate Health Sciences at UTHSC Digital Commons. It has been accepted for inclusion in Theses and Dissertations (ETD) by an authorized administrator of UTHSC Digital Commons. For more information, please contact jwelch30@uthsc.edu. 


\title{
Tetraspanin CD9: Contributions to Cancer Cell and Vascular Cell Phenotypes from the Sixth Man
}

\author{
Abstract \\ Cancer and vascular disease are the two most predominant causes of mortality in the United States. \\ Potential regulatory mechanisms for these two diseases have consumed research interests. Tetraspanins \\ are cell surface proteins that organize the cell membrane. Cellular membrane organization is a \\ prerequisite for cellular signaling to occur. Deregulation of cellular signaling often precedes the formation \\ of cancer or vascular disease phenotypes. This insinuates the necessity to understand how tetraspanins \\ contribute to membrane organization and subsequent downstream signaling. This work examines \\ tetraspanin CD9 contributions in a model of cancer cell invasion and vascular cell contraction. The \\ findings presented here demonstrate that CD9 expression promotes human fibrosarcoma cell invasion by \\ upregulating matrixmetalloproteinase- 9 expression. These effects were dependent upon an extracellular \\ region of CD9 and involved the presence and activity of the epidermal growth factor receptor. In the \\ vascular cell model, CD9 elicited the actin arrangement and contraction of human aortic smooth muscle \\ cells in a RhoA dependent manner. Taken together these provide insight on how tetraspanins regulate \\ diverse cellular phenotypes.

\section{Document Type} \\ Dissertation \\ Degree Name \\ Doctor of Philosophy (PhD)

\section{Program} \\ Biomedical Sciences \\ Research Advisor \\ Lisa K. Jennings, Ph.D. \\ Keywords \\ Cancer Biology, CD9, Matrix Metalloproteinases, MMP-9, Tetraspanin, Vascular Biology

\section{Subject Categories} \\ Diseases | Medicine and Health Sciences | Neoplasms
}


Tetraspanin CD9: Contributions to Cancer Cell and Vascular Cell Phenotypes from the Sixth Man

\author{
A Dissertation \\ Presented for \\ The Graduate Studies Council \\ The University of Tennessee \\ Health Science Center
}

In Partial Fulfillment

Of the Requirements for the Degree

Doctor of Philosophy

From The University of Tennessee

By

Michael James Herr, II

December 2013 
Portions of Chapter 2 and 4 (C) by Public Library of Science.

Portions of Chapter 3 and 4 (C) by Biochemical and Biophysical Research Communications.

All other material @ 2013 by Michael James Herr, II.

All rights reserved. 


\section{DEDICATION}

This dissertation is dedicated to my loving wife, Ashley, and my parents, Michael and Clara Herr. Without their unconditional love, support, and motivation these pages would be blank. 


\section{ACKNOWLEDGEMENTS}

I would like to first acknowledge my mentor Dr. Lisa K. Jennings for providing me with an unparalleled learning environment. Without her total confidence, continual encouragement, and boundless expertise I would have relinquished this work. I would also like to thank my committee members Dr. John Cox, Dr. Malinda Fitzgerald, Dr. Karen Hasty, and Dr. Mitchell Watsky. Their guidance and advice resulted in my accomplishments as a graduate student. Dr. Jayaprakash Kotha initiated my laboratory career. His extraordinary patience and persistence provided me with the solid foundation on which this work began. I will continue to use the guidance these people have provided me throughout my entire scientific career.

I would like to acknowledge the medical students that worked in the laboratory with me during the summers. The technical support and comedic relief from Chuck Gomez, Eric Zhou, Nikolaus Hagedorn, Blake Smith, Lindsey Lands, and Scott Mabry got me though the long days in the laboratory. The technical help from Scott Mabry was especially exceptional and led to a strong finish of my graduate career. Jessica Jameson, an undergraduate summer student, was also very helpful in closing out my graduate studies.

I thank Shila Cholera and Dr. Henry Speich for being helpful laboratory colleagues. They both kept the laboratory going, my morale in check, and became great friends during this experience. I also thank Mary Holmes for staying in touch after our brief time together at the start of my studies. She served as a grandmother figure during my graduate experience and made sure that I knew I was going to graduate (eventually). Also, the non-tetraspanin love, support, and laughter from my friends Rob Coleman, Andrew Hamm, and Bailey Lipscomb helped me maintain a clear perspective on life during my time in the laboratory.

Finally, I would like to acknowledge Ashley Elliott Herr, my loving wife. We met at the beginning of my graduate career and were married near the end. I am so grateful for her unfailing love and emotional support, and I am so happy she stayed with me through this process! I acknowledge my parents, Michael and Clara Herr, for their support, love, and guidance throughout my entire life. I would not be where I am today without all of these people. For that, I am grateful. 


\begin{abstract}
Cancer and vascular disease are the two most predominant causes of mortality in the United States. Potential regulatory mechanisms for these two diseases have consumed research interests. Tetraspanins are cell surface proteins that organize the cell membrane. Cellular membrane organization is a prerequisite for cellular signaling to occur.

Deregulation of cellular signaling often precedes the formation of cancer or vascular disease phenotypes. This insinuates the necessity to understand how tetraspanins contribute to membrane organization and subsequent downstream signaling. This work examines tetraspanin CD9 contributions in a model of cancer cell invasion and vascular cell contraction. The findings presented here demonstrate that CD9 expression promotes human fibrosarcoma cell invasion by upregulating matrixmetalloproteinase- 9 expression. These effects were dependent upon an extracellular region of CD9 and involved the presence and activity of the epidermal growth factor receptor. In the vascular cell model, CD9 elicited the actin arrangement and contraction of human aortic smooth muscle cells in a RhoA dependent manner. Taken together these provide insight on how tetraspanins regulate diverse cellular phenotypes.
\end{abstract}




\section{PREFACE}

Sixth man \'siksth 'man \noun. Basketball. 1. a player who is not a starter but comes off the bench much more often than other reserves 2 . the first player to be substituted in a game 3. a player that plays minutes equal to or exceeding some of the starters and posts similar statistics. 4. often a player who can play multiple positions.*

*Adapted with permission from http://en.wikipedia.org/wiki/Sixth man 


\section{TABLE OF CONTENTS}

CHAPTER 1. TETRASPANINS ..................................................................................

The Importance of Membrane Organization .......................................................... 1

Tetraspanin Features and History ...................................................................... 1

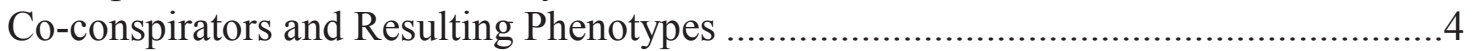

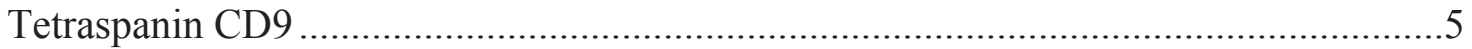

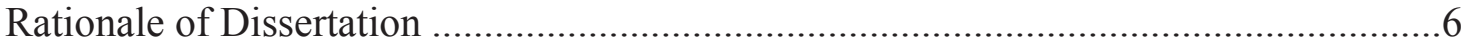

\section{CHAPTER 2. TETRASPANIN CD9 PROMOTES THE INVASIVE PHENOTYPE OF HUMAN FIBROSARCOMA CELLS VIA \\ UPREGULATION OF MATRIX METALLOPROTEINASE-9...............................7}

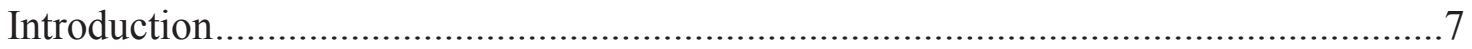

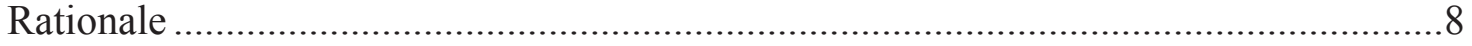

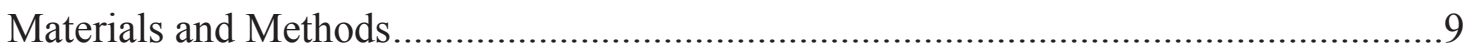

Reagents and Antibodies.................................................................................... 9

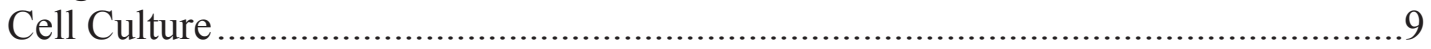

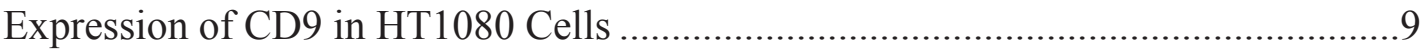

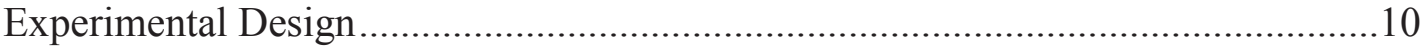

RNA Extraction and qRT PCR Analysis ............................................................ 10

Gelatin Zymography ..................................................................................... 10

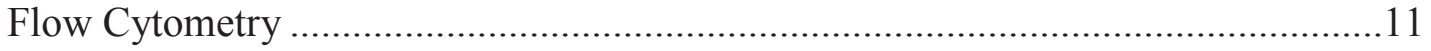

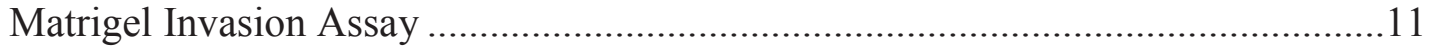

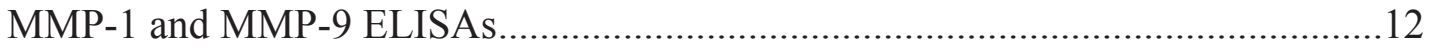

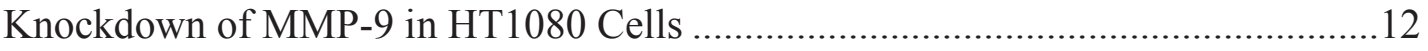

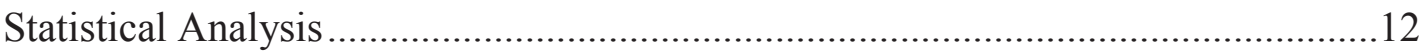

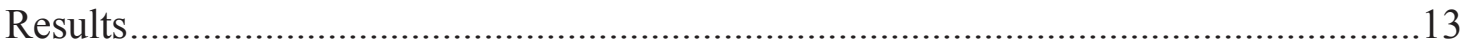

CD9 Overexpression in HT1080 Cells Did Not Alter the Expression of Other

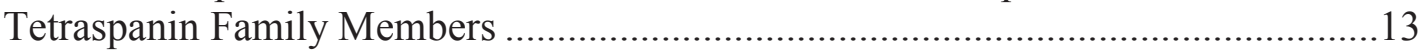

CD9-HT1080 Cells Have Increased Cell Invasion and MMP-9 Production and

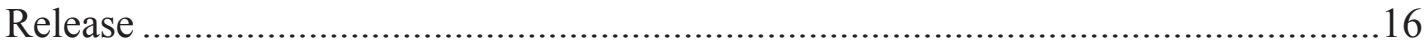

Increased CD9-HT1080 Cell Invasion Is a Consequence of Increased MMP-9 .......19

CD9 Second Extracellular Loop Contributes to Increases in MMP-9 Expression....21

\section{CHAPTER 3. PRO-MMP-9 UPREGULATION IN HT1080 CELLS EXPRESSING CD9 IS REGULATED BY EPIDERMAL GROWTH FACTOR

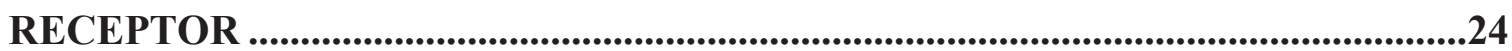

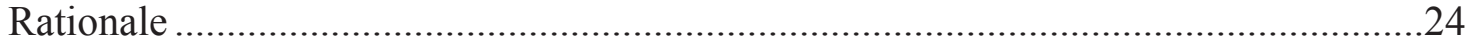

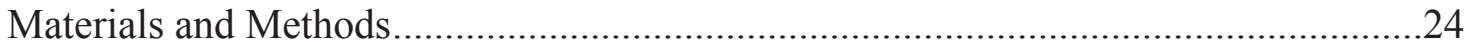

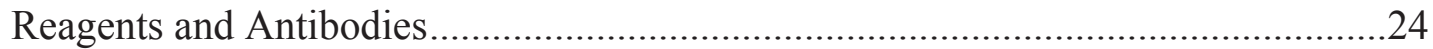

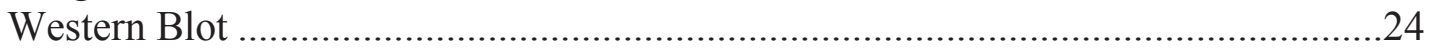

Receptor Tyrosine Kinase Inhibitor Treatment .................................................25

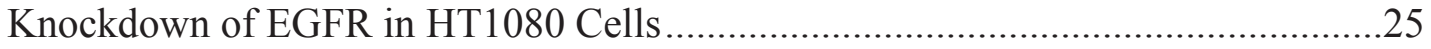

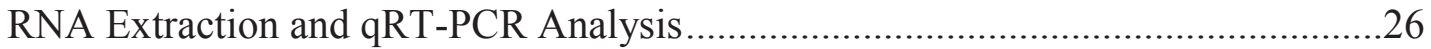

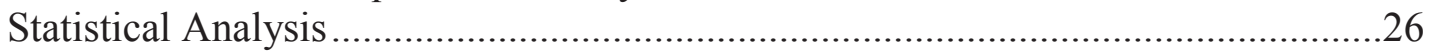




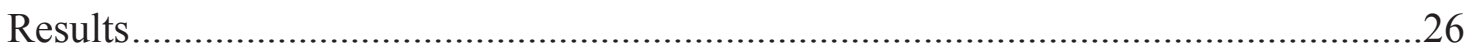

Inhibiting EGFR Signaling Decreases Pro-MMP-9 Release from CD9-HT1080

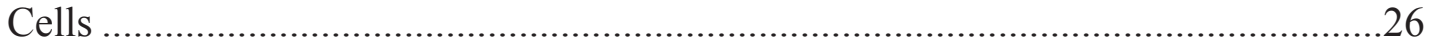

Knockdown of EGFR in CD9-HT1080 Cells Attenuates the Release of Pro-

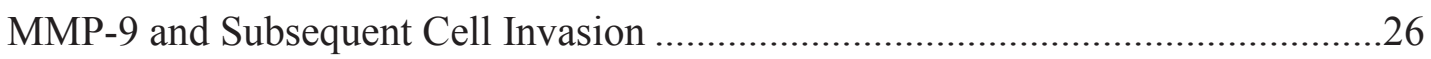

CHAPTER 4. CD9 CONTRIBUTIONS TO CANCER CELL BIOLOGY . .31

\section{CHAPTER 5. TETRASPANIN CD9 REGULATES CELL CONTRACTION AND ACTIN ARRANGEMENT IN HUMAN AORTIC SMOOTH MUSCLE

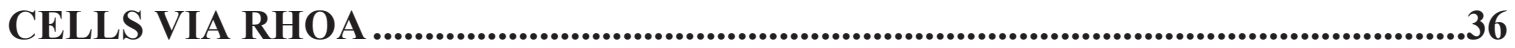

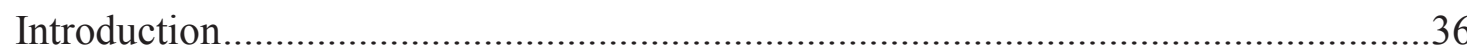

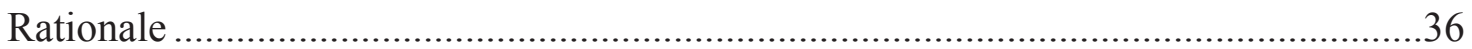

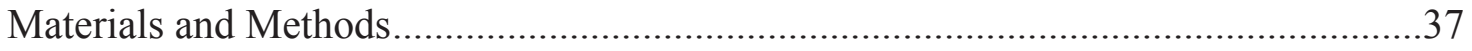

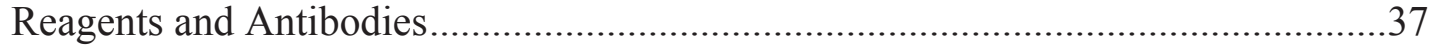

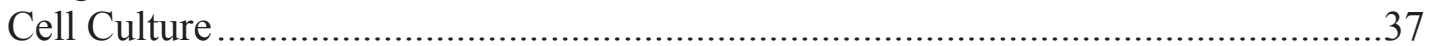

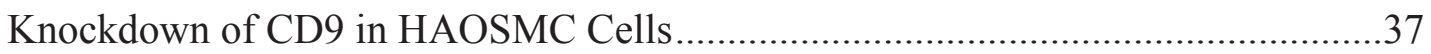

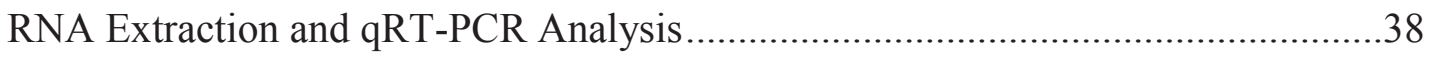

Knockdown of RhoA in HAOSMCs ..................................................................

Measurement of the Area of Crystal Violet Stained Cells...........................................38

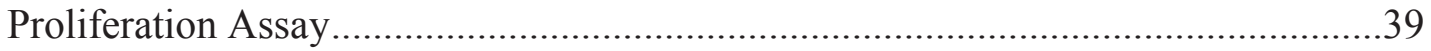

Immunofluorescent Staining of F-actin ..................................................................39

Detection of Total and GTP-Bound RhoA …………….........................................

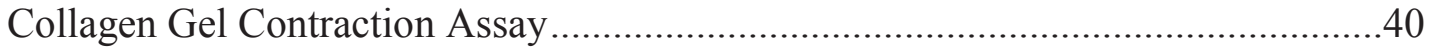

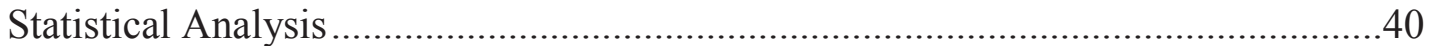

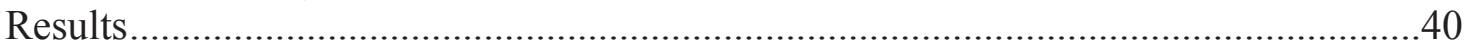

CD9 Deficiency Results in Altered Cell Morphology, Proliferation, and SMC

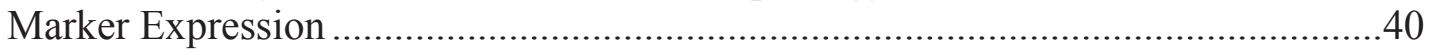

CD9 Deficient HAOSMC Have Altered Actin Arrangement and Decreased Contractile Capabilities because of RhoA-Mediated Pathways ..................................42

Activation of RhoA Restores the CD9 shRNA HAOSMC Phenotype.......................45

Deficiency of Active RhoA or Loss of Total RhoA Mimics the CD9 shRNA

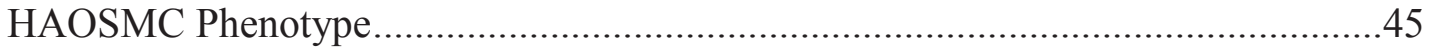

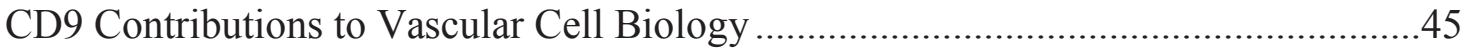

CHAPTER 6. INSIGHTS INTO CD9 FUNCTION FROM THESE TWO

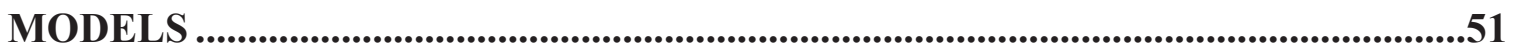

CHAPTER 7. FUTURE DIRECTIONS ...........................................................................54

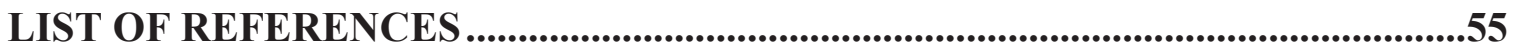

APPENDIX A. QRT-PCR PRIMERS ..........................................................................72

APPENDIX B. SUPPLEMENTARY FIGURES FROM CHAPTERS 5 AND $6 . . . . . .75$

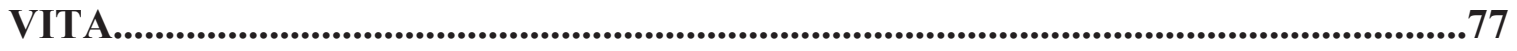




\section{LIST OF FIGURES}

Figure 1-1. Proposed full-length structure of tetraspanin CD9 .........................................

Figure 2-1. Overexpression of CD9 in HT1080 cells does not alter the expression of other tetraspanins.

Figure 2-2. CD9-HT1080 cells have stable mRNA expression of integrins though $\alpha 2$ and $\beta 1$ are reduced at the cell surface.

Figure 2-3. The invasive phenotype of HT1080 cells is increased upon CD9 overexpression.

Figure 2-4. MMP-9 expression and release are greatly enhanced in CD9-HT1080 cells.

Figure 2-5. Silencing MMP-9 in CD9-HT1080 cells is sufficient to suppress the invasive phenotype.

Figure 2-6. Characterization of the second extracellular loop (EC2) deletion mutant of CD9 in HT1080 cells.

Figure 2-7. An increase in MMP-9 expression and release and subsequent cell invasion requires the second extracellular loop (EC2) of CD9.

Figure 3-1. CD9-HT1080 cells release less pro-MMP-9 after treatment with a broad spectrum receptor tyrosine kinase inhibitor sunitinib.

Figure 3-2. Epidermal growth factor receptor tyrosine kinase inhibitors reduce the expression of pro-MMP-9 and inhibit CD9-HT1080 cell invasion.

Figure 3-3. Knockdown of EGFR results in decreased pro-MMP-9 expression and release without affecting the expression or localization of CD9.

Figure 5-1. Knockdown of tetraspanin CD9 in human aortic smooth muscle cells (HAOSMCs) does not affect CD81 or CD151 cell-surface expression........41

Figure 5-2. CD9 deficient HAOSMCs have an altered cell morphology, decreased cell size and proliferation, and an increased level of calponin mRNA.

Figure 5-3. HAOSMCs lacking CD9 display altered actin arrangement and a decrease in active RhoA and collagen gel contraction.

Figure 5-4. Activation of RhoA restores the contractile capabilities of CD9 shRNA HAOSMC and partially restores actin arrangement.

Figure 5-5. Suppression of active RhoA or knockdown of total RhoA in HAOSMC mimics the phenotype of CD9 shRNA HAOSMC. 
Figure 6-1. The proposed CD9 signaling pathway derived from both model systems. ..53

Figure B-1. Expression of microRNAs between Ctr and CD9 shRNA HAOSMC. ........75

Figure B-2. The expression of integrin $\alpha 5$ and $\beta 1$ subunits on the cell surface of

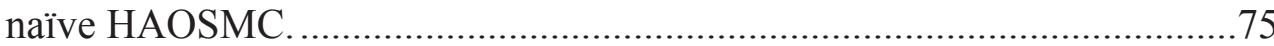

Figure B-3. Inhibition of pro-MMP-9 gelatinolytic activity by LY294002, U0126,

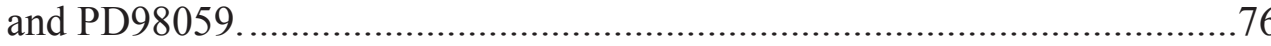




\section{LIST OF ABBREVIATIONS}

$\begin{array}{ll}\text { BrdU } & \text { Bromodeoxyuridine } \\ \text { BSA } & \text { Bovine Serum Albumin } \\ \text { CD } & \text { Cluster of Differentiation } \\ \text { cDNA } & \text { Copy Deoxyribonucleic Acid } \\ \text { CHO } & \text { Chinese Hamster Ovary } \\ \text { CN03 } & \text { RhoA Activator } \\ \text { CT } & \text { Cycle Threshold } \\ \text { CT04 } & \text { RhoA Inhibitor (C3 Transferase) } \\ \text { Ctr } & \text { Scrambled Control } \\ \text { DAR } & \text { Donkey Anti-Rabbit } \\ \text { DMEM } & \text { Dulbecco's Modified Eagle's Medium } \\ \text { EC1 } & \text { Extracellular Loop 1 } \\ \text { EC2 } & \text { Extracellular Loop2 } \\ \text { ECM } & \text { Extracellular Matrix } \\ \text { EGF } & \text { Epidermal Growth Factor } \\ \text { EGFR } & \text { Epidermal Growth Factor Receptor } \\ \text { ELISA } & \text { Enzyme-Linked Immunosorbent Assay } \\ \text { ERK } & \text { Extracellular Signal-Regulated Kinase } \\ \text { ERM } & \text { Ezrin-Radixin-Moesin } \\ \text { FAK } & \text { Focal Adhesion Kinase } \\ \text { FBS } & \text { Fetal Bovine Serum } \\ \text { FITC } & \text { Fluorescein Isothiocyanate } \\ \text { FN } & \text { Fibronectin } \\ \text { G418 } & \text { Geneticin } \\ \text { GAM } & \text { Goat Anti-Mouse } \\ \text { GAR } & \text { Goat Anti-Rabbit } \\ \text { GS } & \text { Goat Serum } \\ \text { HAOSMC } & \text { Human Aortic Smooth Muscle Cell } \\ \text { HEK293 } & \text { Human Embryonic Kidney Cells } \\ \text { HRP } & \text { Horseradish Peroxidase } \\ \text { HT1080 } & \text { Human Fibrosarcoma } \\ \text { Ig } & \text { Immunoglobulin } \\ \text { IL } & \text { Interleukin } \\ \text { mAb } & \text { Monoclonal Antibody } \\ \text { MAPK } & \text { Mitogen-Activated Protein Kinase } \\ \text { MMP } & \text { Matrix Metalloproteinase } \\ \text { mRNA } & \text { Messenger RNA } \\ \text { NSCLC } & \text { Non-Small Cell Lung Cancer } \\ \text { PBS } & \text { Phosphate Buffered Saline } \\ \text { PI3-K } & \text { Phosphatidylinositol-3 Kinase } \\ \text { PKC } & \text { Pretein Kinase C } \\ \text { PSG } & \text { Pluoride } \\ \text { PVDF } & \end{array}$




$\begin{array}{ll}\text { qRT-PCR } & \text { Quantitative Real-Time Polymerase Chain Reaction } \\ \text { SDS } & \text { Sodium Dodecyl Sulfate } \\ \text { shRNA } & \text { Short Hairpin Ribonucleic Acid } \\ \text { siRNA } & \text { Small Interfering Ribonucleic Acid } \\ \text { SmBM } & \text { Smooth Muscle Basal Medium } \\ \text { SMC } & \text { Smooth Muscle Cell } \\ \text { TBST } & \text { Tris Buffered Saline with Tween-20 } \\ \text { TGF } \alpha & \text { Transforming Growth Factor } \alpha \\ \text { TIMP } & \text { Tissue Inhibitor of Metalloproteinase } \\ \text { TM } & \text { Transmembrane } \\ \text { UTHSC } & \text { University of Tennessee Health Science Center }\end{array}$




\section{CHAPTER 1. TETRASPANINS}

\section{The Importance of Membrane Organization}

The elaborately regulated process of cellular signaling depends upon membrane organization. Transmembrane proteins form multimolecular complexes to relay information from the extracellular environment into the cell. Deregulation of cellular signaling precedes numerous pathologic events; therefore, thorough understanding of membrane organization and its effects is necessary. Of the countless proteins that regulate membrane organization, tetraspanins are a relatively new member with alluring contributions. This dissertation focuses specifically on the functions of one tetraspanin, CD9, in two model systems. The material presented here details how CD9 influences cancer and vascular cell phenotypes by assuming the position of a sixth man. This comparison personifies the incredible auxiliary role CD9 plays in the regulation of cellular phenotypes.

\section{Tetraspanin Features and History}

Tetraspanins are a group of 32 distinct mammalian proteins consisting of four transmembrane domains. These hydrophobic domains traverse the cell membrane resulting in intracellular amino- and carboxy- termini (Figure 1-1). These termini are on average 9 to 40 amino acids in length, as determined by comparison of tetraspanin family members [1]. Extracellularly, tetraspanins feature two loops of varying size. The first extracellular loop (EC1) between the first and second transmembrane domain is approximately 22 amino acids in length. The second, much larger, extracellular loop (EC2) between the third and fourth transmembrane domain contains 69 to132 amino acids and is subdivided into constant and variable regions [2]. The intracellular loop located between EC1 and EC2 is a mere 4 amino acids in length [1]. All tetraspanins exhibit full conservation of a cysteine-cysteine-glycine amino acid motif and two further downstream cysteines in their EC2. This feature distinguishes them from other four transmembrane proteins and contributes to the formation of disulfide bonds in the EC2 variable region. The resulting three dimensional conformation of the EC2 is unique for each tetraspanin, and has been utilized to generate highly specific and functional monoclonal antibodies (mAbs). Transmembrane proteins are inherently difficult to purify and stabilize for crystallography analysis. Consequently, little is known about the fulllength structural features of tetraspanins. Crystallographic studies have been conducted only on a homodimerized EC2 of CD81 $[3,4]$. These studies provided novel insight into the subdomain patterns of CD81 EC2; however, the structure of other tetraspanins to date is entirely speculative.

Tetraspanins were discovered in the 1980s. The first member was discovered using the mAb BA-2 on the leukemic cell line NALM-6 [5]. This antigen was termed p24 antigen as an allusion to its molecular weight of 24 kilodaltons [5]. p24 was found to be highly expressed on the cell surface of a variety of cells using different, specific mAbs 


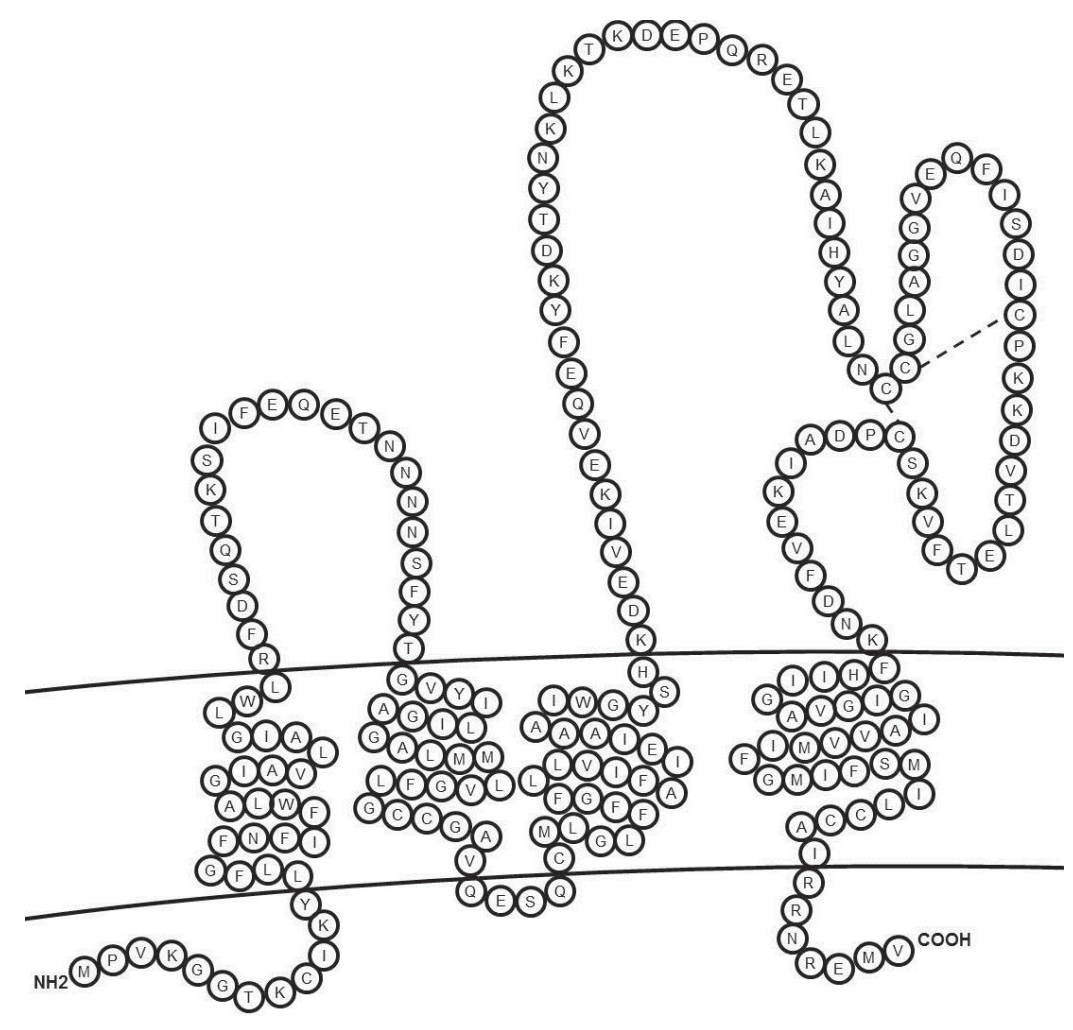

Figure 1-1. Proposed full-length structure of tetraspanin CD9.

and immunofluorescent assays [6-9]. The p24 nomenclature was changed to cluster of differentiation 9 (CD9) in 1984 at the First International Workshop on Leukocyte Differentiation Antigens [10].The Jennings' laboratory were the first to report the molecular cloning and sequencing of full-length cDNA for p24/CD9 in 1991 [11].The gene encoding CD9 is located on chromosome 12p and consists of eight exons spanning an approximately $20 \mathrm{kB}$ region of the human genome. Transcription generates a $1.4 \mathrm{~Kb}$ mRNA that translates to a protein of 228 amino acids with a calculated molecular weight of $24 \mathrm{kDa}$ [11]. Figure 1-1 details the predicted structure of full-length CD9 within the cell membrane. These discoveries initiated interest in tetraspanins as a novel cell-surface marker.

After decades of work, tetraspanins were found to be ubiquitously expressed in the majority of mammalian cells and tissues, yet their function was somewhat elusive. Cell surface proteins that participate in cellular signaling largely operate by a receptorligand interaction. Tetraspanins are unique in that only two members of the entire family, CD9 and CD81, exhibit some interaction with ligands. CD9 serves as a receptor for pregnancy-specific glycoprotein 17 (PSG17) [12]. PSGs are a group of soluble proteins secreted by the placenta to regulate cytokine production during pregnancy [13]. Binding of PSG17 to CD9 on macrophages induced the secretion of anti-inflammatory cytokines IL-10, IL-6, PGE2, and TGF- $\beta 1$, and was blocked by PKC inhibition [14]. The interaction between CD9 and PSG17 was fascinating and may have potentially served as 
a paradigm for how CD9 functions. However, the benefits or consequences of this interaction are not understood. There has not been any further exploration of this phenomenon in mouse models, and PSG17 is not expressed in humans. In another example, the hepatitis C virus envelope glycoprotein E2 bound to CD81 as determined by intensive studies involving amino acid mutations, peptide mapping, and monoclonal antibody treatments [15]. It was concluded that E2 binds the EC2 of CD81 to facilitate viral entry into cells $[16,17]$. Although evidence for E2 binding CD81 is very convincing, viral binding and entry into cells is multifaceted; therefore, the relevance of this interaction is not entirely clear. Accordingly, the idea that tetraspanins function as cell surface receptors aside from these two examples has not been widely pursued.

Despite the blatant scarcity of ligand interactions, there is plenty of evidence that suggest tetraspanins regulate multiple essential cellular events including proliferation, migration, and metastasis. Less than half of the 32 tetraspanins have been adequately scrutinized for their contributions to these processes. Genetic analysis in mice has revealed the EC2 and their ability to form complexes with other membrane proteins to be fundamental for tetraspanin function [18]. Membrane partner proteins for tetraspanins were found to include integrins, Ig superfamily proteins, transmembrane receptors, and signaling enzymes [19]. These interactions were initially determined using cell lysis detergents that fail to completely solubilize tetraspanins followed by coimmunoprecipitation experiments [20]. The use of low stringency detergents (e.g. 1\% Brij 99 or CHAPS) led to the downstream analysis of rather large complexes, which resulted in a lack of conclusive evidence for direct interactions. Consequently, tetraspanin interactions with other membrane proteins are now more scrupulously considered to be primary, secondary, or tertiary.

Primary interactions are formed between tetraspanins and non-tetraspanin partners [21]. These interactions demonstrate high stoichiometry, are detected under stringent lysis buffer conditions (e.g. $1 \%$ Triton X-100 or $1 \%$ NP-40), and retain the ability to be stabilized by covalent crosslinking [20]. These stipulations would appear to limit the number and complexity of primary tetraspanin interactions. However, these interactions are grossly convoluted by the fact that they may differ depending on cell type and may associate at different regions of the tetraspanin [21]. For example, CD81 associates with the Ig superfamily protein CD19 in B cells [22], but associates with CD4 and CD8 in T cells [23]. Additionally, CD81 associates with CD19 extracellularly [24, 25] and with EWI-2 intracellularly [26, 27]. Hence, tetraspanin primary interactions are direct but diverse and only begin to confound tetraspanin association with other partner proteins

Secondary and tertiary tetraspanin interactions are defined by their existence in either mild (e.g. 1\% Brij 96 or 1\% Brij 97) or low stringency detergents (e.g. 1\% CHAPS), respectively [21]. Secondary interactions include tetraspanin-tetraspanin associations into homo- or hetero-multimers [28]. These interactions are strengthened by the presence of divalent cations and are dependent upon palmitoylation of juxtamembrane cysteines as determined by site directed mutagenesis [29, 30]. The addition of palmitic acid strengthens tetraspanin association with the hydrophobic cell membrane and ancillary protein interactions [30]. CD9 association with CD81 is 
abolished upon the mutation of juxtamembrane cysteines in CD9 thus providing strong evidence for the importance of palmitoylation in the formation of tetraspanin complexes [30]. Secondary interactions depend on more than the sole presence of tetraspanins and partner proteins on the cell surface, and, unlike primary interactions, are not highly stoichiometric [21]. Tertiary interactions simply represent additional proteins associated with tetraspanins under low stringency buffer conditions. Taken together, primary, secondary, and tertiary interactions result in the formation of membrane microdomains called tetraspanin webs [31] or tetraspanin-enriched microdomains [32]. The formation of these complexes illustrates how tetraspanins may regulate cellular phenotypes. As a consequence of these interactions it becomes difficult to pinpoint the exact contributions of a particular tetraspanin.

\section{Co-conspirators and Resulting Phenotypes}

Integrins are the most characterized and essential cell surface partner to tetraspanins. Integrins are heterodimers of one $\alpha$ and one $\beta$ subunit that primarily function to bind cells to extracellular matrix (ECM). There are 18 different $\alpha$ and 8 different $\beta$ subunits. The majority of the $\alpha$ and $\beta$ subunits are followed by Arabic numerals for distinction. Of the greater than 40,000 potential heterodimer combinations, only 24 have been reported in mammalian cells. These 24 distinct combinations are widely expressed and contribute to integrin specificity for certain ECM ligands [33]. Upon binding ECM, integrins may relay messages to the cell to promote or inhibit several cellular activities including apoptosis, adhesion, and migration [34,35]. It is not a coincidence that processes attributed to integrin function are similar to those attributed to tetraspanins. Numerous reports have determined that tetraspanins function primarily by their association and ability to manipulate integrin activities.

Specific complexes of tetraspanins with $\beta 1$ integrins modulate integrin-mediated cellular phenotypes [36-38]. The tetraspanin CD151 EC2 primary interaction with the integrin $\alpha 3 \beta 1$ is arguably the most characterized tetraspanin-integrin interaction $[39,40]$. CD151 and $\alpha 3 \beta 1$ associate in a high stoichiometric ratio approaching 1:1 and are able to be covalently crosslinked [41-43]. Treatment with monoclonal anti-CD151 inhibitory antibodies resulted in the increased adhesion and decreased migration and invasion when plated on laminin, an $\alpha 3 \beta 1$ integrin ligand [36, 44]. These effects were not apparent on fibronectin, a ligand for $\alpha 5 \beta 1[36,44]$. The same outcomes were observed using monoclonal anti- $\alpha 3$ antibodies [44]. Notably, $\alpha 3 \beta 1$ expression in the absence of CD151 has not been observed [20]. It has been hypothesized that CD151 may be required for $\alpha 3 \beta 1$ cell surface expression due to their association in early biogenesis within the endoplasmic reticulum $[39,43]$. This interaction may depend on the tyrosine (Y)-based sorting motif found at the C-terminus of CD151 [45]. This YXX $\phi$ motif, where $\mathrm{X}$ is any amino acid and $\phi$ is a hydrophobic amino acid, is also found in two other tetraspanins, CD63 and CD82, and is required for endosomal and lysosomal recycling pathways [46, 47]. CD151 associates with both CD9 and CD81 [48, 49]. As a result, CD151 association with $\alpha 3 \beta 1$ links CD9 and CD81 to $\alpha 3 \beta 1$ [50]. The loss of CD151 expression dissolved these interactions and blocked $\alpha 3 \beta 1$-dependent cell motility [50]. Likewise, knockdown 
of CD9 or CD81, or treatment with Gö6976, a PKC inhibitor, inhibited cell motility [50]. This indicates that CD9 and CD81 promote $\alpha 3 \beta 1$-dependent cell motility through a integrin-tetraspanin-PKC dependent pathway [50]. The interaction between CD151 and $\alpha 3 \beta 1$ and the consequences of this interaction provides insight for how tetraspanins and integrins may work collectively to either promote or inhibit cellular phenotypes.

Ig superfamily proteins also associate with tetraspanins. EWI-2 and EWI-F appear to be the most significant Ig superfamily partners. Both proteins contain a glutamic acidtryptophan-isoleucine motif not apparent in other Ig superfamily proteins [27]. EWI-2 and EWI-F form primary interactions with CD9 and CD81 independently as suggested by EWI-2/-F-CD9 and EWI-2/-F-CD81 high stoichiometry and cross linking experiments [27]. These associations may link CD9 and CD81 to ezrin-radixin-moesin (ERM) proteins as EWI-2/-F co-localized and co-immunoprecipitated with ERM proteins [51]. EWI-2 siRNA treatment resulted in increased cell migration and polarity and increased the phosphorylation of ERM [51]. CD9 and CD81 may negatively regulate cell migration by helping link EWI-2 to ERM proteins [51]. The associations with integrins and Ig superfamily proteins provide a mechanism for how tetraspanins regulate cellular phenotypes.

\section{Tetraspanin CD9}

Conclusive evidence of tetraspanin function was predominantly achieved in one of three ways: 1) knockout mice, 2) functional antibody analyses, or 3) knockdown or overexpression experiments. The first tetraspanin knockout mice generated were for tetraspanin CD9 [52-54]. These mice were viable and only suffered from significantly reduced female fertility [52-54]. The lack in fertility was attributed to the inability of sperm to fuse with CD9 deficient ova [52]. The unexceptional phenotype of CD9-/- mice was not entirely without merit. It was discovered that CD81-/- mice demonstrated similarly diminished female fertility [55]. Sequence alignment studies of CD9 and CD81 provided evidence for potentially overlapping functions between these two proteins. This gave rise to the hypothesis that some tetraspanins may compensate in the absence of others.

Sequence alignment provides some cause to separately consider mouse and human CD9 findings. Although the two are $89 \%$ identical, $23 \%$ of their differences lie in the EC2 of CD9 [56]. Further dissection of EC2 into constant and variable regions increases the percentage of difference between mouse and human CD9 to $32 \%$ in the variable region. This marginal difference is intensified by two details. First, the spermegg fusion properties attributed to mouse CD9 were mapped to residues SFQ (173-175) [57] which align with the human residues TFT (175-177). The non-conservative glutamine to threonine switch in the third position is distinguishing; however, the expression of human CD9 in CD9-/- mouse oocytes repaired sperm-egg fusion to $90 \%$ suggesting the switch is trivial and not associated with a phenotypic change. Second, the association of CD9 to heparin-binding EGF-like growth factor (HB-EGF) was dependent upon three human CD9 residues G158, V159, and T175 [58]. The expression of human 
and monkey CD9 upregulated the binding of diphtheria toxin to cells as a consequence of CD9-pro-HB-EGF association. Mouse CD9 expression did not have the same result. The corresponding required residues in mouse CD9 are P156, L157, and S173. The valine to leucine and threonine to serine are conservative changes that most likely do not contribute to differences in mouse and human CD9. However, the glycine to proline switch is the most pronounced, non-conservative difference. This proline is absent when human CD9 restores the sperm-egg fusion properties in CD9-/- mice, thus the fusion abilities of CD9 are likely influenced independently of this proline residue. Nevertheless, the proline at position 156 in mouse CD9 plausibly distinguishes the functions of mouse and human CD9 in some phenotypes.

\section{Rationale of Dissertation}

As a result of the previous findings regarding tetraspanins, this body of work will focus specifically on the functions of one tetraspanin, CD9, in two well-defined human model systems. This dissertation is divided into two sections. The first section, Chapters 2 through 4, details the function of CD9 in a cancer cell biology model of invasion. The second section, Chapter 5, details the function of CD9 in a vascular biology model of contraction. Chapter 6 is discussion of how the findings in both model systems may overlap. 


\section{CHAPTER 2. TETRASPANIN CD9 PROMOTES THE INVASIVE PHENOTYPE OF HUMAN FIBROSARCOMA CELLS VIA UPREGULATION OF MATRIX METALLOPROTEINASE-9*}

\section{Introduction}

Tetraspanins' role in proliferation, migration, and invasion led to their implication in the pathogenesis of tumor cell metastasis. The effects tetraspanins have on multiple cell phenotypes provide an assortment of possibilities for them to regulate cancer cell metastasis. Anti-CD151 blocking antibodies repressed metastasis solely by inhibiting cell motility without affecting proliferation or EMC degradation [59]. Contrarily, expression of tetraspanin CO-029 increased intrahepatic metastasis without affecting tumor growth at the primary site [60]. This indicates that CO-029 expression affects invasion without affecting proliferation. Multiple other combinations of tetraspanin regulation quickly emerged and each tetraspanin was rapidly labeled as either a tumor suppressor or promoter based on study findings. Unfortunately, this simplification neglected to recall the diverse expression of tetraspanins on mammalian cells, their cell-type dependent interactions, and their hierarchy of membrane organization. As a result, some tetraspanin labels were muddled as they were found to be suppressors in one cell line and promoters in another. Tetraspanin function is now carefully considered in the context of the cell line(s) or model used to demonstrate the results.

Two tetraspanins - CD9 and CD151 - make the most prominent contributions to cancer cell biology $[61,62]$. There is a considerable amount of evidence indicating CD151 promotes metastasis and no evidence at the present indicating it suppresses metastasis $[61,63]$. CD151 overexpression is observed in many tumors including brain [64], breast [65], colon [66], lung [67], pancreas [68], and prostate [69]. Its

overexpression is associated with a poor prognosis [63]. CD151 is so tightly linked with metastasis that it was found to be a better prognosis predictor than histologic grading in primary prostate cancers [69]. CD9 on the other hand is noticeably labeled as a tumor suppressor [70-72]. Nonetheless, there is an increased amount of evidence that tips the balance and supports a role for CD9 in cancer metastasis [73-75]. In vivo studies suggested that increased CD9 expression correlated with advanced gastric cancer and a poor prognosis $[76,77]$. Another study conducted on prostatic carcinoma progression noted a significant increase in CD9 expression in primary, metastasizing adenocarcinoma compared to advanced, non-metastasizing adenocarcinomas [78]. Strong CD9 expression in histologic analysis of metastasizing cancers implies its significance in the metastatic capabilities of cancer cells.

Tetraspanins may specifically regulate the invasive properties of cancer cells by controlling the expression and release of matrix metalloproteinases (MMPs) and tissue

\footnotetext{
* Adapted with permission from Public Library of Science. Herr MJ, Kotha J, Hagedorn N, Smith B, Jennings LK (2013) Tetraspanin CD9 promotes the invasive phenotype of human fibrosarcoma cells via upregulation of matrix metalloproteinase-9. PLoS One 8: e67766.
} 
inhibitors of metalloproteinases (TIMPs). MMPs are a family of 23 mammalian zincdependent endopeptidases that facilitate the degradation of specific components of the ECM preceding cellular invasion [79-81]. The majority of MMPs are secreted as soluble, inactive proteins that have regulatory domains called pro-domains [80]. These prodomains may be cleaved off by other proteases in a series of regulated steps that result in their activation [82]. Other MMPs are membrane bound and may by regulated by their association with other membrane proteins [82]. There are four distinct TIMPs that endogenously regulate MMPs with varying specificity $[79,83]$. When first discovered as promoters of invasion, MMPs quickly became prominent pharmacologic targets to alleviate metastasis. Eventually, broad spectrum inhibitors were developed to regulate MMP activity in vivo. However, these inhibitors demonstrated lack of clinical efficacy and studies were discontinued primarily because pharmacological intervention after metastasis had occurred was futile [84-86]. Interest in MMP research has since shifted to finding other ways to regulate their expression, release, and activity prior to metastasis.

The regulation of MMP and TIMP activity by tetraspanins is a well-documented event. Expression of CD63 [87] and CD151 [88] are involved in the downregulation of MT1-MMP activity either by proteolysis or association, respectively. TIMP1 cell surface expression depends on CD63 expression and their association in human breast epithelial cells [89]. Furthermore, double deficiency of CD9 and CD81 resulted in increased amounts of MMP-2 and MMP-9 in a mouse macrophage cell line [90], and CD151 activated pro-MMP-7 in osteoarthritic chondrocytes [91]. CD151 expression and clustering led to the activation of $\alpha 3 \beta 1$ and $\alpha 6 \beta 1$ integrins which activated the FAK/Src/p38MAPK pathway [92]. This triggered cJun to bind AP-1 and increase MMP9 expression in CD151-deficient human melanoma cells [92]. Multiple cancerous cell lines expressing CD9 either endogenously or exogenously exhibited diminished cell motility [70, 93, 94]; however, there is notable ambiguity on the effect CD9 expression may have on the invasive cell phenotype by regulating MMP and TIMP production. In keratinocytes, CD9 and MMP-9 expression were indirectly related [94]. Similarly, CD9null mice experience significant wound healing delay due to increased MMP-9 expression in an in vivo wound healing model [95]. In human melanoma cells CD9 expression induced the expression of MMP-2 and inhibited MMP-9 [96]. In contrast, CD9 expression in a small cell lung cancer cell line suppressed MMP-2 expression [97]. Thorough analysis of tetraspanin web components, MMP expression, and a clear distinction between migration and invasion in a cell-specific context is lacking. Thus, CD9-specific effects on MMP expression and cellular invasion is somewhat ambiguous.

\section{Rationale}

Human fibrosarcoma (HT1080) cells are a highly invasive cell line commonly used as an in vitro model of metastasis [98-101]. These cells endogenously express low levels of the tetraspanin CD9. It was explored whether or not CD9 overexpression had any phenotypic effect on HT1080 cell invasion to better understand the contribution of CD9 to metastasis. 


\section{Materials and Methods}

\section{Reagents and Antibodies}

Dulbecco's Modified Eagle's Medium (DMEM), fetal bovine serum (FBS), goat serum (GS), penicillin-streptomycin, Geneticin (G418), full-length human plasma fibronectin (FN), and phosphate buffered saline (PBS; $\mathrm{pH} 7.4$ ) were purchased from Gibco (Grand Island, NY). Antibodies to anti-human CD9 EC2 (mAb7) were generated prior to this work and was previously described [102]. A rabbit polyclonal antibody specific for the first extracellular loop of CD9 (Rap2) was also previously generated and described [103]. Anti-human $\alpha 2$ antibody (mAb1950Z) was purchased from Millipore (Temecula, CA). Anti-human CD81 (sc-7637), $\alpha 4$ (sc-6589), $\alpha 5$ (sc-13547), $\alpha 6$ (sc13542), and $\beta 1$ (sc-53711) were purchased from Santa Cruz Biotechnology (Santa Cruz, CA), anti-human CD63 (\#566019) and anti-human CD151 (\#556056) were purchased from BD Biosciences (Durham, NC). Polybrene, puromycin, and anti-human $\beta$-tubulin (T2200), IgG, and Fluorescein Isothiocyanate (FITC)-conjugated anti-mouse (F2012) antibodies were purchased from Sigma Aldrich (St. Louis, MO). Matrigel from Engelbreth-Holm-Swarm mouse tumor (\#354234) and $8.0 \mu \mathrm{m}$ pore cell culture inserts (353097) were purchased from BD Biosciences (Bedford, MA). Lipofectamine 2000 transfection reagent was purchased from Invitrogen (Carlsbad, CA).

\section{Cell Culture}

Human fibrosarcoma (HT1080) cells were purchased from American Type Culture Collection (Manassas, VA) were cultured in DMEM supplemented with $10 \%$ FBS, $1 \%$ penicillin-streptomycin in a humidified, $5 \% \mathrm{CO}_{2}$, and $37^{\circ} \mathrm{C}$ incubator. Cells were regularly passaged every 72-96 hours and were used between passages 2 and 5 after bringing out of liquid nitrogen.

\section{Expression of CD9 in HT1080 Cells}

Wild type HT1080 cells were transfected by electroporation with either the empty $\mathrm{pRC} / \mathrm{CMV}$ plasmid (Mock), the pRC/CMV plasmid containing full-length human CD9 cDNA insert (CD9), or the pRC/CMV plasmid containing CD9 cDNA insert without the nucleotides coding for the second extracellular loop amino acids 173-192 ( $\Delta 6)$. To obtain stable transfectants, transfected cell populations were selected by the addition of media containing Geneticin (G418, $0.75 \mathrm{mg} / \mathrm{ml})$. All cells were cultured in a humidified, 5\% $\mathrm{CO}_{2}, 37^{\circ} \mathrm{C}$ incubator. 


\section{Experimental Design}

For each experiment, FN was diluted to $10 \mu \mathrm{g} / \mathrm{ml}$ in PBS and $2 \mathrm{ml}$ was added to each well of 6 -well cell culture dishes and allowed to incubate at $37^{\circ} \mathrm{C}$ for $3 \mathrm{hrs}$. The FNPBS solution was then aspirated and any residual solution was washed with PBS. Subconfluent HT1080 cells were harvested, counted, and suspended as 5.0x10 cells $/ \mathrm{ml}$ in serum-free (SF) DMEM. $1.0 \times 10^{6}$ cells were added to each FN-coated well in a final volume of $2 \mathrm{ml}$ of SF DMEM and allowed to incubate for 24 hours before the media was collected and the cells were harvested.

\section{RNA Extraction and qRT PCR Analysis}

RNA was extracted from cells using the RNeasy minikit (74104, Qiagen, Valencia, CA) per the manufacturer's instructions and eluted in DNase/RNase free water. The RNA quantity was estimated using a nanodrop spectrophotometer (Thermo Scientific, Rockford, IL) and RNA integrity was assessed using Agilent bioanalyzer 2100 (Santa Clara, CA). Considerations were taken to use RNA with 260/280 and 260/230 ratios higher than 1.90 (2.0 or slightly higher being perfect) and a RNA integrity number greater than 9.90 (10.0 being completely undegraded). cDNA was made from $1 \mu \mathrm{g}$ of total HT1080 RNA with an RNA cDNA synthesis kit from Applied Biosystems (Foster City, $\mathrm{CA}$ ). The resulting cDNA was tested in triplicate by qRT-PCR using TaqMan chemistry and probes (Roche, Indianapolis, IN) and a Roche Lightcycler 480 system at the UTHSC Molecular Resource Center. Forward and reverse primers were designed using the Roche Universal Probe Library Design Software and ordered from Sigma Aldrich (Tables A-1 and A-2). Primer efficiency was tested on serial dilutions of universal human RNA. Primers with an efficiency of greater than 1.80 (2.0 indicating perfect binding even at $1: 1,000$ dilution of cDNA) were used in subsequent experiments. Fold changes in mRNA expression were calculated from the averaging the resulting cycle threshold (CT) values. Average CT values were normalized (subtracted) to Cyclophilin-D housekeeping gene $(\Delta \mathrm{CT})$. The $\Delta \mathrm{CT}$ values for the control treated cells were subtracted from the experimental treatment values $(\Delta \Delta \mathrm{CT})$. Fold changes in the experimental group relative to the control group mRNA were calculated by $2-\Delta \Delta \mathrm{CT}$. Fold changes greater than 2 or less than 0.5 were considered to be meaningful deviation from the control. The fold changes from three independent experiments were averaged to determine the mean fold change and standard deviation from the mean.

\section{Gelatin Zymography}

Cell culture supernatant was harvested from cells plated on $10 \mu \mathrm{g} / \mathrm{ml} \mathrm{FN}$ for 24 hours as described above and clarified by a two-step centrifugation at $800 \mathrm{xg}$ and $1400 \mathrm{xg}$ at $4^{\circ} \mathrm{C}$. The resulting culture supernatant was mixed with non-reducing sample buffer and subjected to electrophoresis on 10\% SDS-polyacrylamide gels containing $1 \mathrm{mg} / \mathrm{ml}$ final concentration of porcine gelatin (Sigma Aldrich). After electrophoresis, SDS was removed by washing gels with $2.5 \%$ (v/v) Triton X-100 solution. The gels were 
incubated in digestion buffer (50 mM Tris, $200 \mathrm{mM} \mathrm{NaCl}$, and $10 \mathrm{mM} \mathrm{CaCl}$ ) for 14 hours at $37^{\circ} \mathrm{C}$ and then fixed in a solution containing $50 \%$ ethanol and $10 \%$ acetic acid for 2 hours at room temperature. The gels were then washed twice in $50 \%$ methanol and $10 \%$ acetic acid solution and stained with $0.1 \%$ Coomassie brilliant blue R-250 (BioRad, Hercules, CA) in $20 \%$ methanol and $10 \%$ acetic acid solution for 2 hours. The gels were destained with a $50 \%$ methanol and $10 \%$ acetic acid solution, scanned using a HewlettPackard Office Jet Pro 8500 Premier scanner. Gelatinolytic bands were indicated by the absence of Coomassie staining. Band intensity was subjected to densitometry analysis using NIH Image J software. In the cases where pro-MMP-9 and pro-MMP-2 were considered, relative intensity was calculated by dividing the intensity of the MMP-9 band by the MMP-2 band, then normalizing the data to the corresponding control treatment bands. In the cases where pro-MMP-9 was considered alone, relative intensity was calculated by dividing by the pro-MMP-9 band in the experimental treatment lane by the band in the control treatment lane. A minimum of three independent experiments were performed for quantitation of relative band density.

\section{Flow Cytometry}

Cells were harvested, counted, and suspended at $5.0 \times 10^{5}$ cells $/ \mathrm{ml}$ in $5 \%$ goat serum-DMEM (blocking media) and incubated on ice for 45 minutes to block nonspecific binding. All subsequent antibody incubations were performed on ice. Primary antibody was added to a final concentration of $5 \mu \mathrm{g} / \mathrm{ml}$ and incubated for 1 hour. Unbound primary antibody was removed by washing the cells three times. One wash consisted of pelleting the cells (800xg for $5 \mathrm{~min}$ ), discarding the supernatant, and suspending the cell pellet using $1 \mathrm{ml}$ of ice-cold PBS by pipetting. The cells were incubated with secondary FITC-conjugated antibody at a final concentration of $5 \mu \mathrm{g} / \mathrm{ml}$ in blocking media for 1 hour. The secondary antibody was removed by washing three times, and the cells were suspended in room-temperature PBS after the last wash for data acquisition. Analysis of the data was performed using a FACS Calibur flow cytometer equipped with Cell Quest Pro software (Becton-Dickinson, Bedford, MA). The geometric mean fluorescence intensity values were averaged among three or more independent experiments.

\section{Matrigel Invasion Assay}

Matrigel diluted to $250 \mu \mathrm{g} / \mathrm{ml}$ in matrigel coating buffer $(0.01 \mathrm{M}$ Tris, $0.7 \% \mathrm{NaCl}$, $\mathrm{pH} 8.0$, sterile filtered) was added to $8.0 \mu \mathrm{m}$ pore cell culture inserts and allowed to solidify at $37^{\circ} \mathrm{C}$ for $1 \mathrm{hr} .1 .0 \times 10^{5}$ Mock- and CD9-HT1080 cells were added to separate cell culture inserts, and 1\% FBS-DMEM was added to the bottom well as a chemoattractant. As a control for migration, equal amounts of cells were added to uncoated cell culture inserts. As a negative control, cells were added to matrigel-coated inserts and serum-free DMEM was added to the bottom well. The 24-well tissue culture plates were placed in a humidified, $5 \% \mathrm{CO}_{2}, 37^{\circ} \mathrm{C}$ incubator. After 20 hours incubation, the inside of the tissue culture insert was cleared of cells by scrubbing with a cotton 
swab. The cells on the bottom of the insert were fixed in ice-cold $100 \%$ methanol for 2 minutes, rinsed twice with PBS, and stained using $0.05 \%$ crystal violet for 30 minutes. After rinsing off residual crystal violet with PBS, the culture insert membranes were air dried, cut out, and mounted onto microscope slides with Permount (Fisher). Cells were counted in 10 random fields of view per membrane. Counts from at least three independent repeats were averaged to come up with the average number of cells/field of view.

\section{MMP-1 and MMP-9 ELISAs}

ELISA kits for MMP-1 (ELH-MMP1) and MMP-9 (BMS2016/2) were purchased from RayBiotech, Inc (Norcross, GA) and eBioscience (San Diego, CA), respectively. Analysis of pro- and active-proteinase expression was performed per the manufacturer's protocol using cleared supernatant from Mock- and CD9-HT1080 cells incubated for 24 to 48 hours on $10 \mu \mathrm{g} / \mathrm{ml} \mathrm{FN-coated} \mathrm{cell} \mathrm{culture} \mathrm{plates} \mathrm{in} \mathrm{serum-free} \mathrm{DMEM.} \mathrm{Samples}$ were run in duplicate, and results were compared to a curve generated using reconstituted protein standards supplied with each kit. The lower limits of detection for MMP-1 and MMP-9 were less than $8 \mathrm{pg} / \mathrm{ml}$ and $50 \mathrm{pg} / \mathrm{ml}$, respectively. The calculated overall intraassay coefficients of variation were less than $10 \%$.

\section{Knockdown of MMP-9 in HT1080 Cells}

Small interfering RNA (siRNA) oligomer duplexes targeting MMP-9 were ordered from Sigma Aldrich (St. Louis, MO). Three different MMP-9 siRNAs were initially screened for their effects on tetraspanin, integrin, and MMP expression. One siRNA was successful at silencing MMP-9 expression without affecting other tetraspanins, integrins, and MMPs pertinent to this study and was chosen for subsequent experiments. A non-specific, scrambled siRNA was used as a control. Transfection was performed on a subconfluent monolayer of Mock- or CD9-HT1080 cells using Lipofectamine 2000 transfection reagent. After 6 hours incubation with siRNA and Lipofectamine 2000, the cell monolayer was washed and the cells were incubated with complete media. The cells were harvested and used in subsequent experiments 48 hours after transfection.

\section{Statistical Analysis}

All experiments were repeated at least three independent times and most samples were tested in either duplicate or triplicate. Statistical analysis was carried out using SPSS software, and graphs were generated using GraphPad Prism 6 software. The bars represent the mean, and error bars represent the standard deviation from the mean. An independent samples t-test or Mann-Whitney U Test was used to compare two means of normally distributed or non-normally distributed samples, respectively. Analysis of Variance (ANOVA) was used to compare three means of normally distributed 
homogenous data. Tukey's HSD post-hoc analysis was conducted to determine any difference among the groups. Welch's ANOVA was used for three sample means with non-normally distributed data, and Dunnet's T3 post-hoc analysis was used to determine any difference among these means. Each test was run at a 95\% confidence level and Pvalues less than 0.05 were considered statistically significant.

\section{Results}

\section{CD9 Overexpression in HT1080 Cells Did Not Alter the Expression of Other Tetraspanin Family Members}

Human fibrosarcoma (HT1080) cells endogenously expressed low levels of CD9 on their cell surface as indicated by flow cytometry (Figure 2-1A). A population of CD9expressing HT1080 cells was generated by transfecting wild-type HT1080 cells with a plasmid containing a full-length human CD9 cDNA insert. Likewise, the same plasmid without the CD9 insert was used to generate Mock-HT1080 cells. Stably transfected cell colonies were generated by multiple passages of these transfected cells in G418containing selection media. CD9 mRNA levels were upregulated approximately 20 -fold in CD9-HT1080 compared to Mock-HT1080 cells (Figure 2-1B). The mRNA levels of other constitutively expressed members of the tetraspanin family - including CD63, CD81, and CD151 - were not significantly changed as a result of CD9 expression (Figure 2-1C). Flow cytometry was used to further confirm that changes in mRNA expression corresponded with the proper trafficking of tetraspanins and their expression on the cell surface. Increased CD9 expression may have consequences on the cell surface expression of other tetraspanins due to rearrangement of the tetraspanin-enriched microdomain. A prominent increase was observed in the expression of CD9 at the cell surface of CD9-HT1080 cells relative to the Mock transfected HT1080 cells (Figure 2-1D). The mean fluorescence intensity was $11.4 \pm 2.3$ and 538.8 \pm 149.1 for Mock- and CD9-HT1080 cells, respectively ( $<<0.001)$. Exogenous expression of CD9 did not significantly affect the cell surface expression of tetraspanins CD63, CD81, or CD151 (Figure 2-1D). Thus, any phenotypic differences between Mock- and CD9-HT1080 cells may be attributed directly to upregulation of CD9 expression.

Other major regulators of activity within tetraspanin-enriched microdomains include integrins [1,104]. Changes in the mRNA expression of integrin subunits $\alpha 2, \alpha 4$, $\alpha 5, \alpha 6$, and $\beta 1$ between Mock- and CD9-HT1080 cells were measured using qRT-PCR. CD9 expression did not elicit any modifications in integrin subunit mRNA production (Figure 2-2A). The cell surface expression of integrin subunits $\alpha 4, \alpha 5$, and $\alpha 6$ was unaffected by CD9 overexpression as determined by flow cytometric analysis of unpermeabilized cells (Figure 2-2B). However, the cell surface expression of $\alpha 2$ and $\beta 1$ integrin subunits was lower in CD9 transfectants (Figure 2-2B). CD9-HT1080 $\alpha 2$ fluorescence intensity values were 1.4 fold less and $\beta 1$ values were 1.2 fold less than Mock-HT1080 values ( $<0.001$, and $\mathrm{p}=0.002$, respectively). These findings suggest a 
A

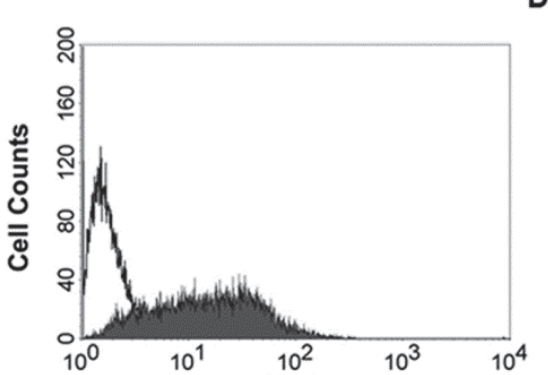

B

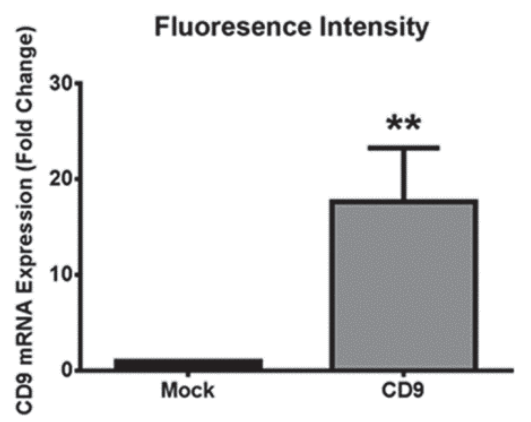

C

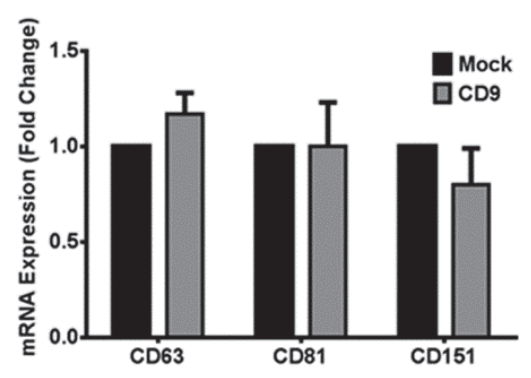

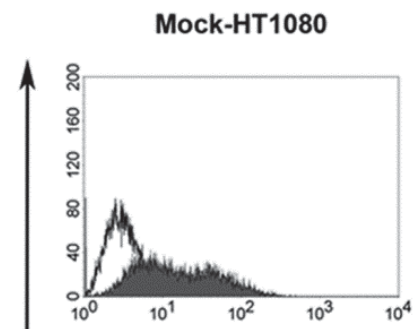
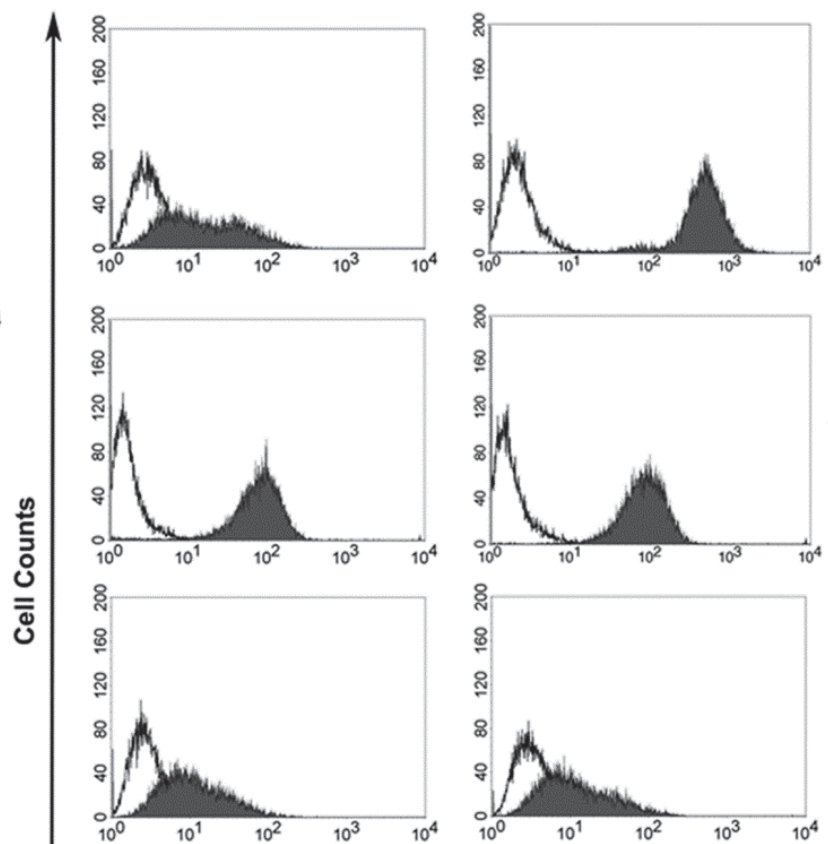

$\operatorname{CD} 9$
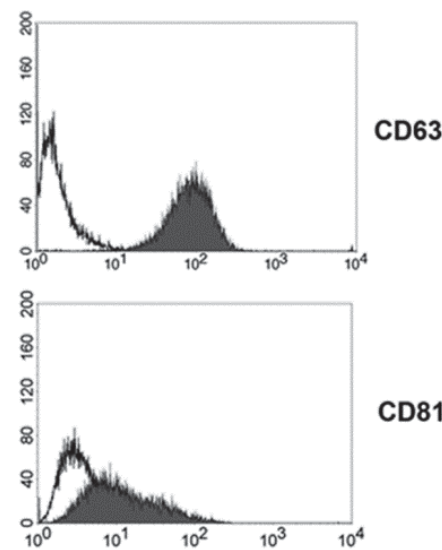

CD81
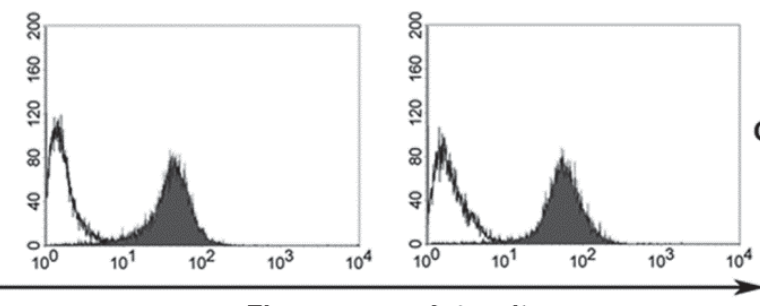

CD151

Figure 2-1. Overexpression of CD9 in HT1080 cells does not alter the expression of other tetraspanins.

(A) The cell surface expression of CD9 on wild-type HT1080 cells was assessed using flow cytometric analysis after binding a monoclonal antibody specific for CD9 (mAb7, shaded histogram). A non-specific isotype-matched antibody (IgG) was used as a negative control (unshaded histogram). (B, C) Total RNA was collected from Mock- and CD9-HT1080 cells, reverse transcribed to cDNA, and probed using primers specific for integral tetraspanins using qRT-PCR. The fold change in mRNA expression of tetraspanins was calculated from resulting cycle threshold values normalized to cyclophilin D. (D) Flow cytometry was used to assess the cell surface expression of key tetraspanins on the cell surface of Mock- (left panels) and CD9- (right panels) HT1080 cells $* *, p<0.001$. 

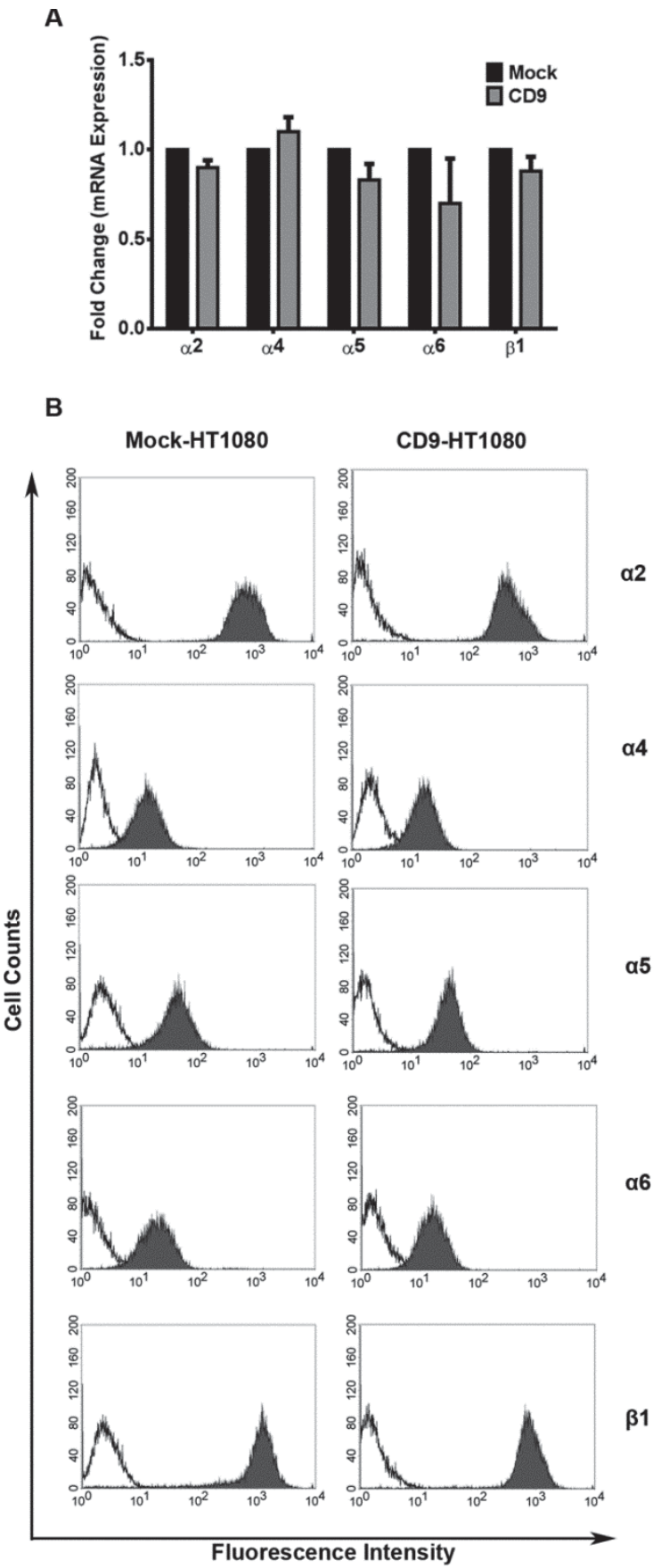

Figure 2-2. CD9-HT1080 cells have stable mRNA expression of integrins though $\alpha 2$ and $\beta 1$ are reduced at the cell surface.

(A) The fold change in mRNA expression of integrins was compared between Mock- and CD9-HT1080 cells using qRT-PCR. (B) Cell surface expression of the same integrin subunits (shaded histograms) was evaluated by flow cytometry. A non-specific isotypematched antibody ( $\mathrm{IgG}$ ) was used as a negative control (unshaded histograms). 
small though statistically significant decrease in the integrin heterodimer $\alpha 2 \beta 1$ at the cell surface.

\section{CD9-HT1080 Cells Have Increased Cell Invasion and MMP-9 Production and Release}

Tetraspanins are known to regulate the metastatic phenotype of tumor cells [59, 60]. A matrigel invasion assay was used to establish any differences in the invasive phenotype of HT1080 cells following the expression of CD9. After 20 hours of invasion, $45 \%$ more CD9-HT1080 cells migrated through matrigel-coated cell culture inserts compared to Mock-HT1080 cells ( $\mathrm{p}=0.002$; Figure 2-3A and 2-3B). This infers that the presence of CD9 on the cell surface contributes to an increase in the invasive capabilities of HT1080 cells.

Invasion of cancer cells is tightly regulated by a balance in MMP and TIMP production $[81,82]$, and tetraspanins have previously been demonstrated to regulate MMP and TIMP expression in other cell lines [90-92, 105]. CD9 regulation of MMP and TIMP expression in HT1080 cells was a conceivable mechanism to augment cellular invasion. qRT-PCR was used to examine if CD9 overexpression had any effect on relative MMP or TIMP mRNA levels. The results indicated a 4.1-fold increase in the production of MMP-9 mRNA in cells overexpressing CD9 compared to Mock (Figure 2-4A). A 3.9-fold decrease in the expression of MMP-1 mRNA was also observed. The mRNA expression levels of other relevant MMPs and three TIMPs including MMP-2, MMP-3, MMP-7, MMP-8, MMP-14 (MT1-MMP), MMP-16 (MT2-MMP), TIMP-1, TIMP-2, and TIMP-3 were unchanged between Mock- and CD9-HT1080 cells (Figure 2-4A). Upon using multiple different and efficient primers, TIMP-4 mRNA expression was not detectable in either Mock- or CD9-HT1080 cells.

MMP-1 and MMP-9 specific ELISAs were used to establish if the observed mRNA changes resulted in changes in soluble proteinase release into the media. MMP-1 proteinase concentration in the supernatants from CD9-HT1080 cells tended to be less than that detected in the Mock cells; however, this change was not statistically significant (Figure 2-4B). Consistent with increased MMP-9 mRNA levels, MMP-9 proteinase concentration in the supernatant of CD9-HT1080 cells was 3.7 fold higher than MockHT1080 cells (Figure 2-4C). The concentration of MMP-9 was on average much greater than the concentration of MMP-1 (Figure 2-4B and 2-4C). There was a very strong direct correlation between the levels of CD9 mRNA expression and the proteinase concentration of MMP-9 in the CD9-HT1080 cell supernatant after 48 hours (Pearson correlation coefficient $=+0.973, p=0.027$ ). These findings suggest the possible involvement of CD9 expression inducing MMP-9 mRNA synthesis and release into the supernatant.

Variations in the secretion of gelatinase MMP-9 in cell culture supernatants were confirmed using a gelatin zymogram. Pro-MMP-9 gelatinolytic band intensity was augmented in the cell culture supernatant of CD9-HT1080 cells (Figure 2-4D). 
A

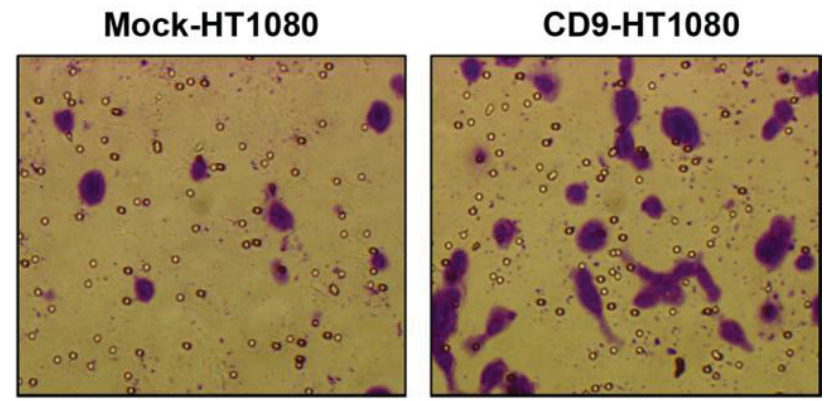

B

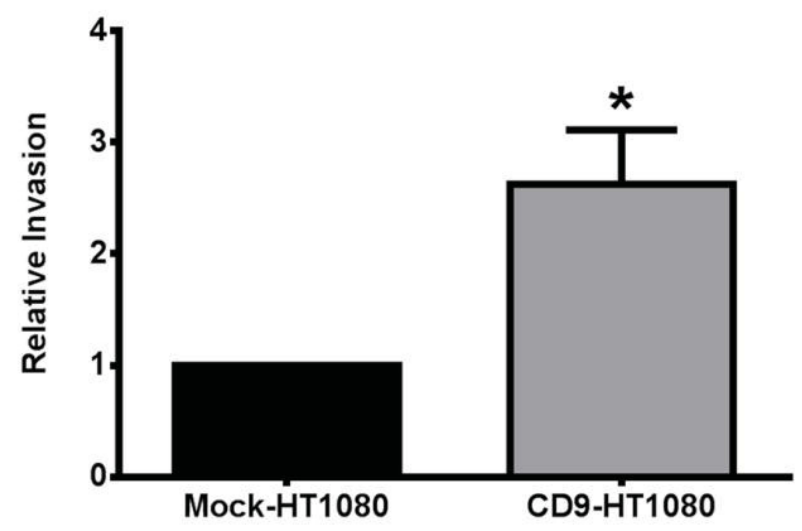

Figure 2-3. The invasive phenotype of HT1080 cells is increased upon CD9 overexpression.

A matrigel invasion assay was used to assess the invasive properties of Mock- and CD9HT1080 cells. Cells were allowed to invade through matrigel and adhere to the bottom of a cell culture insert as detailed in the Materials and methods section. (A) A representative image of stained cells after 20 hours of invasion though matrigel. (B) Invasion through matrigel-coated inserts was compared to cells that invaded through uncoated inserts and results shown are normalized to Mock-HT1080 cell invasion *, $\mathrm{p}<0.05$. 
A

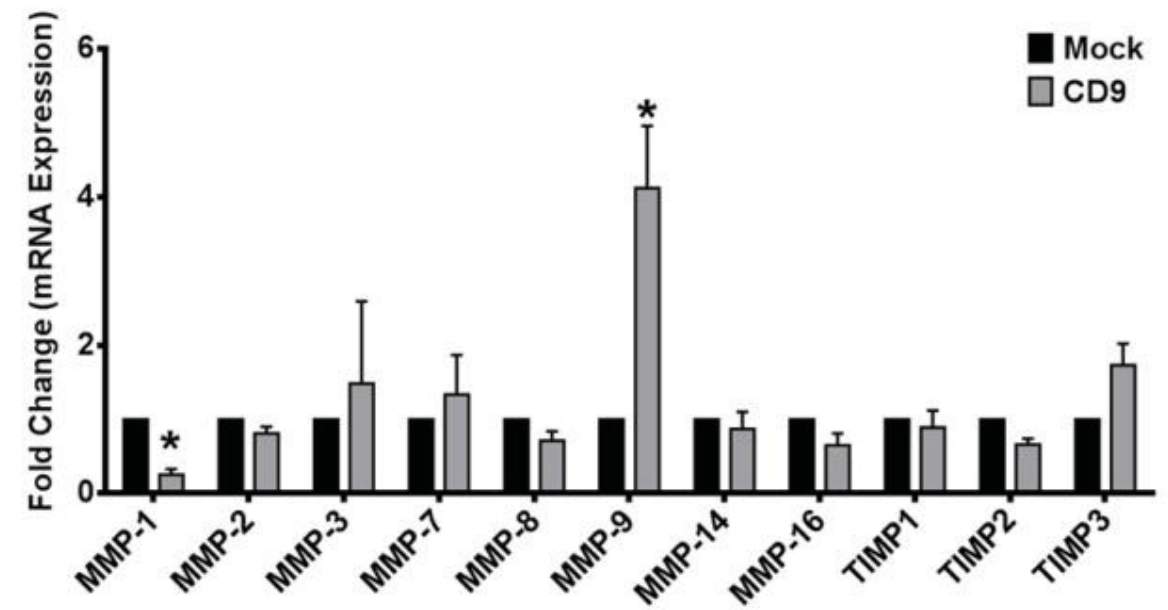

B

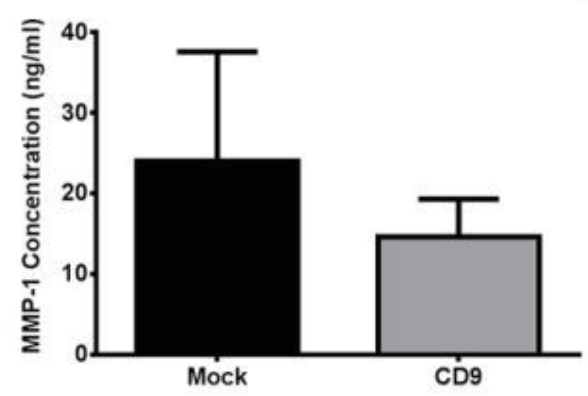

D

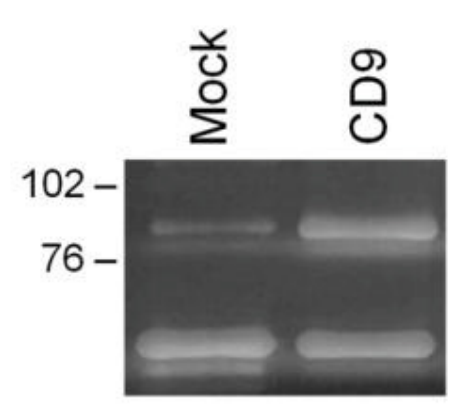

C

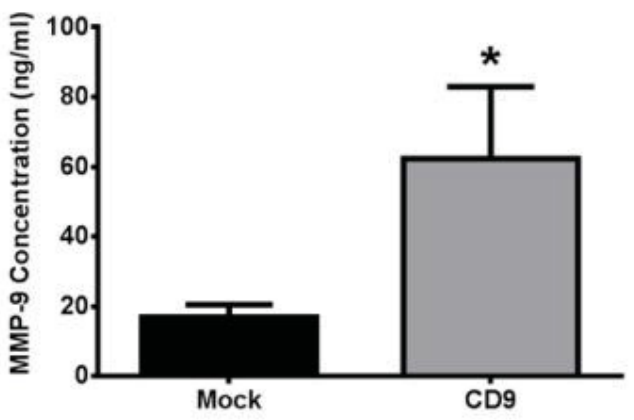

E

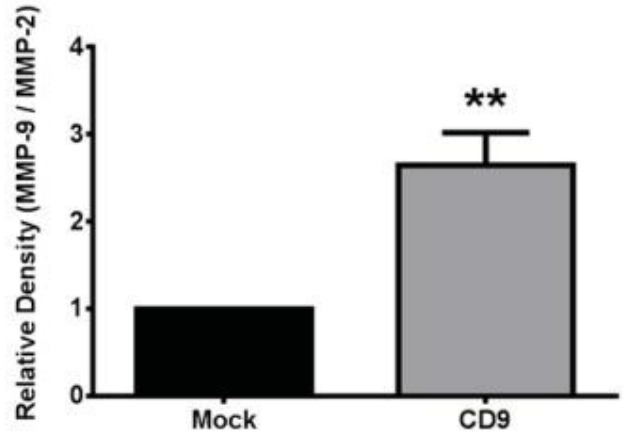

Figure 2-4. MMP-9 expression and release are greatly enhanced in CD9-HT1080 cells.

(A) Fold changes in MMP and TIMP mRNA expression for Mock- and CD9-HT1080 cells were calculated from cycle threshold values using qRT-PCR. (B, C) Specific ELISA kits were used to measure the concentration ( $\mathrm{ng} / \mathrm{ml}$ ) of pro- and active- MMP-1 and MMP-9 in the cleared supernatant of Mock- and CD9-HT1080 cells. (D) A representative gelatin zymogram of Mock- and CD9- HT1080 cell conditioned media. The absence of Coomassie staining at $92 \mathrm{kDa}$ indicates the presence of pro-MMP-9 and at $72 \mathrm{kDa}$ represents pro-MMP-2. (E) Quantification of the relative band intensity was calculated by densitometry analysis as described in the Materials and methods section *, $\mathrm{p}<0.05$; **, $\mathrm{p}<0.001$. 
The $72 \mathrm{kDa}$ pro-MMP-2 gelatinolytic band was similar in both Mock- and CD9-HT080 conditioned media and served as a loading internal control. Quantification of the relative density of the enzymatic bands established that pro-MMP-9 secretion was two-fold greater in CD9-HT1080 cells compared to Mock cells (Figure 2-4E). The amount of proMMP-2 in the cell supernatant was not significantly different between Mock- and CD9HT1080 cells.

\section{Increased CD9-HT1080 Cell Invasion Is a Consequence of Increased MMP-9}

Increased MMP-9 mRNA expression and proteinase release into the media was possibly responsible for the increased invasive cell phenotype observed in the CD9HT1080 cells. To test this hypothesis, short-interfering RNA (siRNA)-mediated silencing approach was utilized to transiently knock down MMP-9 expression in CD9-HT1080 (CD9+MMP9 siRNA). A scrambled control siRNA was transfected into Mock- and CD9-HT1080 cells and used as a control (Mock+Ctr siRNA and CD9+Ctr siRNA). Upon transfection, there was significantly less MMP-9 mRNA expression in CD9+MMP-9 siRNA compared to CD9+Ctr siRNA (Figure 2-5A). The mRNA expression levels of CD9, CD81, CD151, MMP-1, and MMP-2 were unchanged upon transfection with MMP-9 siRNA. Treatment with MMP-9 siRNA in CD9-HT1080 cells resulted in 46\% decrease MMP-9 proteinase concentration in the conditioned media compared to CD9+Ctr siRNA as measured by ELISA (Figure 2-5B). There was no significant difference in the MMP-9 concentration of Mock+Ctr siRNA and CD9+MMP9 siRNA HT1080 cell conditioned media. These results confirm that silencing of MMP-9 in CD9HT1080 cells lowers the expression and release of MMP-9 to that observed in MockHT1080 cells.

Gelatin zymography analysis of cell supernatants fully supported the qRT-PCR and ELISA findings. There was a significant difference in the amount of pro-MMP-9 in the cell culture supernatant between the three groups of transiently transfected cells. CD9+MMP-9 siRNA gelatin degradation decreased 51\% compared to CD9+Ctr siRNA (Figure 2-5C and 2-5D). However, there was no significant difference in gelatinolytic band intensity between Mock+Ctr siRNA and CD9+MMP-9 siRNA HT1080 cells. Moreover, an invasion assay was used to determine the effect of silencing MMP-9 in CD9-HT1080 cells. There was a 58\% reduction in the invasive capabilities of CD9+MMP-9 siRNA HT1080 cells compared to CD9+Ctr cells (Figure 2-5E and 2-5F). No statistical difference was observed between the relative invasion of Mock $+\mathrm{Ctr}$ and CD9+MMP-9 siRNA HT1080 cells. These results support the concept that the expression of MMP-9 elicited by overexpression of CD9 is responsible for the observed invasive phenotype of CD9-HT1080 cells. 
A

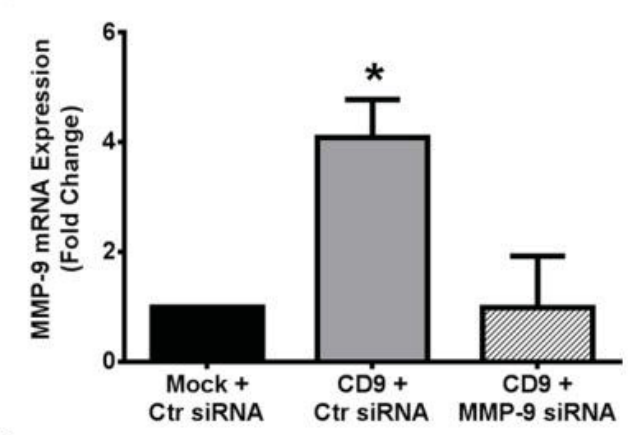

B

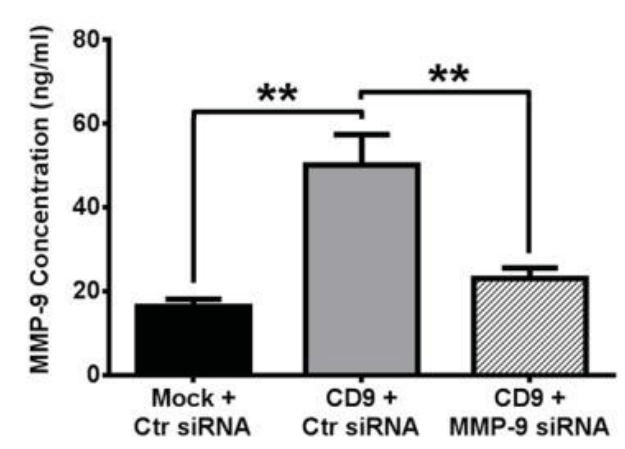

C

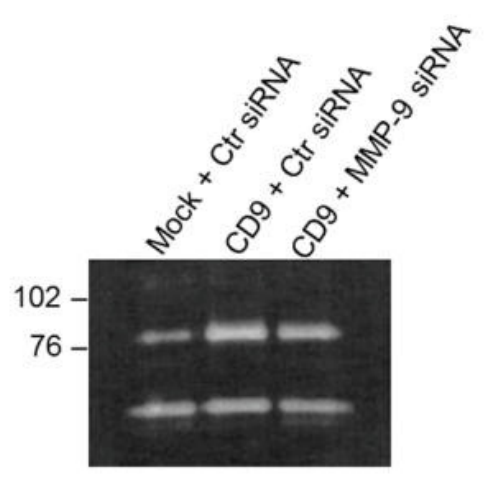

D

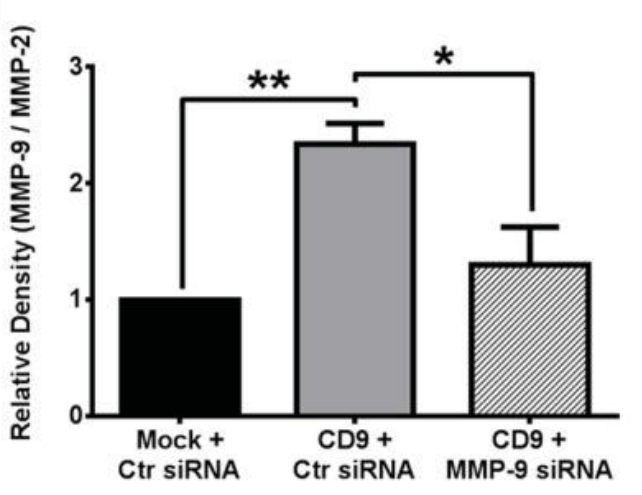

E

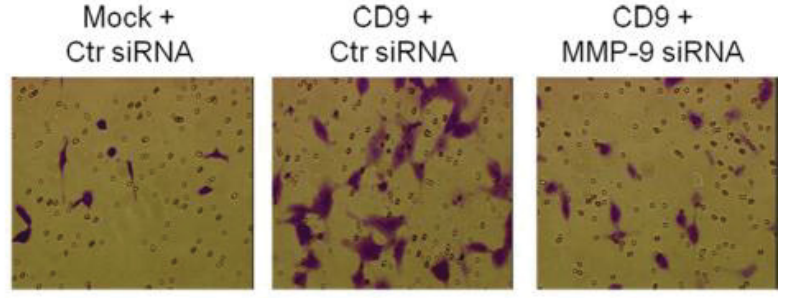

$\mathbf{F}$

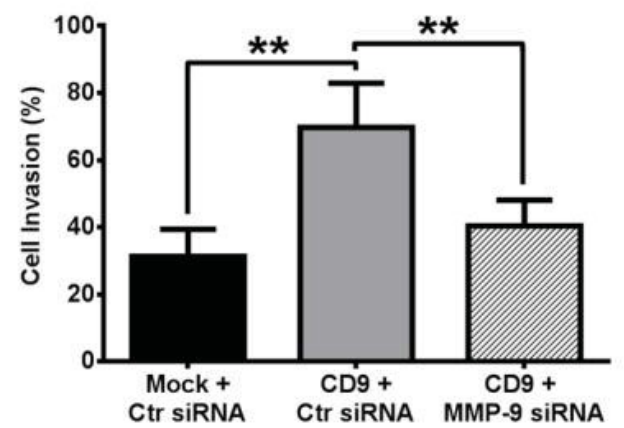

Figure 2-5. Silencing MMP-9 in CD9-HT1080 cells is sufficient to suppress the invasive phenotype.

CD9-HT1080 cells were transiently transfected with short-interfering RNA directed to MMP-9 (CD9 + MMP-9 siRNA). Likewise, Mock- and CD9- HT1080 cells were transfected with a scrambled siRNA as a negative control (Mock + Ctr siRNA or CD9 + Ctr siRNA). (A) qRT-PCR analysis was used to measure changes in MMP-9 mRNA levels among Ctr and MMP-9 siRNA transfected cells. (B) Changes in release of MMP-9 $(\mathrm{ng} / \mathrm{ml})$ in to the cleared culture supernatant were examined using a MMP-9 specific ELISA kit. (C) Pro-MMP-9 levels in the supernatants of transiently transfected cells was measured using gelatin zymography and (D) quantified by densitometry. (E) A representative image of cells invading though matrigel after transfection with siRNA. (F) Percent cell invasion through matrigel-coated inserts after 20 hours was quantified and the results were normalized to Mock + Ctr siRNA treated cells $*, \mathrm{p}<0.05 ; * *, \mathrm{p}<0.001$. 


\section{CD9 Second Extracellular Loop Contributes to Increases in MMP-9 Expression}

Multiple independent groups have attributed a myriad of functions to the EC2 of CD9. CD9 EC2 has been demonstrated to be responsible for association with heparinbinding epidermal growth factor-like growth factor [106, 107], cell motility [37, 108], cell-adhesion and fibronectin matrix assembly [108, 109], association with other tetraspanins [110], and association with transmembrane TGF $\alpha$ [111]. Consideration of these findings led to the hypothesis that increases in MMP-9 expression and release into the media may be attributed to the highly functional CD9 EC2. Wild-type HT1080 were stably transfected with a CD9 mutant lacking EC2 amino acids 173-192 ( $\Delta 6$-HT1080). Primers were designed to detect the levels of mRNAs that code for the amino acids at the N-terminal and first transmembrane region (TM1; amino acids 5 to 35) and the CD9 EC2 (EC2; amino acids 158-185). Upon transfection, CD9 EC2 mRNA in $\triangle 6-\mathrm{HT} 1080$ cells was undetectable; however, the levels of CD9 EC2 mRNA were not significantly different between Mock- and $\Delta 6$-HT1080 cells (Figure 2-6A). CD9 TM1 mRNA levels were not significantly different between CD9- and $\Delta 6$-HT1080 cells (Figure 2-6B) Confirmation of CD9 EC2 deletion mutant cell surface expression was assessed by flow cytometry. As seen in the left column of Figure 2-6C, the binding of $\mathrm{mAb} 7-\mathrm{a}$ monoclonal antibody specific for CD9 EC2 - was similar for both Mock- and $\Delta 6$ HT1080 cells. Binding of the anti-CD9 EC1 antibody, Rap2, was not detectable in MockHT1080 cells, but was similar in CD9- and $\Delta 6$-HT1080 cells (Figure 2-6C, middle column). Anti-CD151 antibody bound similarly to all three cell lines (Figure 2-6C, right column).

MMP-9 mRNA levels were 7.8 fold lower in $\Delta 6$-HT1080 compared to CD9HT1080 cells ( $<<0.001$; Figure 2-7A). MMP-2 mRNA levels between $\Delta 6$-HT1080 and CD9-HT1080 cells were unchanged. The concentration of MMP-9 in the supernatant of $\Delta 6$-HT1080 cells $(11.9 \pm 1.6 \mathrm{ng} / \mathrm{ml})$ was not significantly different from Mock-HT1080 revealed earlier $(16.9 \pm 3.5 \mathrm{ng} / \mathrm{ml})$. Quantification of MMP-9 gelatin degradation of $\Delta 6$ HT1080 cells was 33\% lower than degradation observed in CD9-HT1080 cells (Figure 2-7B and 2-7C). There was no significant difference in pro-MMP-9 gelatinolytic band intensity between Mock- and $\Delta 6$-HT1080 cells, and pro-MMP-2 degradation was similar among all three treated cells. A matrigel invasion assay using these cell lines revealed that $\triangle 6$-HT1080 cells were significantly less invasive than CD9-HT1080 cells (Figure 2-7D and 2-7E). There was no significant difference between the invasive properties of Mock- and $\Delta 6$-HT1080 cells. These data suggest a specific role for the second extracellular loop of CD9 in the induction of MMP-9 expression, release, and degradation. 
A

B

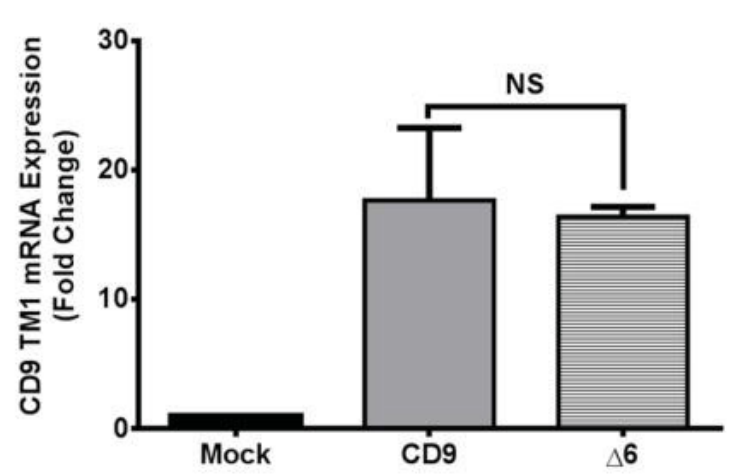

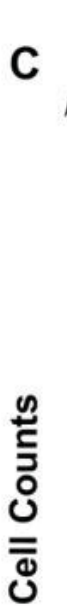
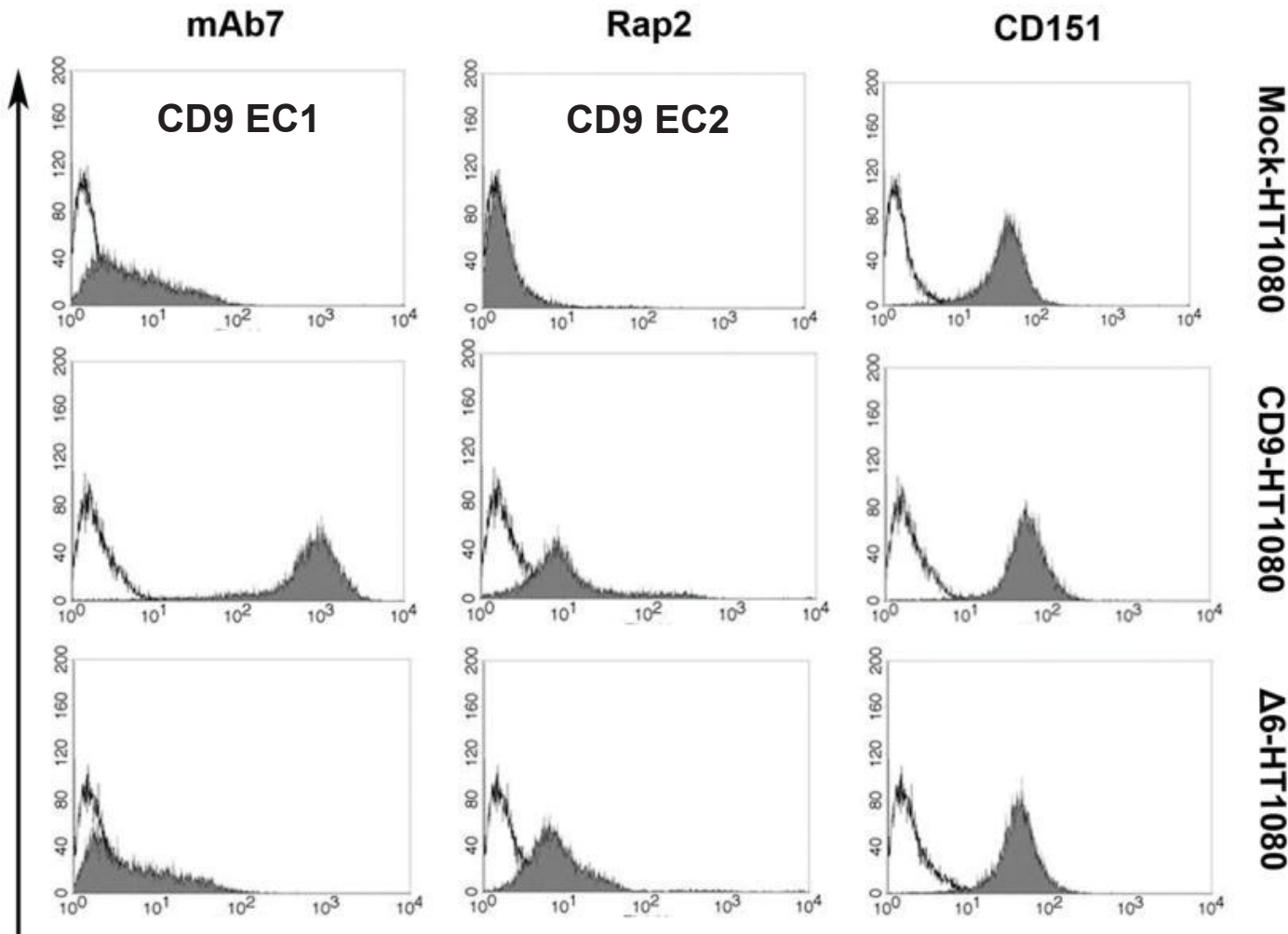

Fluoresence Intensity

Figure 2-6. Characterization of the second extracellular loop (EC2) deletion mutant of CD9 in HT1080 cells.

Upon transfection with the EC2 deletion mutant in HT1080 cells, mRNA expression was measured using primer pairs specific for the nucleotides coding the EC2 (A) and TM1 (B) regions of CD9. (C) Flow cytometric analysis of Mock-, CD9-, and $\Delta 6-\mathrm{HT} 1080$ cells is indicated by each row, and each column indicates CD9 EC2 (mAb7), CD9 TM1 (Rap2), or CD151 binding (shaded histograms) **, $\mathrm{p}<0.001$. 
A

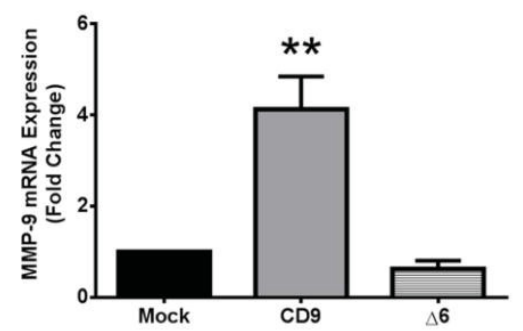

B

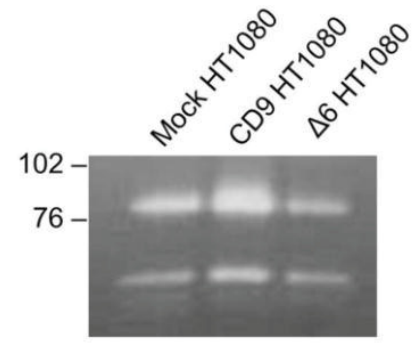

C

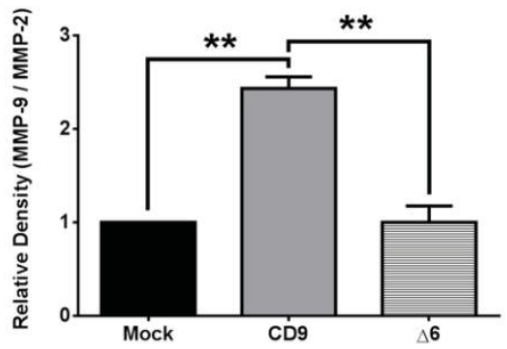

D

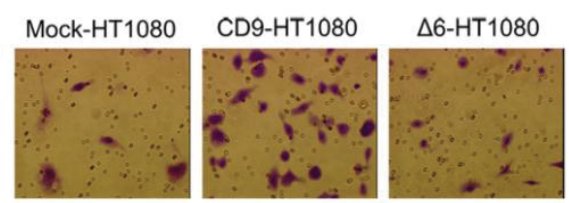

E

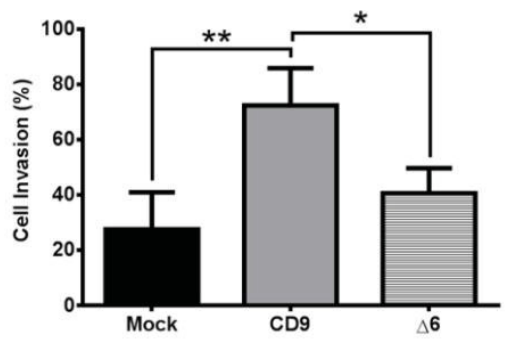

Figure 2-7. An increase in MMP-9 expression and release and subsequent cell invasion requires the second extracellular loop (EC2) of CD9.

(A) MMP-9 mRNA expression was measured in Mock-, CD9-, and $\Delta 6-\mathrm{HT} 1080$ cells using qRT-PCR $(\mathrm{B}, \mathrm{C})$ Release of pro-MMP-9 and pro-MMP-2 was measured by gelatin zymography and quantified using Image J. (D,E) A representative picture of cell invasion through matrigel coated inserts and relative quantification of cell invasion *, $\mathrm{p}<0.05 ; * *, \mathrm{p}<0.001$. 


\title{
CHAPTER 3. PRO-MMP-9 UPREGULATION IN HT1080 CELLS EXPRESSING CD9 IS REGULATED BY EPIDERMAL GROWTH FACTOR RECEPTOR $^{\dagger}$
}

\begin{abstract}
Rationale
The observed attenuation of CD9-mediated increase in the expression and release of pro-MMP-9 in the absence of EC2 warranted further exploration. Interestingly, CD9 has been demonstrated to associate with epidermal growth factor (EGF) receptor (EGFR) and regulate its activity; however, CD9 regulation of EGFR is not entirely clear. EGFR expression and activity was strongly connected to the augmentation of MMP-9 expression in multiple reports [112-115], and previous work in a HT1080 model system demonstrated CD9 co-immunoprecipitated with EGFR [94]. Consequently, it was hypothesized that CD9 EC2 may regulate MMP-9 expression via EGFR.
\end{abstract}

\section{Materials and Methods}

\section{Reagents and Antibodies}

The reagents used in this chapter were similar to those used in the Material and Methods section of Chapter 2. The anti-EGFR antibody (4267) was purchased from Cell Signaling Technologies (Danvers, MA). The horseradish peroxidase (HRP)-conjugated secondary antibodies anti-rabbit (NA934VS) and anti-mouse (NA931VS), and molecular weight marker (RPN800E) were purchased from GE Healthcare (Pittsburgh, PA). Receptor tyrosine kinase inhibitors sunitinib (S-8803), gefitinib (G-4408), erlotinib (E4997), lapatinib (L-4804) and AG1478 (T-7310) were purchased from LC laboratories (Woburn, MA).

\section{Western Blot}

All lysates were made in a TX-100 lysis buffer (1\% TX-100, 20mM tris-HCl, $150 \mathrm{mM} \mathrm{NaCl}, 0.5 \%$ deoxycholate, and $0.1 \%$ sodium dodecyl sulfate) including protease (P8340) and phosphatase inhibitor cocktails (P0044, P5726) purchased from Sigma Aldrich. Lysate concentration was determined using a colorimetric Bradford Assay (Pierce, Thermo Scientific, Rockford, IL) and a standard curve generated by dilutions of bovine serum albumin (BSA). Absorbance measurements were obtained using a VersaMax tunable microplate reader at 750nm (Molecular Devices, Sunnyvale, CA).

\footnotetext{
$\dagger$ Adapted with permission from Biochemical and Biophysical Research Communications: Herr MJ, Mabry SE, Jameson JF, Jennings LK (2013) Pro-MMP-9 upregulation in HT1080 cells expressing CD9 is regulated by epidermal growth factor receptor. Biochem Biophys Res Commun.
} 
Protein concentrations for each sample were determined by comparison to the standard curve.

Equal concentrations of lysate mixed with reducing or non-reducing buffer were loaded onto a SDS-polyacrylamide gels of differing percentages depending on proteins of interest. The gels were run in a tray buffer with a final concentration of 50mM Tris- $\mathrm{HCl}$, $200 \mathrm{mM}$ glycine, and $0.1 \%(\mathrm{w} / \mathrm{v})$ sodium dodecyl sulfate (SDS) $\mathrm{pH}$ 8.3. The proteins were transferred to a polyvinyl difluoride (PVDF) membrane in a buffer containing $25 \mathrm{mM}$ Tris- $\mathrm{HCl}, 200 \mathrm{mM}$ glycine, $1 \% \mathrm{SDS}$, and 20\% (v/v) methanol. After the transfer, non-specific sites of binding were blocked using 5\% (w/v) BSA in Tris-buffered saline with 1\% (v/v) Tween-20 (TBST) solution. Anti-human CD9 (mAb7, 1:500), anti-human total EGFR $(1: 5,000)$, or anti-human $\beta$-tubulin $(1: 20,000)$ was diluted in 5\% BSA-TBST and incubated overnight at $4^{\circ} \mathrm{C}$. After washing off the primary antibody with TBST, a HRP-conjugated anti-mouse antibody $(1: 5,000)$ for $\mathrm{mAb} 7$ or anti-rabbit antibody $(1: 50,000)$ for EGFR and $\beta$-tubulin was diluted in 5\% BSA-TBST, added to the blots, and incubated for 1 hour at room temperature. The blots were again washed as described earlier and incubated with Pierce ECL 2 Western blotting substrate for 5 minutes. X-ray film was used to detect chemiluminescence and the films were developed using a Konica Minolta X-ray machine. Band density was determined using NIH ImageJ software, and $\mathrm{mAb} 7$ band densities were normalized the corresponding to $\beta$-tubulin band densities.

\section{Receptor Tyrosine Kinase Inhibitor Treatment}

Each inhibitor was reconstituted in DMSO to the following stock concentrations: sunitinib $50 \mu \mathrm{M}$, gefitinib $100 \mu \mathrm{M}$, erlotinib $100 \mu \mathrm{M}$, lapatininb $100 \mu \mathrm{M}$, and AG1478 $100 \mu \mathrm{M}$. These stock concentrations were further diluted using DMSO and added to $2 \mathrm{ml}$ of serum-free DMEM and cell mixture to get a final concentration of $10 \mu \mathrm{M}, 5 \mu \mathrm{M}$, or $1 \mu \mathrm{M}$ inhibitor with an equivalent final volume of DMSO for each treatment. Likewise, the same volume of DMSO without inhibitor was added to the cells as a negative control. The cells and DMSO or diluted inhibitor were incubated for $30 \mathrm{~min}$ at $37^{\circ} \mathrm{C}$, then added to the FN-coated wells and placed in the incubator for 24 hours. After 24 hours, no difference in cell confluence was observed between the different treatments.

\section{Knockdown of EGFR in HT1080 Cells}

Small interfering RNA (siRNA) targeting EGFR was ordered from Cell Signaling Technology (\#6480). A non-specific, scrambled siRNA (AM4635) purchased from Ambion (Life Technologies, Grand Island, NY) was used as a control. Prior to transfection, $10 \mu \mathrm{l}$ of Lipofectamine 2000 was incubated to $0.5 \mathrm{ml}$ of serum-free DMEM for 5 minutes at room temperature and $600 \mathrm{pmol}$ of siRNA in $0.5 \mathrm{ml}$ of serum-free DMEM was added to Lipofectamine dilution and allowed to incubate for 20 minutes. HT1080 cells were 70\% confluent upon transfection, and cell monolayers were washed three times with PBS, and then $1 \mathrm{ml}$ of Lipofectamine-siRNA mixture was added drop wise to the cells in a 6-well cell culture plate. After 6 hours, the mixture was aspirated 
and monolayers were rinsed with serum-supplemented DMEM and allowed to incubate for 24-48 hours before preforming experiments.

\section{RNA Extraction and qRT-PCR Analysis}

RNA extraction and qRT-PCR analysis was performed as detailed in the Materials and Methods section of Chapter 2. The same primers listed in Table A-1 were used for analysis with the addition of the EGFR primer listed in Table A-3.

\section{Statistical Analysis}

Sample testing and statistical analysis was performed as detailed in the Materials and Methods section of Chapter 2.

\section{Results}

\section{Inhibiting EGFR Signaling Decreases Pro-MMP-9 Release from CD9-HT1080 Cells}

Protein levels of CD9 expression were confirmed using an anti- human CD9 monoclonal antibody (mAb7) with Western blot (Figure 3-1A). The presence of CD9 in the Mock-HT1080 cells was only evident upon prolonged blot exposure (data not shown).Pro-MMP-9 expression in CD9-HT1080 cells was significantly attenuated upon treatment of the cells with a broad spectrum tyrosine kinase inhibitor, sunitinib, and was dose dependent (Figure 3-1B). Quantification of gelatin degradation revealed a significant decrease in CD9-HT1080 cells treated with sunitinib at 5 and $10 \mu \mathrm{M}$ concentrations. Further investigation on the role of EGFR in pro-MMP-9 release was carried out using multiple tyrosine kinase inhibitors with previously demonstrated specificity for EGFR. Getfitnib, erlotinib, lapatinib, and AG1478 all demonstrated a dose-dependent inhibition of pro-MMP-9 release in CD9-HT1080 cells (Figure 3-2A through 3-2D). Moreover, CD9-HT1080 cells were significantly less invasive through matrigel after treating with $10 \mu \mathrm{M}$ of gefitinib (Figure 3-2E). These findings show that CD9 augments pro-MMP-9 release and subsequent cell invasion through matrigel via EGFR activation.

\section{Knockdown of EGFR in CD9-HT1080 Cells Attenuates the Release of Pro-MMP-9 and Subsequent Cell Invasion}

Upon discovering that inhibiting EGFR signaling negatively regulated the CD9mediated increase in pro-MMP-9 release, EGFR expression was explored as a possible mediator. siRNA directed against EGFR was used to knock down EGFR expression in CD9-HT1080 cells and a scrambled (Ctr) siRNA was used as a control treatment. 


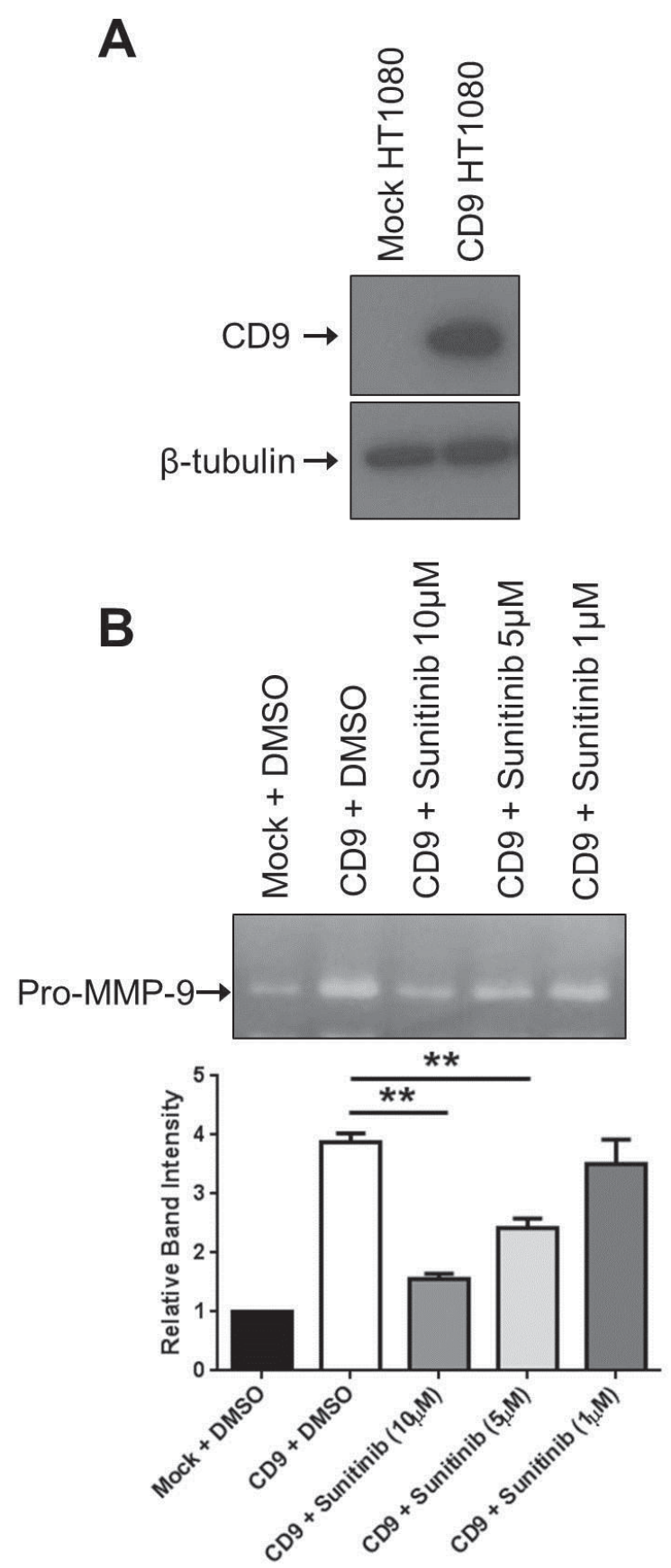

Figure 3-1. CD9-HT1080 cells release less pro-MMP-9 after treatment with a broad spectrum receptor tyrosine kinase inhibitor sunitinib.

(A) The expression of CD9 in HT1080 cells was assessed by Western blot analysis. (B) Pro-MMP-9 release into serum-free media of HT1080 cells plated on $10 \mu \mathrm{g} / \mathrm{ml} \mathrm{FN}$ for 24 hrs was measured using gelatin zymography as described in the materials and methods. Gelatinolytic activity was quantitated by measuring band intensity over three independent repeats. Data are presented as mean $\pm \mathrm{SD}(* * \mathrm{p}<0.01)$. 


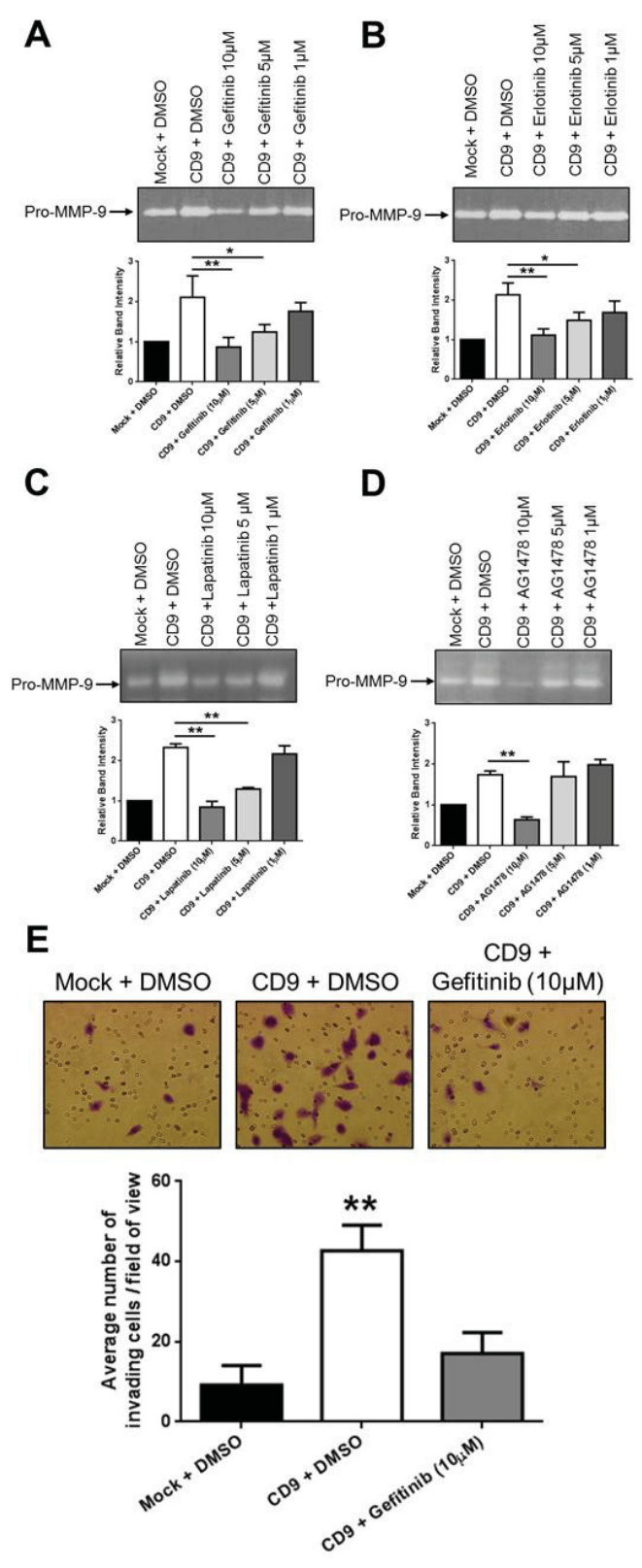

Figure 3-2. Epidermal growth factor receptor tyrosine kinase inhibitors reduce the expression of pro-MMP-9 and inhibit CD9-HT1080 cell invasion.

(A-D) Pro-MMP-9 gelatinolytic activity of Mock and CD9-HT1080 cells treated with DMSO or EGFR specific tyrosine kinase inhibitors gefitinib, erlotinib, lapatinib, and AG1478, respectively, was measured after $24 \mathrm{hrs}$ on FN using gelatin zymography and quantitated. Data are presented as mean $\pm \mathrm{SD}\left({ }^{*} \mathrm{p}<0.05, * * \mathrm{p}<0.05\right)$. (E) Representative images of matrigel invasion assays used to assess cellular invasion in Mock and CD9HT1080 cells treated with DMSO or gefitinib after 20 hours. Cells that invaded through matrigel were fixed and stained with crystal violet. Quantitation of the number of invasive cells per field of view is presented in the bar graph below $(* * \mathrm{p}<0.05)$. 
The mRNA and protein levels of CD9 were not affected by Ctr or EGFR siRNA treatment. However, total EGFR mRNA levels were significantly decreased in the EGFR siRNA treated CD9-HT1080 cells and were not affected upon treatment with Ctr siRNA (Figure 3-3A). MMP-9 mRNA levels were also significantly decreased in the EGFR siRNA treated CD9-HT1080 cells compared to the Ctr siRNA treated CD9-HT1080 cells (Figure 3-2A). The protein levels of CD9 in the CD9-HT1080 cells were unaffected by treatment with EGFR siRNA (Figure 3-3B). Total EGFR levels were similar between the Mock and CD9-HT1080 cells treated with Ctr siRNA, but were less in CD9-HT1080 cells treated with EGFR siRNA (Figure 3-3B). Because CD9 and EGFR were demonstrated to co-immunoprecipitate from HT1080 cells [94], any changes in the cell surface expression of CD9 upon knockdown of EGFR were evaluated using flow cytometry. There were no significant differences in CD9 cell surface expression as a consequence of EGFR knockdown in CD9-HT1080 cells (Figure 3-3C). Thus, any phenotypic changes may be attributed to total EGFR expression levels or signaling events and not to changes in CD9 expression or localization.

Pro-MMP-9 release into the media and cellular invasion changes were assessed after treatment with Ctr and EGFR siRNA using gelatin zymograms and matrigel invasion assays, respectively. Upon knockdown of EGFR, there were significantly decreased levels of pro-MMP-9 released into the media of cells as demonstrated by gelatin degradation (Figure 3-3D). Furthermore, the CD9-HT1080 cells lacking EGFR were significantly less invasive than their Ctr siRNA treated CD9-HT1080 cells (Figure 3-3E). These results indicated that the absence EGFR in CD9-HT1080 cells was sufficient to decrease MMP-9 mRNA and protein levels, and this absence reduced CD9HT1080 invasion without affecting the mRNA, protein, or cell surface levels of CD9.

Conclusively, the expression of CD9 augments the invasive phenotype of human fibrosarcoma cells by upregulating pro-MMP-9 expression and release. This phenomenon is specifically coordinated by the second extracellular loop of CD9 and involves epidermal growth factor receptor expression and activity. 
A
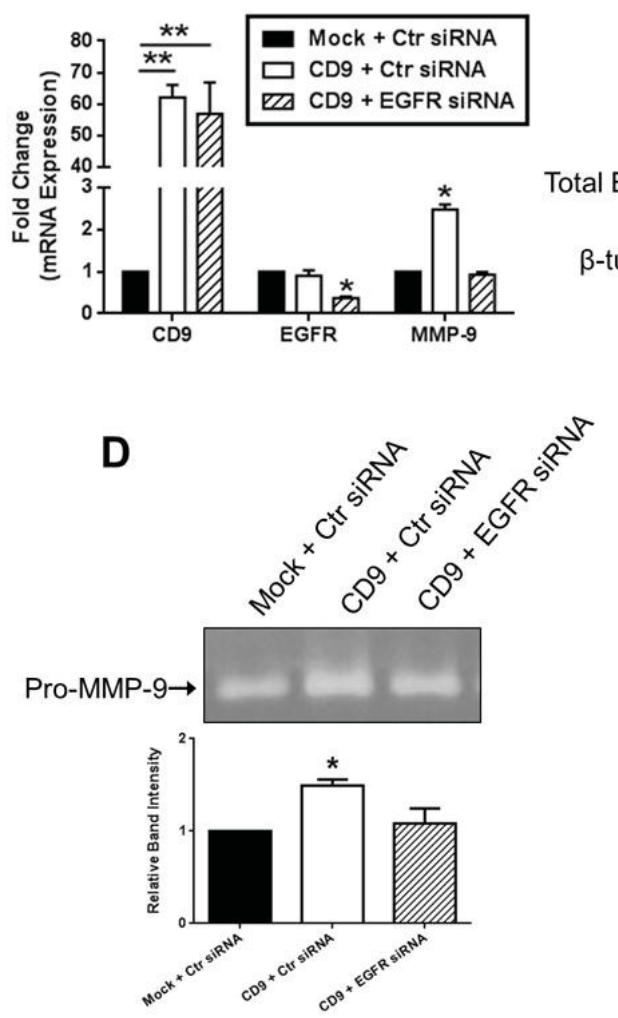

B

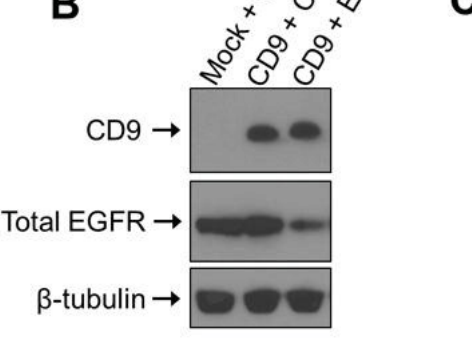

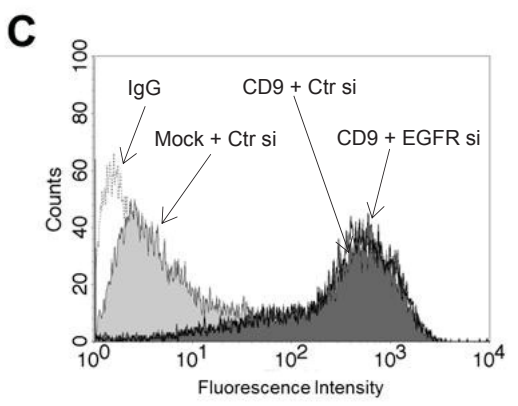

E
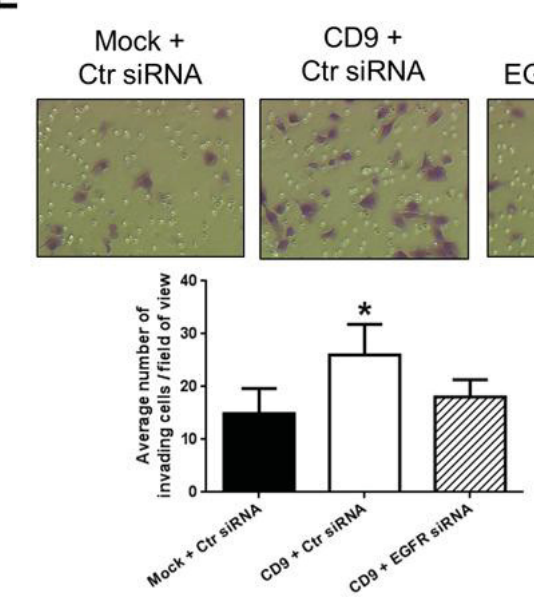

Figure 3-3. Knockdown of EGFR results in decreased pro-MMP-9 expression and release without affecting the expression or localization of CD9.

(A) The fold change in mRNA expression of CD9, EGFR, and MMP-9 in Mock and CD9-HT1080 cells treated with Ctr or EGFR siRNA was measured using qRT-PCR. (B) Protein expression of CD9 and total EGFR expression was measured using Western blot analysis of Mock and CD9-HT1080 cell lysates treated with Ctr or EGFR siRNA. (C) Flow cytometric analysis of nonpermeabilized Mock and CD9-HT1080 cells for CD9 expression after treatment with Ctr or EGFR siRNA. Dotted line represents non-specific $\mathrm{mIgG}$ binding, light-gray shaded histogram is $\mathrm{mAb} 7$ (anti-CD9) staining of Mock $+\mathrm{Ctr}$ siRNA, dark gray shaded histogram is $\mathrm{mAb} 7$ staining of CD9 + Ctr siRNA, and the solid line unshaded histogram is mAb7 staining of CD9 + EGFR siRNA. (D) Pro-MMP-9 release in to the cell media after treatment with Ctr or EGFR siRNA was assessed using gelatin zymography. (E) Matrigel invasion assay of Mock and CD9-HT1080 cells after treatment with Ctr or EGFR siRNA and quantification of the average number of cells that invaded per field of view. Bar graphs represent mean $\pm \mathrm{SD}\left(* \mathrm{p}<0.01,{ }^{* *} \mathrm{p}<0.05\right)$. 


\section{CHAPTER 4. CD9 CONTRIBUTIONS TO CANCER CELL BIOLOGY ${ }^{* \dagger}$}

An invasive and metastatic human carcinoma cell line was used to explore the contribution of tetraspanin CD9 to tumor cell invasion. Typical tetraspanin cell surface density is between 30,000 to 100,000 copies per cell $[19,28,116]$. Although the exact number of CD9 molecules on the cell surface was not determined, CD9 expression in CD9-HT1080 cells at the mRNA and cell surface levels was similar to the previously published endogenous expression of CD9 in other cancerous cell lines including colon [117] and non-small cell lung cancer [70].

Tetraspanins function at the cell surface through organizing multimolecular complexes composed of tetraspanins and associating molecules, including integrins [ $[$, 118]. Upon expression of a single tetraspanin, the expression levels of other tetraspanins or integrins may fluctuate at the mRNA or cell surface level to compensate for microdomain organization. This rarely explored phenomenon may explain why CD9 function in various cancer cell lines is not fully congruent $[74,97,119]$. The studies here indicate increased CD9 at the cell surface level was not sufficient to stimulate or suppress mRNA expression of other integral members within the functional tetraspanin-enriched microdomain. The cell surface expression of other tetraspanin members that play prominent roles in cancer cell invasion including CD63 [120], CD81 [90, 105, 121], and CD151 [122-124] were unaffected by CD9 overexpression. These findings suggest the increased invasive phenotype of CD9-HT1080 cells may be attributed primarily to increases in CD9.

Interestingly, there was a significant decrease in the cell surface levels of both $\alpha 2$ and $\beta 1$ integrins in CD9-HT1080 cells compared to Mock cells. CD9 expression may slightly downregulate the cell surface expression of the $\alpha 2 \beta 1$ integrin subunit thus affecting MMP-1 expression. There is convincing evidence that MMP-1 expression is induced only in osteogenic cell lines that express $\alpha 2 \beta 1$ [125]. Moreover, blockade with either MMP-1 or $\alpha 2$ antibodies significantly decreased keratinocyte migration, indicating that $\alpha 2$ may regulate MMP-1 expression [126]. Decreased MMP-1 mRNA expression observed in CD9-HT1080 cells may be related to reduced $\alpha 2 \beta 1$ cell surface expression. In spite of that, the findings at the mRNA level did not fully translate to a significant decrease in MMP-1 proteinase release in the cell supernatant as determined by ELISA. This finding led to the exclusion of $\alpha 2 \beta 1$ or MMP- 1 as mediators of the phenotypic differences between Mock- and CD9-HT1080 cells.

\footnotetext{
* Adapted with permission from Public Library of Science. Herr MJ, Kotha J, Hagedorn N, Smith B, Jennings LK (2013) Tetraspanin CD9 promotes the invasive phenotype of human fibrosarcoma cells via upregulation of matrix metalloproteinase-9. PLoS One 8: e67766.

†Adapted with permission from Biochemical and Biophysical Research Communications: Herr MJ, Mabry SE, Jameson JF, Jennings LK (2013) Pro-MMP-9 upregulation in HT1080 cells expressing CD9 is regulated by epidermal growth factor receptor. Biochem Biophys Res Commun.
} 
The invasive phenotype observed in CD9-HT1080 cells was the result of significant increases in MMP-9 mRNA expression and proteinase release into the media. This conclusion was endorsed by the fact that silencing MMP-9 in CD9-HT1080 reverted the invasive phenotype of these cells to mimic that of the Mock-transfected cells. An earlier study did not observe this invasive phenotype in CD9-HT1080 cells using a matrigel invasion assay [71]. This difference may be the result of higher cell numbers and increased chemoattractant the earlier study used in the invasion assays, which would have overwhelmed the possibility of observing any differences in cell invasion. However, when using conditions more similar to this report's experimental design, Zvieriev et al. demonstrated that exogenous CD9 expression increased in vitro matrigel invasion in a prostate cancer cell line [127]. A recent study corroborated the finding that silencing of MMP-9 in HT1080 cells decreases their invasive capabilities both in vitro and in a xenograft model of invasion [128].

Other laboratories have demonstrated that tetraspanin expression may indirectly result in the regulation of MMP production by influencing TIMP expression and activity. Jee and colleagues demonstrated that KAI1/CD82 upregulated TIMP-1 to suppress tumor cell invasion in lung carcinoma model [129]. TIMP-1 complexes with pro-MMP-9 and inhibits its conversion to the active proteinase [130]. Furthermore, tetraspanin CD63 interacts with TIMP-1 at the cell surface to regulate cell survival and apoptosis in a breast epithelial cell line [89]. All four TIMP expression levels were compared between Mock and CD9-HT1080 cells. TIMP-4 expression was not detectable in either Mock- or CD9HT1080 cells ruling out its contributions. This finding is most likely due to the fact that TIMP-4 expression is prominent only in the brain, heart, ovary, and skeletal muscles of adult mice [131] and was originally isolated in the human heart with very low or absent levels of expression in other major organs [132]. The absence of a significant change in the mRNA expression of TIMP-1, TIMP-2, or TIMP-3 upon CD9 overexpression favors the idea that CD9 expression does not regulate MMP expression via changes in TIMP mRNA levels.

Strong evidence involves PI3K-Akt [133-136] signaling preceding MMP-9 increases in cancer cell lines. This pathway signals to the downstream transcription factors NF- $\kappa$ B $[133,137]$ and AP-1 $[138,139]$ to increase MMP-9 production. Specifically, Thant, et al. found the PI3K-Akt pathway to be essential for FN-dependent MMP-9 secretion and invasion of ovarian cancer cells [140]. LY294002, wortmannin, and a dominant-negative Akt construct blocked MMP-9 production in multiple human hepatocellular carcinoma cell lines [133]. MMP-9 production was stimulated through the PI3K, Akt, JNK1/2 pathway in human limbal epithelial cell outgrowth and was not affected by MEK1/2 or p38MAPK inhibition [141].Lisa Jennings and colleagues previously demonstrated in two cell lines that CD9 expression enhances Akt phosphorylation $[142,143]$. Both of the CD9-elicited phenotypes were nullified upon treatment with LY294002 or wortmannin [142, 143]. Preliminary studies with CD9HT1080 cells indicated a 25\% decrease in MMP-9 gelatinolytic band intensity using the PI3K inhibitor LY294002 in a gelatin zymography analysis of CD9-HT1080 conditioned media (Herr et al., unpublished observations). The same PI3K-Akt pathway may be responsible for the observed increase in MMP-9 expression and secretion in CD9- 
HT1080 cells. Chen, et al. substantiate this hypothesis by demonstrating that CD9 expression in HT1080 cells resulted in increased Akt phosphorylation [94].

The second extracellular loop (EC2) of CD9 is responsible for the upregulation of diphtheria toxin binding [58], and gamete fusion [57]. Deletion of CD9 EC2 in a CHO cell line led to decreased motility and increased cell adhesion and fibronectin matrix assembly $[103,108]$. Herein, it was demonstrated that CD9 EC2 was critical in eliciting MMP-9 expression in CD9-HT1080 cells. Upon EC2 deletion, the observed increases in MMP-9 expression and release were reduced to levels found in Mock-HT1080 cells or after silencing of the proteinase. Furthermore, the increase in the invasive phenotype of CD9-HT1080 cells was reduced upon deletion of CD9 EC2. These findings confirm and extend previously published data that CD9 EC2 is of immense importance in the full functioning of this tetraspanin.

It is well-established that EGFR activation results in increased MMP-9 expression and release $[112,144]$ and that MMP-9 expression results in increased cell invasion [133, 145]. The mechanism for how CD9 may regulate MMP-9 expression is not entirely clear. Murayama et al. demonstrated that the EC2 of CD9 associates with EGFR and $\beta 1$ integrin. Treatment with an anti-CD9 monoclonal antibody, ALB6, enhanced EGFR internalization after EGF treatment [93]. ALB6 has been reported as an inhibitory antibody to CD9 [73, 146-148]; therefore, inhibition of CD9 resulted in increased EGFR internalization. In the same study, CD9 and EGFR expression in Chinese hamster ovary cells $(\mathrm{CHO})$ resulted in increased receptor internalization upon EGF treatment [93]. Hence, these findings were severely confused by the fact that CD9 inhibition and overexpression had the same outcome. To further befuddle this mechanism, another group demonstrated that CD9 does not associate with EGFR, but regulates EGFR juxtacrine signaling in HEK293 cells by associating with the transmembrane EGFR ligand TGF $\alpha$ [111].

The findings in this current report showed that CD9 regulated the release of proMMP-9 in HT1080 cells via EGFR expression and activity. EGFR activity was proved necessary using four distinct EGFR tyrosine kinase inhibitors. All inhibitors demonstrated a dose-dependent inhibition of pro-MMP-9 indicating their specificity. Treatment with $10 \mu \mathrm{M}$ gefitinib inhibited pro-MMP-9 release to a level comparable to Mock-HT1080 cells. For this reason, the same concentration of gefitinib was used to suppress CD9-HT1080 cell invasion. Inhibition of EGFR activity with gefitinib was sufficient to inhibit pro-MMP-9 release which resulted in decreased cellular invasion in CD9-HT1080 cells. The expression of total EGFR protein in Mock, CD9, and $\Delta 6$ HT1080 cells was not significantly different as determined by Western blot (Figure 3-3B, unpublished observations). Correspondingly, the regulation of EGFR signaling must be at the level of cell surface receptor expression and at the level of EGFR phosphorylation (activity). The experimental design of plating the cells on FN in serumfree media was similar to multiple other studies that demonstrated ECM-mediated activation of EGFR in the absence of EGFR ligands [149-151]. Kotha, et al. established that CD9 associates with integrin $\alpha 5 \beta 1$ using co-immunoprecipitation in multiple cell lines and that it plays a role in enhancing the activation state of $\beta 1$ integrins $[142,143]$. 
Full-length CD9 expression may stabilize CD9- $\alpha 5 \beta 1$ interactions with fibronectin and augment ECM-mediated EGFR activation to stimulate increased pro-MMP-9 release.

Moro et al. conducted an elaborate study to tease out how integrins may activate EGFR in the absence of EGFR ligands [151]. When an $\alpha$-associated $\beta 1$ integrin subunit is engaged either by antibody treatment or ECM, the activated $\alpha$ subunit associated with autophorphorylated cSrc and the $\beta 1$ subunit cytoplasmic tail associates with phosphorylated p130Cas [151]. It was hypothesized that active $\mathrm{cSrc}$ then phosphorylates EGFR at tyrosine 845 [151]. The phosphorylated EGFR is then brought into a complex with the $\alpha$ and $\beta 1$ integrin subunits and autophosphorylation of EGFR occurs and downstream signaling commences [151]. Studies from the Jennings' laboratory nicely assimilate the findings from this paper and the CD9- $\alpha 5 \beta 1$-EGFR proposed signaling mechanism. First, CD9 expression increased the phosphorylation of p130Cas upon binding fibronectin [142]. CD9 expression also intensified $\beta 1$ integrin subunit activation in response to FN [142]. Second, CD9 EC2 was elegantly demonstrated to bind directly to $\mathrm{FN}$ and promote the CD9-FN-induced motile phenotype [108]. Thus, CD9 may not only serve to regulate $\beta 1$ integrin confirmation but also bring the triad in closer proximity to FN. Consequently, in the absence of CD9 (Mock-HT1080 cells) or when CD9 is not associated with $\alpha 5 \beta 1$ integrin or helping to bind FN ( $\Delta 6$-HT1080 cells), EGFR signaling is weakened. Therefore, pro-MMP-9 expression and release, and cell invasion would not be increased over baseline invasion. The same results were observed when EGFR activation was inhibited using EGFR-specific tyrosine kinase inhibitors and when EGFR expression was decreased using siRNA. In summary, it is hypothesized that CD9 regulates EGFR signaling in HT1080 cells by a CD9- $\alpha 5 \beta 1$-FN interaction that stimulates EGFR phosphorylation.

The pitfall to this hypothesis is that EGFR largely signals downstream through the p38MAPK, ERK pathway [152, 153], but previous findings suggest PI3K is the major downstream signaling pathway from CD9 expression [142, 143]. Although MMP-9 expression is primarily evoked through the PI3K pathway, there is sufficient evidence to suggest ERK signaling may also elicit MMP-9 expression [154-156]. The most imaginable scenario is that signaling to MMP-9 occurs through both pathways. Supporting evidence from Sil et al. demonstrated that adhesion to FN induced MMP-9 mRNA, protein, and activity in murine melanoma cells via the alpha5beta1 integrin and the FAK, ERK, and PI3K pathways [157]. Preliminary data in this laboratory suggest treatment of CD9-HT1080 cells with U0126 and PD98059 to block pro-MMP-9 release to levels comparable with Mock-HT1080 cells (Figure B-3). Cell signaling is a very dynamically regulated process especially at the cell-ECM junction. CD9's partnership with multiple different proteins is cell type specific, but in HT1080 cells CD9 has been demonstrated to co-immunoprecipitate EGFR.

In summary, these findings demonstrate for the first time a specific link between tetraspanin CD9 and metalloproteinase MMP-9 expression that significantly affects the invasive phenotype of HT1080 cells. Therefore, CD9 consequently may play an important role in tumor cell invasion and promoting metastasis. This potential relationship between CD9 expression and the tumor cell phenotype is supported by 
studies that used inhibitory anti-CD9 antibodies to decrease tumor weight in two separate in vivo models $[73,147]$. Additionally, the CD9 EC2 region is a potentially new target for regulating MMP-9 production. Together, these key findings support a model in which tetraspanin CD9 may have considerable therapeutic potential for the treatment of metastasizing cancers. 


\section{CHAPTER 5. TETRASPANIN CD9 REGULATES CELL CONTRACTION AND ACTIN ARRANGEMENT IN HUMAN AORTIC SMOOTH MUSCLE CELLS VIA RHOA}

\section{Introduction}

Smooth muscle cells (SMCs) located in the medial layer of the arterial wall are primarily responsible for regulating the physiomechanical properties of arteries. These cells are unique in that they are not terminally differentiated and retain their ability to transform their phenotype from contractile or differentiated to synthetic or dedifferentiated. The switch from a contractile to synthetic phenotype is a well-studied, though complex, occurrence and is primarily characterized by a change in cell morphology from elongated to more rounded cells and by a decrease in smooth muscle cell marker expression [158]. Vascular smooth muscle cells (VSMC) in the synthetic state are associated with coronary artery disease including atherosclerosis and restenosis as well as with hypertension

Understanding the mechanisms that control VSMC phenotype switching during vascular development and in vascular disease is an intense area of investigation. The importance of cell surface proteins, specifically integrins and tetraspanins, and their regulation of interactions with the extracellular matrix (EMC) have been previously demonstrated to play a relevant role in vascular cell biology $[159,160]$. Tetraspanins function primarily as cell surface organizers and play an integral role in the potentiation of cellular responses from the extracellular environment. It has been demonstrated that the action of integrins is dependent on their interaction with tetraspanins [161]. Tetraspanins are ubiquitously expressed in vascular and hematopoietic cells and have implications in multiple physiologic and pathologic functions, yet they are understudied in the field of vascular biology [160].

Tetraspanin CD9 has been implicated in multiple essential cellular processes relevant to the smooth muscle cell synthetic phenotype including proliferation [111], migration [162], and neointimal formation [143]. Specifically, this laboratory and others previously demonstrated an elevated expression level of tetraspanin CD9 on the cell surface of cultured VSMCs in the synthetic state $[143,163]$. The expression of CD9 was closely linked to the dedifferentiated phenotype of smooth muscle cells. Blockade or stimulation of CD9 using monoclonal antibodies resulted in the propagation or modulation of these phenotypes; however, there has not been an explanation as to how CD9 regulates the phenotypic diversity of these cells $[103,164]$.

\section{Rationale}

The present study was designed to further determine the role CD9 plays in regulating the dedifferentiated phenotype of smooth muscle cells. A human model of arterial function, human aortic smooth muscle cells (HAOSMC), was used to specifically 
understand the importance of CD9 on human VSMC phenotypes, namely the capability of the cells to undergo contraction. CD9 knockdown resulted in pronounced morphologic changes and altered cellular actin arrangement. Furthermore, lack of CD9 reduced the highly coordinated contractile capabilities of HAOSMC. GTP-bound RhoA (active RhoA) levels were significantly diminished in cells lacking CD9. Restoration of RhoA activity in the CD9 deficient cells was sufficient to restore the contractile phenotype. Conversely, inhibition of active RhoA or knockdown of total RhoA resulted in a phenotype that mimicked CD9 deficient cells. The reported results outline a previously unexplained mechanism by which CD9 has a key role in regulating SMC contraction and SMC phenotypes.

\section{Materials and Methods}

\section{Reagents and Antibodies}

Smooth muscle cell basal medium (SmBM), fetal bovine serum (FBS), recombinant human epidermal growth factor (rhEGF), recombinant human fibroblast growth factor (rhFGF), recombinant human insulin, and gentamicin sulfate/amphotericinB purchased from Lonza (CC-3182, Walkersville, MD). Alexa-fluor 594 conjugated phalloidin (A12381) and Lipofectamine 2000 was purchased from Life Technologies (Grand Island, NY). The RhoA activator (CN03) and the RhoA inhibitor (CT04) were purchased from Cytoskeleton (Denver, $\mathrm{CO}$ ). Information pertaining to the antibodies used in this chapter may be found in chapter 2 .

\section{Cell Culture}

Primary human aortic smooth muscle cells (HAOSMC) were purchased from Lonza at passage 3. HAOSMC were cultured in a humidified incubator at $37^{\circ} \mathrm{C}$ and $5 \%$ $\mathrm{CO}_{2}$ in SmBM containing a final concentration of $5 \% \mathrm{FBS}, 0.5 \mathrm{ng} / \mathrm{ml} \mathrm{rhEGF}, 2 \mathrm{ng} / \mathrm{ml}$ $\mathrm{rhFGF}, 5 \mu \mathrm{g} / \mathrm{ml}$ insulin, and $50 \mu \mathrm{g} / \mathrm{ml}$ gentamicin sulfate/amphotericin-b (serumsupplemented SmBM). Cells were maintained in the synthetic state by changing media every 48 hours and passaging every 96 hours.

\section{Knockdown of CD9 in HAOSMC Cells}

CD9 lentiviral shRNA was generated in the viral vector core laboratory at the University of Tennessee Health Science Center (UTHSC, Memphis, TN). pLKO.1 CD9 shRNA lentiviral vector plasmids were obtained from Open Biosystems (Thermo Scientific, Pittsburgh, PA) and the plasmids were propagated in DH5 $\alpha$ E. Coli in LB+Carbencillin containing media. pLKO.1 CD9 shRNA or scrambled control (Ctr) shRNA was co-transfected into 293FT cells using ViraPower mix kit (Invitrogen, Grand Island, NY). Cell culture supernatants were harvested 60 hours after transfection, filtered 
through $0.45 \mu \mathrm{M}$ filters, and the lentivirus was concentrated by ultracentrifugation at $50,000 \mathrm{x}$ g for 3 hours. At passage 5, HAOSMC at 70\% confluence were transduced in 6well culture dishes using $2 \mathrm{ml}$ of serum-free SmBM containing $10 \mu 1$ of lentiviral shRNA and a final concentration of $10 \mu \mathrm{g} / \mathrm{ml}$ polybrene. Transduction was complete after 24 hours and selection of cells positive for shRNA constructs was performed 48 hours after transduction using a final concentration of $1.0 \mu \mathrm{g} / \mathrm{ml}$ puromycin. All successive experiments were conducted using HAOSMC between passages 6 and 8 .

\section{RNA Extraction and qRT-PCR Analysis}

RNA extraction and qRT-PCR Analysis was performed as detailed in the Materials and Methods section of Chapter 2. The cDNA was made from 500ng of total HAOSMC RNA and additional primers used are listed in Table A-3.

\section{Knockdown of RhoA in HAOSMCs}

Naïve HAOSMC at passage 5 were transfected with short interfering (siRNA) directed against RhoA (Product \#4390824, ID\# s758) or a scrambled control (Ctr) siRNA sequence (AM4635) purchased from Ambion (Life Technologies, Grand Island, NY). Prior to transfection $10 \mu 1$ of Lipofectamine 2000 was incubated in $0.5 \mathrm{ml}$ of serum-free SmBM for 5 minutes at room temperature, then 600 pmol of siRNA in $0.5 \mathrm{ml}$ of serumfree SmBM was added to Lipofectamine dilution and allowed to incubate for 20 minutes. HAOSMCs were $70 \%$ confluent upon transfection, cell monolayers were washed three times with PBS, then $1 \mathrm{ml}$ of Lipofectamine-siRNA mixture was added dropwise to cells in 6-well cell culture plates. After 6 hours, the mixture was aspirated and monolayers were rinsed with serum-supplemented SmBM and allowed to incubate for 24-48 hours before preforming experiments.

\section{Measurement of the Area of Crystal Violet Stained Cells}

Control and CD9 shRNA HAOSMC plated in serum-supplemented SmBM in 24well culture plates were washed twice with PBS and fixed and permeabilized in ice cold methanol for 5 minutes. The methanol was washed off and a saturating amount of $0.05 \%$ crystal violet was added for 30 minutes. The crystal violet was aspirated and the cells were washed twice with distilled water and allowed to air dry. Pictures were then taken at $4 \mathrm{x}$ and $10 \mathrm{x}$ magnifications using an inverted phase contrast microscope, a Sony $3 \mathrm{CCD}$ color video camera (Tokyo, Japan) and Scion Image software (Frederick, MD). The area of the cells at 10x magnification was measured in arbitrary units using ImageJ software. This experiment was completed three independent times and a total of 25 cells from random fields of view from each experiment were measured to calculate the average area. 


\section{Proliferation Assay}

Proliferation of cells in culture was measured using a bromodeoxyuridine (BrdU) incorporation assay purchased from Cell Signaling Technology (6813, Danvers, MA) per the manufacturer's instructions. Briefly, cells were harvested, counted, and diluted to equal densities in serum-supplemented media and 6,000 cells were added to each well of a 96-well cell culture plate along with 1 xBrdU. After 24, 48, or 72 hours, the media was aspirated and the cells were fixed and DNA was denatured. Anti-BrdU primary antibody was added and incubated for 1 hour. The plate was subsequently washed three times using $1 \mathrm{x}$ washing buffer and a HRP-conjugated secondary antibody was added. After a 30 minute incubation, a 3,3', 5,5'-tetramethylbenzidine (TMB) substrate was added for 15 minutes then a stop solution was added to stop color development. Absorbance was read on a versamax tunable microplate reader at $450 \mathrm{~nm}$. Each group was run in triplicate and averaged. A total of three independent repeats for each group were performed.

\section{Immunofluorescent Staining of F-actin}

Ctr and CD9 shRNA HAOSMC were harvested and seeded at low density onto glass coverslips in 6-well cell culture dishes in serum-supplemented SmBM. After two hours of attachment, the media was aspirated and cells were fixed in $4 \%$ paraformaldehyde (PFA)-PBS solution. After 10 minute incubation the 4\% PFA-PBS solution was aspirated, and the cells were rinsed three times with PBS then permeabilized using $0.1 \%$ TX-100 in PBS for 5 minutes. The TX-100 solution was aspirated and the monolayer of cells was washed three times with 5\% goat serum (GS) in PBS and incubated with 5\% GS-PBS for 30 minutes to block any non-specific binding. Alexafluor-594 conjugated phalloidin (1:50) in 5\% GS-PBS was added to the coverslips and incubated for 30 minutes at room temperature. After aspirating and washing the monolayer of cells with PBS, the coverslips were inverted and mounted to glass slides using Vectashield hard set mounting medium (H-1400, Vector Laboratories, Burlingame, CA). Images were acquired using an Axioplan 2 fluorescent imaging microscope equipped with an AxioCam HRm camera and actin length was quantified using AxioVision software (Zeiss, Oberkochen, Germany).

\section{Detection of Total and GTP-Bound RhoA}

Active and GTP-bound RhoA were measured from cell lysates using a total RhoA ELISA (BK150) or RhoA activation G-LISA kit (BK124) purchased from Cytoskeleton, Inc. (Denver, CO) per the manufacturer's instruction. Briefly, Ctr and CD9 shRNA lysates were made using the provided cell lysis buffer and protease inhibitor cocktail and quantified using the precision red protein assay reagent by measuring the absorbance at $600 \mathrm{~nm}$ on the Versamax plate reader. Lysates were diluted to $0.5 \mathrm{mg} / \mathrm{ml}$ using lysis buffer loaded on to their respective ELISA (total RhoA) or G-LISA (GTP-bound RhoA) plate for protein analysis. Results were obtained as absorbance values at 490nm and were converted to total protein levels using a standard curve obtained with each test. Samples 
were tested in duplicate and values from at least three independent experiments were averaged.

\section{Collagen Gel Contraction Assay}

Collagen gel contraction assays were purchased from Cell Biolabs (CBA-201, San Diego, CA) and used per the manufacturer's instructions. HAOSMC were harvested and the pellet was suspended in serum-free SmBM at $2.0 \times 10^{6}$ cells $/ \mathrm{ml}$. For each assay, $100 \mu 1$ of the cell suspension was mixed with $400 \mu 1$ of neutralized collagen solution and added to one well of a 24-well cell culture plate and allowed to solidify for one hour at $37^{\circ} \mathrm{C}$. After polymerization, $1 \mathrm{ml}$ of complete media was added to the top of each collagen gel. After 48 hours incubation, the gels were released by running a sterile pipette tip along the sides of the well. Some populations of cells were treated with either $20 \mu \mathrm{g} / \mathrm{ml}$ CN03 (RhoA activator) or CT04 (RhoA inhibitor) two hours prior to release. The culture dish was then scanned immediately after being released (time 0 , initial time point) and for 30 minute intervals for six hours. ImageJ software was used to measure the area of each collagen gel and the arbitrary units (AU) for each time point were used to calculate exact percent contraction values from the initial time point using the following formula: [(AU at Initial Time Point/AU at Current Time Point)-AU at Initial Time Point]*100\%.

\section{Statistical Analysis}

Sample testing and statistical analysis was performed as detailed in the Materials and Methods section of Chapter 2. For the contraction assays, a repeated measures t-test was used to compare the changes in contraction among two groups at each time point. Bars or points represent the mean result and error bars represent the standard deviation of the mean.

\section{Results}

\section{CD9 Deficiency Results in Altered Cell Morphology, Proliferation, and SMC Marker Expression}

Smooth muscle cells in culture have augmented CD9 expression that is correlated to their synthetic state $[143,163]$. CD9 lentiviral shRNA was used to knockdown CD9 expression in human aortic smooth muscle cells (HAOSMC). When compared to cells treated with scrambled control (Ctr) lentiviral shRNA, decreased CD9 expression in the CD9 shRNA HAOSMC was observed at the mRNA and protein levels (Figure 5-1A and 5-1B). More importantly, CD9 expression was reduced at the cell surface where it primarily functions (Figure 5-1C). The expression of a closely related tetraspanin, CD81, and another highly functional tetraspanin, CD151, was not affected by CD9 knockdown at the mRNA or cell surface levels (Figure 5-1D and 5-1E). 


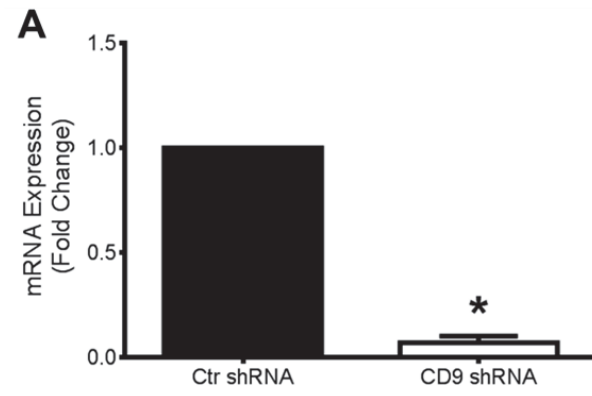

C

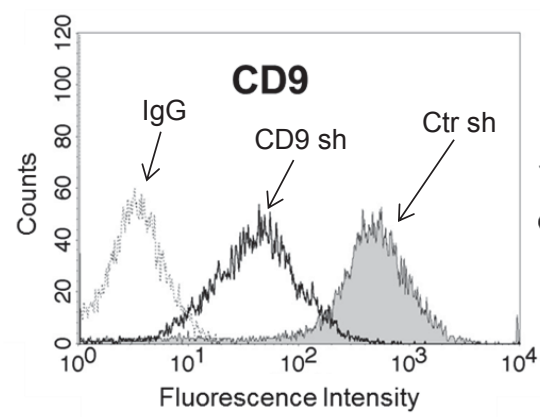

B

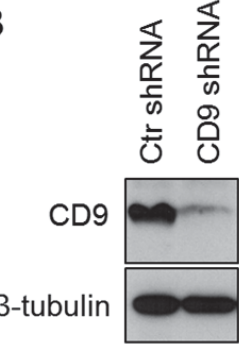

D

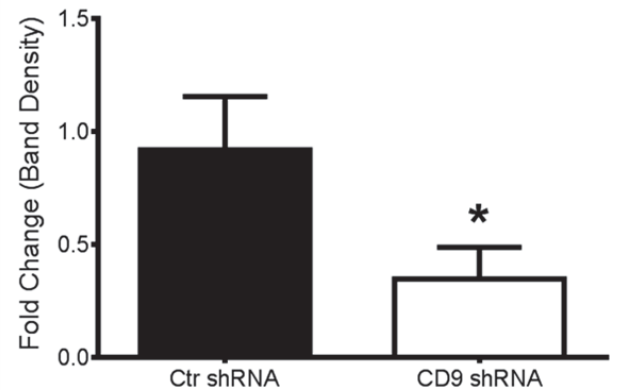

E
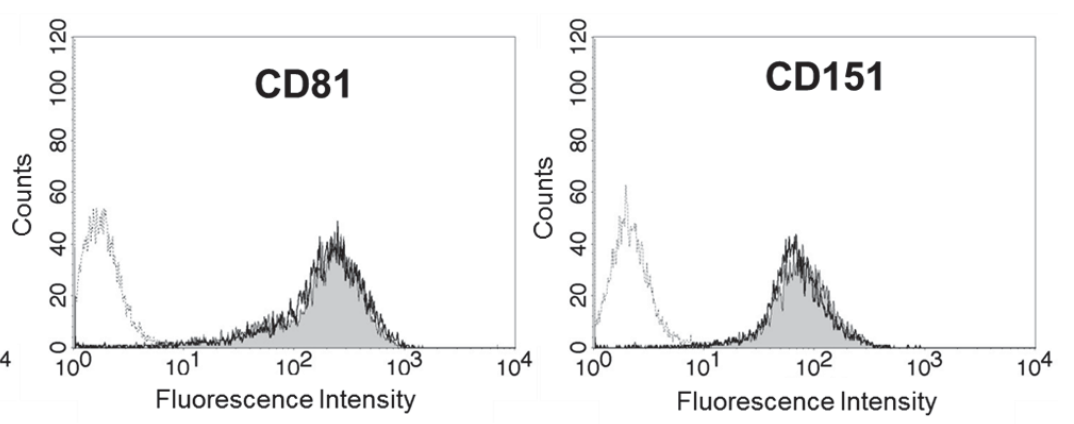

Figure 5-1. Knockdown of tetraspanin CD9 in human aortic smooth muscle cells (HAOSMCs) does not affect CD81 or CD151 cell-surface expression.

(A) The fold change in CD9 mRNA in control (Ctr) shRNA and CD9 shRNA transduced cells was measured using qRT-PCR (n=5; $* \mathrm{P}<0.05)$.(B) Whole cell expression of CD9 was measured by Western blotting using an anti-human CD9 monoclonal antibody $(\mathrm{mAb} 7)$. A representative blot and quantification of three independent blots is presented $(* \mathrm{P}<0.05)$. (C-E) Cell surface expression of CD9, CD81, and CD151 was measured on non-permeabilized HAOSMCs using flow cytometry. Dotted gray lines represent negative control IgG binding, shaded histograms represent Ctr shRNA HAOSMC, and open histograms represent CD9 shRNA binding of indicated anti-human tetraspanin antibodies. A representative histogram from three independent experiments is shown for each antihuman tetraspanin antibody. 
Upon knockdown of CD9 expression a profound difference in cell morphology was observed (Figure 5-2A). HAOSMC lacking CD9 were notably smaller as determined by cell area and more rounded than their Ctr shRNA treated counterparts $(\mathrm{P}<0.01$; Figure 5-2B). Reducing CD9 expression resulted in a cell morphology that resembled the dedifferentiated phenotype of SMCs [165]. CD9 shRNA HAOSMC were also less proliferative than Ctr shRNA cells over 72 hours as determined by bromodeoxyuridine incorporation assays $(\mathrm{P}<0.01$; Figure 5-2C). To further define the phenotype of CD9 shRNA HAOSMCs, the expression levels of smooth muscle cell markers were measured. The mRNA expression of smooth muscle $\alpha$-actin (SM $\alpha$-actin) and SM22 $\alpha$ were not significantly different between the two groups of cells (Figure 5-2D). However, the expression of a third smooth muscle cell marker, calponin, was increased 4-fold ( $\mathrm{P}<0.05$; Figure 5-2D). Hence, the efforts to clarify the exact phenotype of HAOSMC lacking CD9 were not conclusive based on the discrepant expression of three smooth muscle cell markers.

\section{CD9 Deficient HAOSMC Have Altered Actin Arrangement and Decreased Contractile Capabilities because of RhoA-Mediated Pathways}

It was hypothesized that decreased CD9 expression and the resulting phenotype may be a consequence of changes in the cellular cytoskeleton. Alexa fluor-conjugated phalloidin and immunofluorescent microscopy were used to characterize changes in the stress fiber arrangement between $\mathrm{Ctr}$ and CD9 shRNA treated HAOSMC (Figure 5-3A). The CD9 shRNA HAOSMC had a more circular arrangement of significantly shorter actin stress fibers whereas the Ctr shRNA HAOSMC had a more elongated and parallel arrangement of stress fibers $(\mathrm{P}<0.01$; Figure 5-3B). These findings suggested that CD9 may elicit the drastic morphologic difference between the two cell types by regulating the stress fiber arrangement.

As it is well established that actin stress fiber arrangement is a direct consequence of RhoA activity $[166,167]$, the amount of total and GTP-bound RhoA in Ctr and CD9 shRNA HAOSMC was measured using an enzyme linked immunosorbent assay. Total RhoA was not significantly different between the two groups (Figure 5-3C); however, there was significantly less active RhoA detected in the CD9 deficient cells $(\mathrm{P}<0.05$, Figure 5-3D). A collagen gel contraction assay was used to determine if this deficiency had an effect on HAOSMC contraction. CD9 shRNA HAOSMC were $30 \%$ less contractile than their Ctr shRNA counterparts. After 1 hour, the Ctr shRNA cells were significantly more contractile and remained so for the entire assay $(\mathrm{P}<0.05$; Figure 5-3E and 5-3F). The contraction of both groups began to plateau after 4 hours and was unchanged at the conclusion of the assay. 

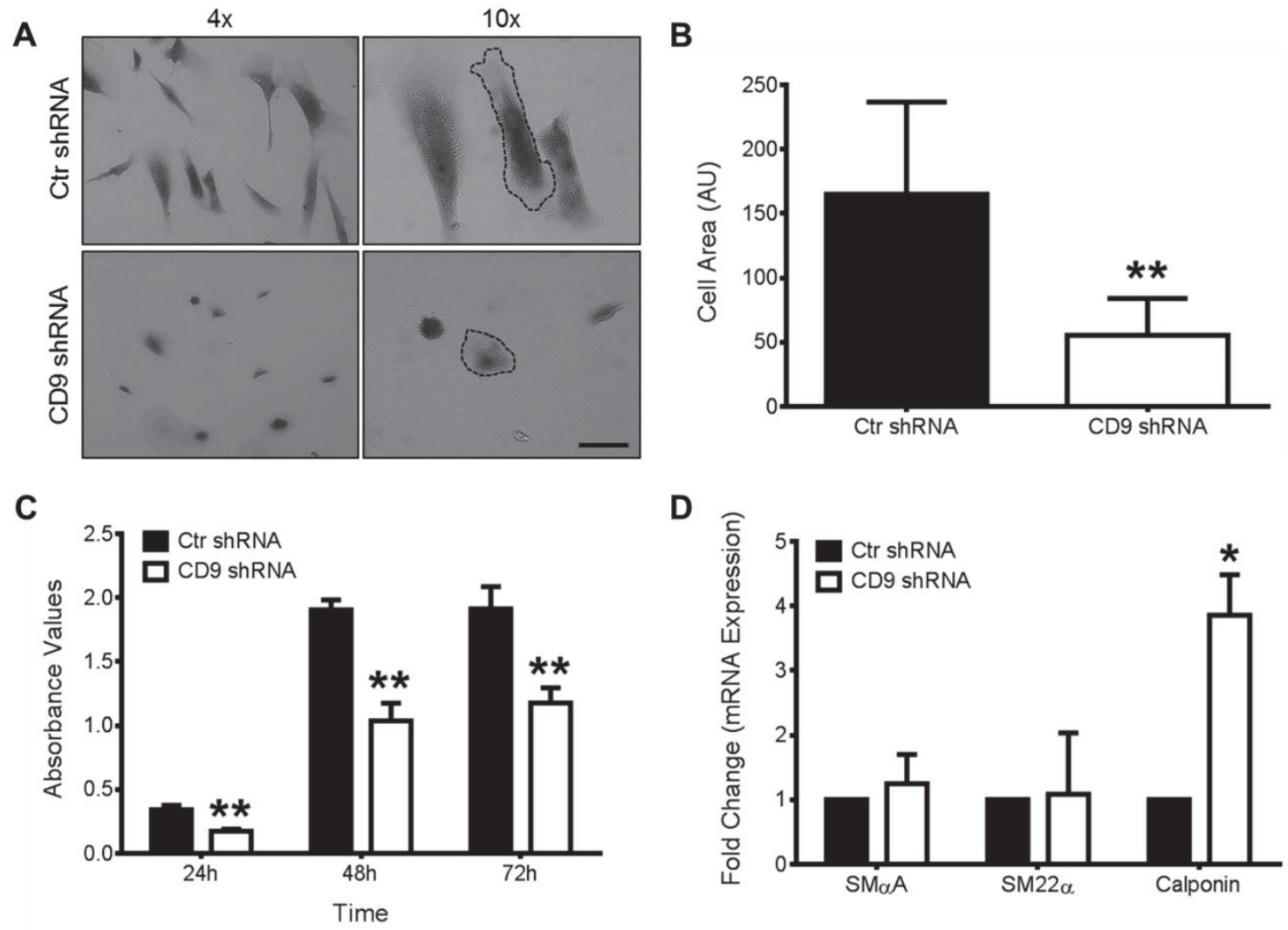

Figure 5-2. CD9 deficient HAOSMCs have an altered cell morphology, decreased cell size and proliferation, and an increased level of calponin mRNA.

(A) Knockdown of CD9 results in smaller and more rounded cells as demonstrated by representative phase contrast images of crystal violet stained cells at different magnifications ( $\mathrm{n}=4$ independent repeats; scale bar, $100 \mu \mathrm{m})$. (B) Quantification of cell area of Ctr and CD9 shRNA HAOSMCs ( $\mathrm{n}=25$ cells; $* * \mathrm{P}<0.01)$. (C) HAOSMCs lacking CD9 are less proliferative after 24, 48, and 72 hours in culture as measured by absorbance values obtained from a BrdU incorporation assay $(\mathrm{n}=5 ; * * \mathrm{P}<0.01$ versus $\mathrm{Ctr}$ shRNA at same time point). (D) mRNA levels of SM $\alpha$-actin, SM22 $\alpha$, and calponin were measured using qRT-PCR $(\mathrm{n}=3 ; * \mathrm{P}<0.05)$. 
A

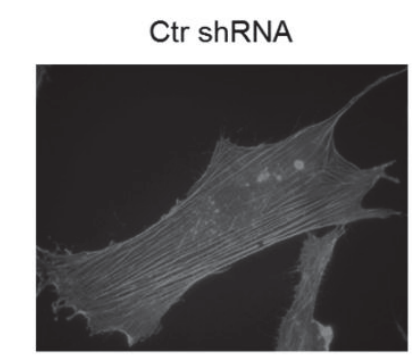

C

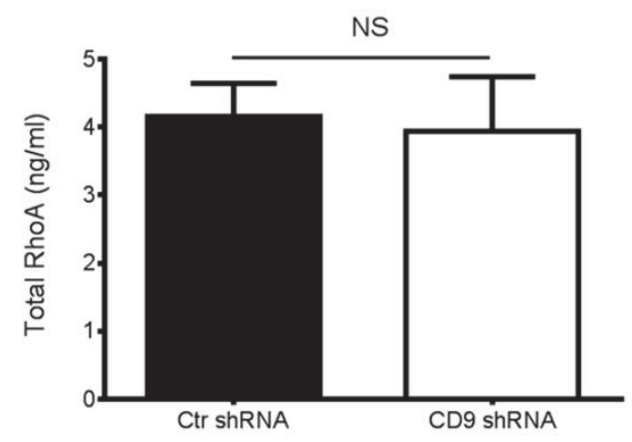

E

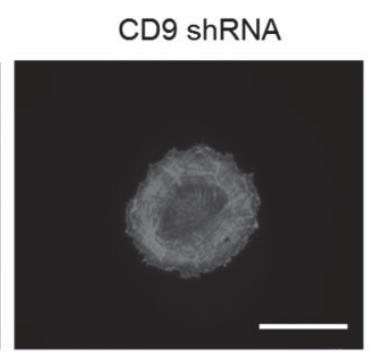

C

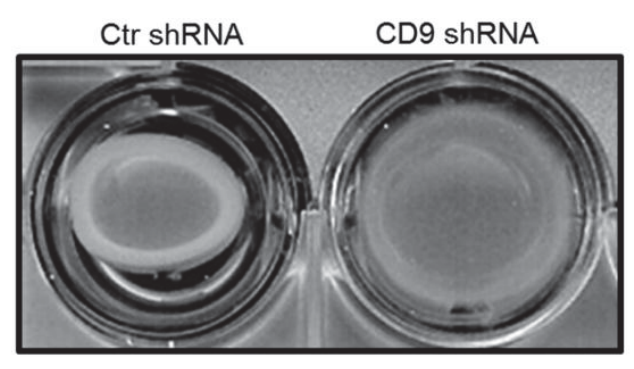

B

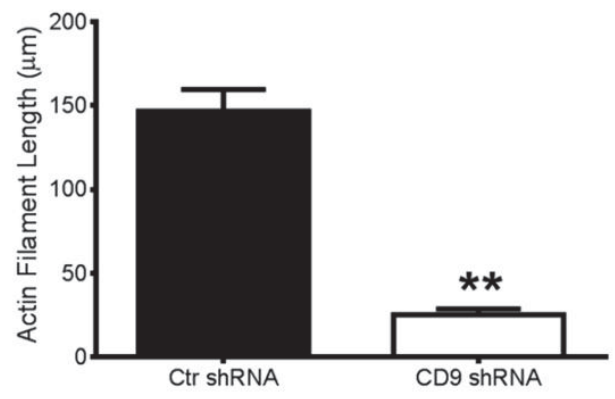

D

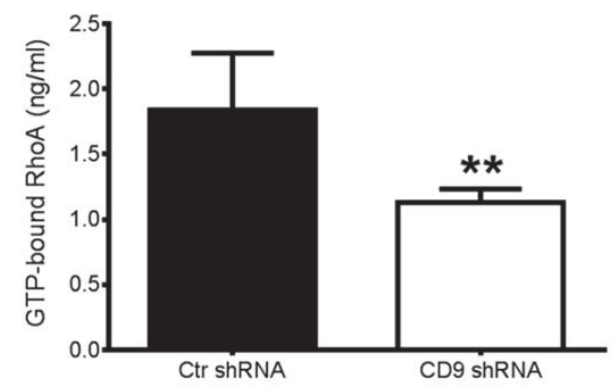

$\mathbf{F}$

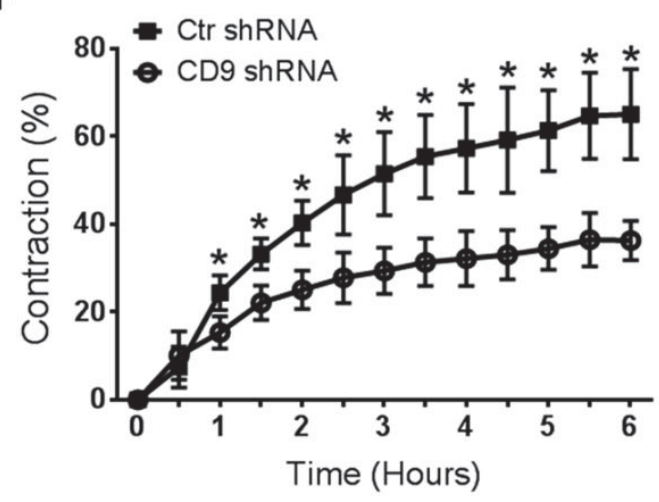

Figure 5-3. HAOSMCs lacking CD9 display altered actin arrangement and a decrease in active RhoA and collagen gel contraction.

(A) Ctr and CD9 shRNA cells were fixed, permeabilized and stained with alexa-fluor 594 conjugated phalloidin and viewed using a immunofluorescent deconvolution microscope (scale bar, $50 \mu \mathrm{m}$ ). (B) Quantification of actin filament length was performed using ImageJ analysis software $(\mathrm{n}=15$ cells; $* * \mathrm{P}<0.01)$. (C and D) Total and GTP-bound (active) RhoA was measured in whole cell lysates from Ctr and CD9 shRNA HAOSMC using an ELISA and the absorbance values were converted to concentration values from a standard curve ( $\mathrm{n}=3$; NS indicates no significant difference; $* * \mathrm{P}<0.01)$. (E and F) A representative image of a collagen gel contraction assay taken at 6 hours and quantification of the percent contraction over time ( $\mathrm{n}=3 /$ time point; $* \mathrm{P}<0.05$ versus CD9 shRNA at indicated time point). 


\section{Activation of RhoA Restores the CD9 shRNA HAOSMC Phenotype}

The observed deficiency of GTP-bound RhoA and loss of the contractile phenotype of CD9 shRNA HAOSMC led to the hypothesis that RhoA was responsible for this phenomenon. The cell permeable RhoA activator CN03 which blocks intrinsic GTPase activity to sustain GTP-bound RhoA in CD9 deficient HAOSMC [168] was used to this end. Upon restoration of GTP-bound RhoA (Figure 5-4A) and without significantly affecting the levels of total $\mathrm{Rho}(\mathrm{P}=0.19$; Figure 5-4B), an increase in the contractile capability of CD9 shRNA HAOSMC was observed (Figure 5-4C). The significant difference in contraction observed between the two cell groups was no longer obvious after treatment of CD9 shRNA cells with CN03 (Figure 5-4D). Comparison of the actin cytoskeleton of CN03 treated CD9 shRNA HAOSMC revealed that actin stress fibers were arranged more parallel to one another than the untreated cells (Figure 5-4E). However, the CN03 treated cells did not display the elongated stress fibers originally observed in the Ctr shRNA HAOSMC. These data indicate that the absence of active RhoA results in a lack of actin arranged in parallel, elongated stress fibers, and that active RhoA is necessary for HAOSMC-mediated collagen gel contraction.

\section{Deficiency of Active RhoA or Loss of Total RhoA Mimics the CD9 shRNA HAOSMC Phenotype}

To further attribute RhoA activity to HAOSMC capability to contract, GTPbound RhoA was inhibited in Ctr shRNA HAOSMC using CT04. CT04 is a cell permeable $\mathrm{C} 3$ transferase derived from $C$. botulinum which works by inhibiting RhoA ADP-ribosylation but does not affect Rac or Cdc42 activity [169]. ELISA analysis confirmed that GTP-bound RhoA was significantly decreased after treatment with CT04 without affecting total RhoA levels (Figure 5-5A and 5-5B). Contraction of CT04-treated Ctr shRNA cells was significantly reduced compared to the untreated cells (Figure 5-5C). This difference was observed for the duration of the assay (Figure 5-5D). In addition to suppressing RhoA activity, the expression of RhoA was knocked down in $\mathrm{Ctr}$ shRNA HAOSMC using short interfering RNA (siRNA). Knockdown of RhoA was confirmed at both the mRNA and protein levels (Figure 5-5E and 5-5F). The absence of RhoA was sufficient to inhibit collagen gel contraction of Ctr HAOSMC treated with siRNA (Figure 5-5G and 5-5H). The RhoA siRNA treated cells were significantly less contractile after 1 hour and remained so after 6 hours. These data lead us to conclude that the absence of RhoA is responsible for the loss of contraction observed in HAOSMC lacking CD9.

\section{CD9 Contributions to Vascular Cell Biology}

This study aimed to further clarify the underexplored role of tetraspanin CD9 in VSMC biology. The augmented expression of CD9 was investigated in the synthetic phenotype of HAOSMCs. It was found that downregulating the expression of CD9 


\section{A}

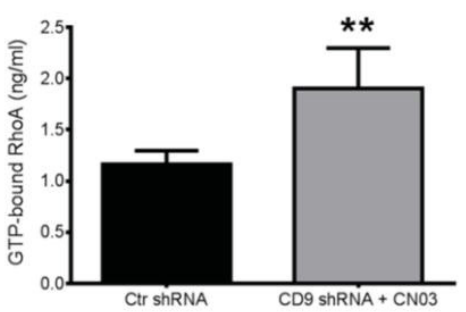

B

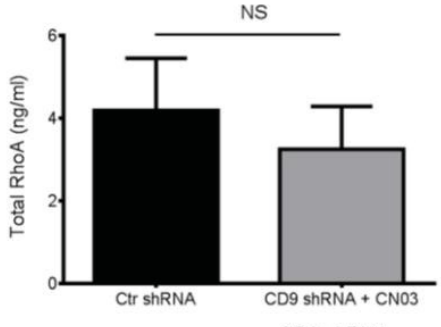

C

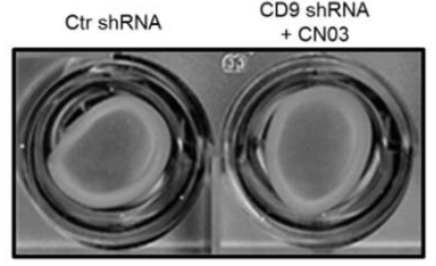

D

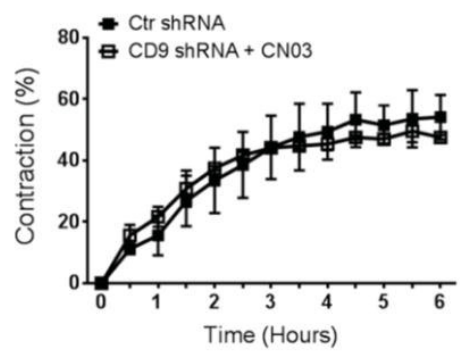

E

Ctr shRNA

CD9 shRNA
+ CNO3
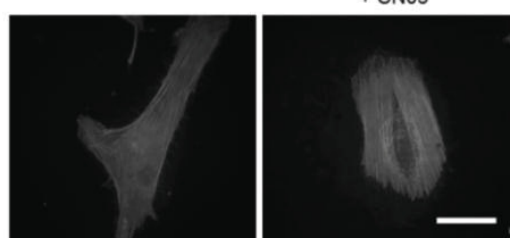

Figure 5-4. Activation of RhoA restores the contractile capabilities of CD9 shRNA HAOSMC and partially restores actin arrangement.

(A and B) GTP-bound (active) and total RhoA was quantitated using whole cell lysates of Ctr shRNA HAOSMC or CD9 shRNA HAOSMC treated with the RhoA activator CN03 $(2.0 \mu \mathrm{g} / \mathrm{ml})$ for two hours $\left(\mathrm{n}=3\right.$; NS indicates no significant difference; $\left.{ }^{* *} \mathrm{P}<0.01\right)$. (C and D) CD9 shRNA cells were treated with $\mathrm{CN} 03(2.0 \mu \mathrm{g} / \mathrm{ml})$ for two hours prior to releasing the sides of a collagen gel contraction assay. A representative image of a collagen gel contraction taken at 6 hours and quantification of collagen gel contraction from $0-6 \mathrm{~h}$ is shown ( $\mathrm{n}=3 /$ time point).(E) A representative Immunofluorescent stained image of $\mathrm{f}$-actin arrangement from three independently repeated experiments in untreated Ctr shRNA and CD9 shRNA treated with $(2.0 \mu \mathrm{g} / \mathrm{ml})$ for two hours (scale bar, $50 \mu \mathrm{m})$. 

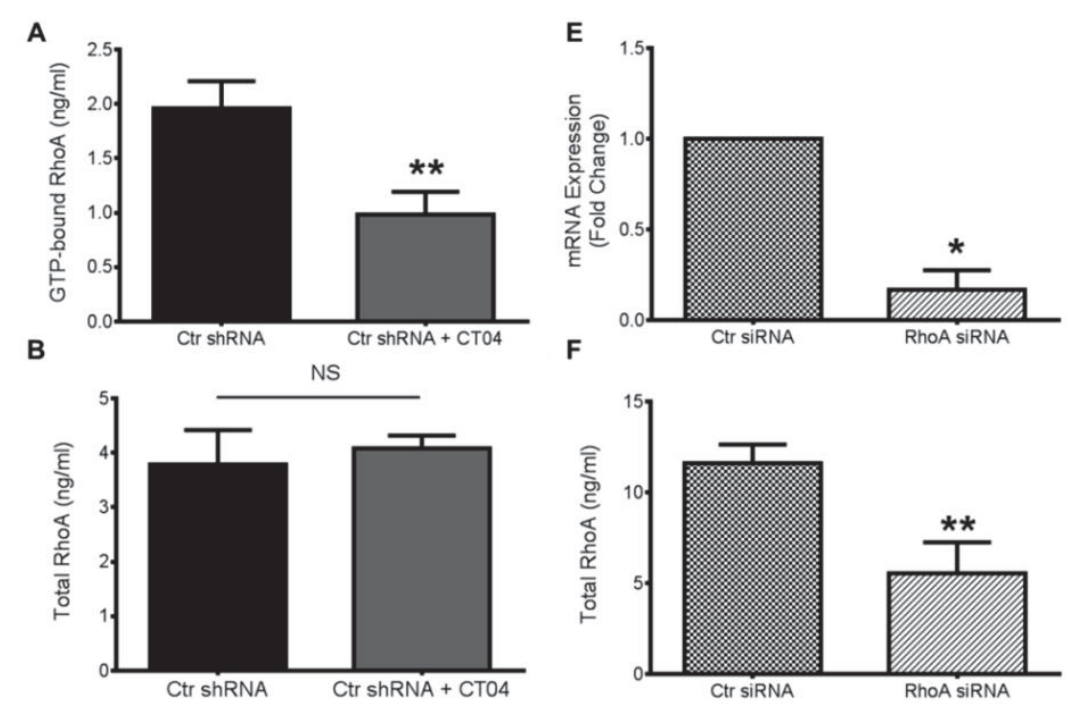

C
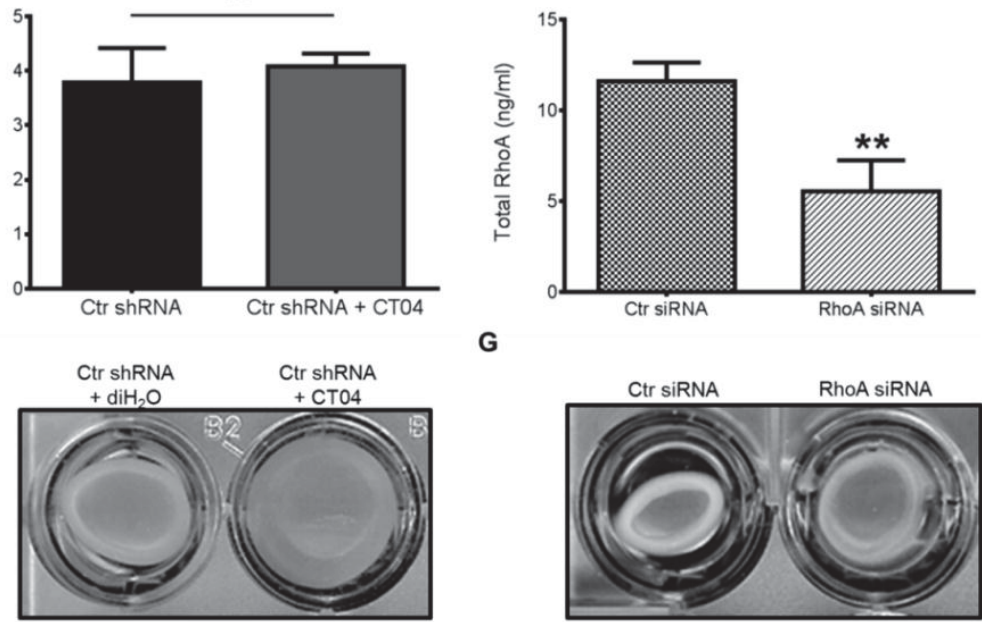

G

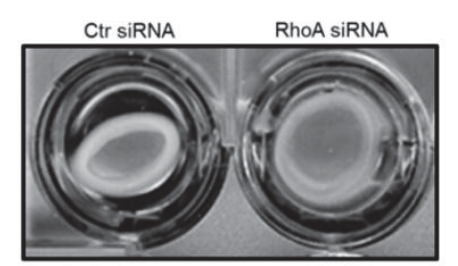

D
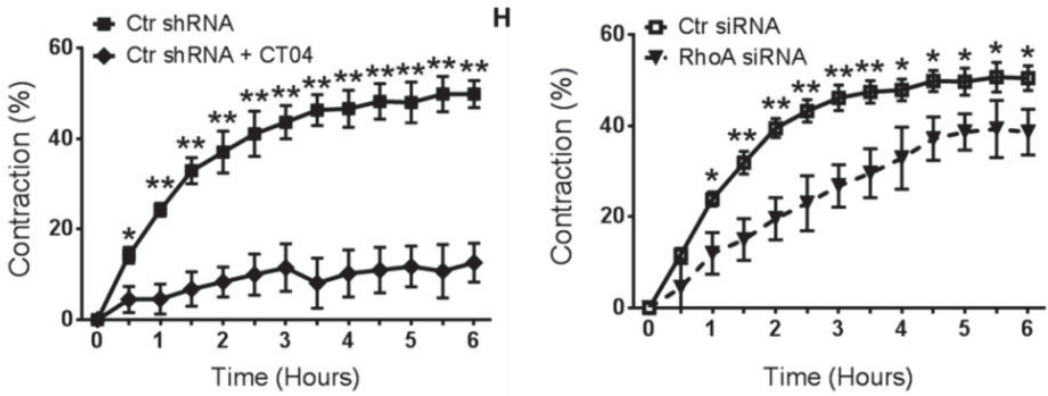

Figure 5-5. Suppression of active RhoA or knockdown of total RhoA in HAOSMC mimics the phenotype of CD9 shRNA HAOSMC.

(A and B) Quantification of the concentration of GTP-bound (active) and total RhoA in untreated or CT04 $(2.0 \mu \mathrm{g} / \mathrm{ml}$ for two hours) treated Ctr shRNA HAOSMC ( $\mathrm{n}=3$; NS indicates no significant difference; $* * \mathrm{P}<0.01$ versus untreated cells). (C and D) Representative image of collagen gel contraction after 6 hours and quantification of collagen gel contraction from 0-6 hours after treating Ctr shRNA HAOSMC with CT04 $(2.0 \mu \mathrm{g} / \mathrm{ml})$ for two hours prior to releasing the sides of the solidified gel $(\mathrm{n}=3 /$ time point; $* \mathrm{P}<0.05, * * \mathrm{P}<0.01$ versus CT04 treated cells at each time point). (E and F) Quantification of the concentration of GTP-bound (active) and total RhoA in scrambled control (Ctr) short interfering RNA (siRNA) or RhoA siRNA transfected HAOSMC $(\mathrm{n}=3$; NS indicates no significant difference; $* * \mathrm{P}<0.01$ versus $\mathrm{Ctr}$ shRNA treatment). (G and $\mathrm{H}$ ) Representative image of collagen gel contraction after 6 hours between $\mathrm{Ctr}$ siRNA and RhoA siRNA transduced HAOSMC and quantification of collagen gel contraction from $0-6$ hours ( $\mathrm{n}=3 /$ time point; ${ }^{*} \mathrm{P}<0.05, * * \mathrm{P}<0.01$ versus $\mathrm{RhoA}$ siRNA). 
resulted in a pronounced morphologic change. The majority of cells lacking CD9 were significantly decreased in size and more rounded in shape. CD9 deficient cells were also less proliferative at 24, 48, and 72 hours; however, the proliferation for both groups of cells plateaued after 48 hours. The fact that cells expressing CD9 were more proliferative than their CD9 shRNA counterparts was not entirely surprising because RhoA activity is directly linked to stimulate cell proliferation $[170,171]$. Significant differences in the expression of commonly explored smooth muscle cell markers excepting for calponin were not observed. Calponin was upregulated upon knocking down CD9. Previous reports generally confirm a phenotypic switch to the dedifferentiated phenotype as indicated by a comprehensive decrease in the expression of multiple smooth muscle cell markers [172-174]. The morphological and proliferative data implied that the smooth muscle cells were in their synthetic state. However, the absence of a change in the expression of SM $\alpha$-actin and SM22 $\alpha$ and the increase of calponin expression challenged this hypothesis.

It was explored that the morphologic difference may be due to a change in the cell cytoarchitecture due to the absence of CD9. These observations suggest that knocking down CD9 disrupts the coordinated signaling between the ECM and the cells that elicits actin arrangement. This hypothesis is supported by the fact that while F-actin appears to be intact and at a similar density between the two cells types, the F-actin in CD9 shRNA cells lacks the parallel arrangement seen with the Ctr shRNA cells. The circular arrangement of F-actin in CD9 shRNA HAOSMC was most likely due to the cell's inability to spatially organize signaling from the ECM due to the loss of CD9 at the cell surface. The observed loss of contractility was consistent with a previous report demonstrating a direct correlation between RhoA expression and VSMC contraction [175].

The CD9 shRNA cell phenotype was then reversed upon restoration of RhoA activity suggesting that the loss of RhoA activity is cause for the inability for actin to properly arrange and the cells to contract. Interestingly, treatment of CD9 shRNA HAOSMC with CN03 resulted in significantly more GTP-bound RhoA compared to untreated Ctr shRNA cells. Despite the increased active RhoA levels in these cells, the plots of contraction over time between the two groups were superimposable. The amount of total RhoA in the Ctr and CD9 shRNA, HAOSMCs accounts for the limits of cell contraction. This idea is substantiated by later findings that loss of GTP-bound RhoA results in a drastic loss of cell contraction while loss of total RhoA results in significant but less pronounced contraction differences.

Rho GTPase activation is multifaceted; however, there is an abundance of literature that suggests that integrins $[176,177]$ and tetraspanins $[178-180]$ may regulate RhoA activation by outside-in signaling from the ECM. The expression of tetraspanin CD151 was recently demonstrated to upregulate the activation of small GTPases including Ras, Rac, and Cdc42, but not RhoA in an adhesion-dependent manner [181]. The authors demonstrated that the expression of tetraspanins CD9, CD81, or CD82 was not able to incite a similar response for Ras, Rac, or Cdc42 activation, but did not measure RhoA expression or activation for these tetraspanins [181]. These experiments 
were conducted on laminin, a well-characterized substrate for $\alpha 3 \beta 1$ and $\alpha 6 \beta 1$ integrins. The $\alpha 3 \beta 1$ and $\alpha 6 \beta 1$ integrins closely associate with CD151 and have been previously demonstrated to activate Rac without affecting Rho [182]. On the other hand, the fibronectin-binding integrin $\alpha 5 \beta 1$ selectively activates Rho [182, 183] and its expression is upregulated after arterial injury [184]. This laboratory has previously demonstrated that CD9 associates with $\alpha 5 \beta 1$ integrin in multiple cell lines including VSMCs $[142,143]$. Perhaps the expression and association of CD9 and $\alpha 5 \beta 1$ in VSMC pathologies stabilizes the interaction between the integrin and ECM to augment RhoA activation. The importance of this interaction is highlighted by the findings that suppression of Rho kinase (ROCK), a direct effector of active RhoA, led to decreased neointimal formation in two animal models $[185,186]$ and prevented the formation of spontaneous hypertension in rats [187].

These results suggest that CD9 does not function as an integrator linking lamellipodial or filopodial extensions. Although Rac activity was not measured in this study, the absence of lamellipodial formation may be due to the previous finding that CD9 expression downregulates WAVE expression, which is the downstream effector of active Rac and directly regulates lamellipodial formation [188]. These results substantiate the hypothesis that CD9 is working directly via RhoA to regulate actin rearrangement and cell contraction in HAOSMCs. Collectively, the previous and current findings from this laboratory and the report that CD151 controls the activity of Ras, Rac, and Cdc42 but not RhoA contribute to the premise that different tetraspanins may regulate different aspects of GTPase signaling.

CD9 may function in microRNA (miRNA)-based translational repression to regulate the contractile phenotype of VSMC. These preliminary studies have indicated no difference in the expression of miRNAs that play a role in suppressing the expression of SMC markers including miR221 and miR222 [189, 190]. Conversely, a change in miR145 expression which positively correlates with the contractile phenotype of VSMCs was not detected [190]. However, an increase in miR-1 expression upon knock down of CD9 expression was observed (Figure B-1). Jiang et al. demonstrated that the induction of miR-1 expression by myocardin resulted in a negative feedback loop and a loss of collagen gel contraction in HAOSMCs [191]. More interestingly, in the same study, miR1 expression suppressed the expression of SMC markers, specifically SM $\alpha$-actin and SM22 $\alpha$ [191]. The miR-1 expression induced upon knockdown of CD9 in this study may play a negative feedback role in the suppression of SM $\alpha$-actin and SM22 $\alpha$ which would otherwise be augmented. Thus, an increase in the expression of SM $\alpha$-actin or SM22 $\alpha$ upon knockdown of CD9 was not observed. Despite a possible block of augmented SM $\alpha$-actin and SM22 $\alpha$ expression, the increase in calponin expression in CD9 deficient cells may be enough to restore them to a contractile phenotype. Long et al. demonstrated that calponin overexpression alone was adequate to suppress neointimal formation in vivo [192]. SMC markers are used ubiquitously throughout the literature to define the phenotype of VSMCs; however, sole reliance on SMC markers to determine the phenotype in this case was not sufficient. 
This study adds to the understanding of how tetraspanin CD9 contributes to the molecular mechanisms that may control VSMC transformation of phenotype. The absence of CD9 alone is enough to effect major changes in the VSMC complex phenotype by regulating the arrangement of the actin cytoskeleton and contraction of HAOSMC through the activity of RhoA. Thus CD9, through signaling mediators, integrins, and the reciprocal coordination of the cell cytoskeleton, is added to the list of factors that provide flexibility for VSMC phenotypic modulation. How CD9-induced changes are involved in contributing to the pathophysiology of vascular injury response and atherosclerotic lesion development remains to be established. 


\section{CHAPTER 6. INSIGHTS INTO CD9 FUNCTION FROM THESE TWO MODELS}

In both of these model systems, CD9 possibly influences the resulting phenotypes by manipulating $\alpha 5 \beta 1$ integrin interaction with fibronectin. Multiple findings from this report support this hypothesis. First, both cell lines demonstrate cell surface expression of $\alpha 5$ and $\beta 1$ integrin subunits (see Figure B-2 for HAOSMC cell surface expression). Second, both cell lines were subjected to fibronectin. All experiments involving HT1080 cells took place on a full-length fibronectin substrate in the absence of serum (Experimental Design in Chapter 2 Materials and Methods). HAOSMC experiments were conducted in serum-containing media in plastic cell culture dishes. HAOSMCs were adherent to uncoated plastic culture dishes under these conditions 20 minutes after plating (personal observations). HAOSMCs in serum-containing media secrete fibronectin to aid in cell adherence and proliferation [193]. This occurrence involves tyrosine kinases and FAK signaling [194]. In fact, the functional RGDS peptide from fibronectin alone, shown previously by this laboratory to bind CD9 [108], can induce the synthetic phenotype of SMCs [195]. The absence of CD9 may slow the production of fibronectin in the CD9 shRNA treated HAOSMC resulting in decreased proliferation observed. However, the secretion of fibronectin or other ECM proteins from Ctr and CD9 shRNA treated HAOSMC was not measured in this report and is of important and future interest. Ctr and CD9 shRNA HAOSMC cell viability must also be assessed. Although care was taken to treat and test both cell types and lysates at equal densities and concentrations respectively, the CD9 shRNA cells resembled an apoptotic phenotype. The CD9 shRNA HAOSMC response to RhoA activation (CN03) suggests that they are viable; however, measuring total and activated caspase- 3 would be necessary to confirm equal viability between the two groups.

Findings from this study strongly implicate that CD9 expression induces PI3Kand ERK-dependent signaling pathways to elicit the observed phenotypes. Tetraspanins not linked to integrins have been demonstrated to signal though PKC-dependent pathways $[161,196]$. These integrin-free tetraspanins are considered to be activated by forming homoclusters [196]. The results presented here, previously in this laboratory, and by others indicate that CD9 does not signal though PKC-dependent pathways to elicit the phenotypes observed herein. In this report Pro-MMP-9 production was diminished upon treatment with LY294002, U0126, and PD98059 (Figure B-3). Kotha et al. determined that CD9 induced phenotypes in a CHO cell line directly depend upon $\alpha 5 \beta 1$ by using an anti- $\alpha 5 \beta 1$ antibody to disrupt CD9-induced motility [142]. This CD9-dependent phenotype was dependent upon PI3K and Akt signaling, but not PKC or MAPK signaling [142]. The lack of MAPK involvement is interesting. This dissertation report proposes that ERK1/2 signaling is a consequence of EGFR activity. CHO cells do not endogenously express EGFR $[111,197,198]$. Therefore, the model system used by Kotha et al. focused precisely on CD9- $\alpha 5 \beta 1$ interaction and concluded that PKC was not involved in the observed phenotype. Other studies involving manipulations of pro-MMP9 expression similarly implicate the PI3K and ERK pathways $[140,141,156]$. PKCdependent activation of MMP-9 only occurs in the presence of phorbol 12-myristate 13- 
acetate stimulation [155]. These findings suggest the CD9- $\alpha 5 \beta 1-\mathrm{FN}$ interaction to signal through PI3K and the CD9-EGFR-FN interaction to signal through the MAPK/ERK pathway. These two pathways converge to elicit the expression of MMP-9 (Figure 6-1).

How is RhoA involved? Actin arrangement phenomena are dependent primarily upon the RhoA/FAK signaling pathway [199, 200]. Earlier reports from this laboratory [103] and others [164] implicated CD9 in FAK signaling. However, these reports are not entirely congruent. More interestingly, RhoA activation elicited the activation of ERK in a MEKK1-dependent manner [201]. EGFR activation contributed to increased cell motility via RhoA activation [202]. In a study observing statin-treated SMCs and MMP-9 secretion, inhibition of RhoA or its downstream effector ROCK diminished experimentally-induced MMP-9 secretion [203]. Conversely, ectopic expression of active-RhoA induced the expression of MMP-9 in human endothelial cells [204]. The increased RhoA activity in this dissertation report probably resulted from the CD9EGFR-FN interaction. However, the CD9- $\alpha 5 \beta 1-F N$ interaction likely plays a prominent role as well. Specifically integrin $\alpha 5 \beta 1$ expression was demonstrated to stimulate RhoA activity in fibroblastic and epitheloid cells [205]. The contribution of RhoA to both the ERK pathway and MMP-9 production were not observed in HAOSMC in this dissertation report. The author relentlessly tried but failed to demonstrate endogenous MMP-9 expression and release in HAOSMC. There are two explanations for this result. First, most, if not all, studies involving human or rat SMCs used cytokines or growth factors to stimulate MMP-9 production [206-208]. Treatment with cytokines or growth factors likely augments cellular signaling events well beyond the hypothetical level induced by manipulating CD9 expression. Furthermore, multiple other signaling pathways are induced by these treatments making it impossible to attribute downstream findings to CD9 expression. Second, the reported activation of EGFR by the integrin-FN association is between 9 and 22 times less than activation by the native ligand EGF [209]. This explains why, if EGFR has a role in SMC MMP-9 release, MMP-9 release is not observed. However, this should not complicate the HT1080-MMP-9 paradigm because HT1080s endogenously secrete copious amounts of MMP-9 [128, 210]. Therefore, even a slight manipulation of signaling may augment MMP-9 expression two to four fold.

The findings presented here demonstrate potentially overlapping CD9 signaling mechanisms in two model systems. The idea that cellular signaling is a linear event is sophomoric. CD9 likely influences the downstream events of multiple associated proteins concurrently resulting in complex cellular phenotypes. The single most alluring finding is that CD9 has an effect on these phenotypes! This highlights the necessity for cell surface organization by tetraspanins to influence cellular phenotype. Therefore, in consideration of basketball being the author's preferred sport, CD9 is likened to the sixth man. The game may still be played in its absence, but its presence significantly influences the outcome. 


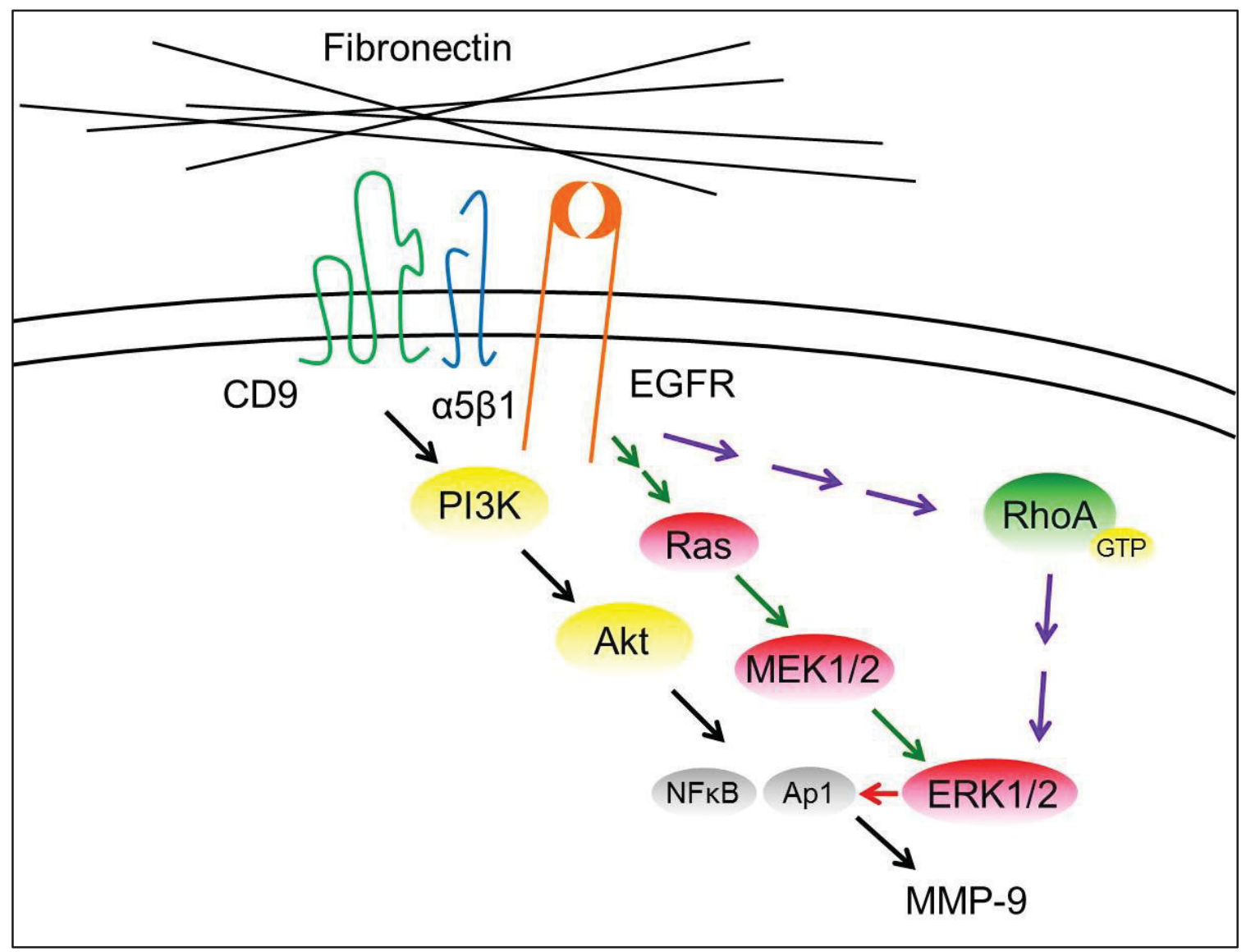

Figure 6-1. The proposed CD9 signaling pathway derived from both model systems.

Black arrows indicate proposed signaling from the CD9- $\alpha 5 \beta 1-\mathrm{FN}$ triad and dark green arrows indicate signaling from the CD9-EGFR-FN interaction observed in HT1080 cells. Purple arrows indicate signaling observed in HAOSMCs. The red arrow indicates where these two pathways possibly converge in eliciting MMP-9 expression. 


\section{CHAPTER 7. FUTURE DIRECTIONS}

The HT1080 cell model system used in this report was integral in elucidating the specific contributions of CD9 to cellular invasion. Yet, the clinical relevance of this model is severely lacking. There are only 500 new cases of human fibrosarcoma reported each year in the United States and the post-treatment survival averages are $90 \%$ (http://www.healthline.com/ galecontent/fibrosarcoma/ accessed November 20, 2013). Veterinarians may benefit from these findings as the incidence of feline fibrosarcoma is rather high [211]. However, the expression of CD9 in feline fibrosarcomas is unknown and may be endogenously low. In either case, the manipulation of CD9 expression would potentially result in unwanted outcomes.

The conclusion that CD9 promotes the invasive phenotype of cancer cells is more usefully applied to a human non-small cell lung cancer (NSCLC) cell line. NSCLCs make up approximately $90 \%$ of all lung cancers (http://www.healthline.com/health/lungcancer-non-small-cell/ accessed November 20, 2013). The occurrence of this type of lung cancer is mostly independent of cigarette smoking (http://www.cancer.org/cancer/ lungcancer-non-smallcell/ accessed November 20, 2013). NSCLC demonstrate all of the necessary characteristics to warrant studying the effect of CD9 expression in these cells. Human NSCLC biopsies demonstrated MMP-9 and membranous EGFR coexpression that positively correlated with a poor prognosis [114]. As previously mentioned (Chapter 4), the level of CD9 expression in NSCLC cells is similar to that achieved in HT1080 cells [70]. Screening for CD9 expression in conjunction with MMP-9 and EGFR in NSCLC biopsies may significantly improve the prognostic value. It has already been concluded that CD9 expression is a poor prognostic indicator in NSCLC malignancies $[212,213]$. Manipulations of CD9 in NSCLC and resultant phenotypes have yet to be discovered.

The influence of CD9 on the contractile phenotype of HAOSMCs is more perplexing. RhoA and SMC contraction is an extremely well-studied event. Focusing efforts on the mechanism of CD9 regulation of RhoA activity would be more beneficial. This phenomenon most likely results from the association of CD9 with $\alpha 5 \beta 1$ integrin. The lack of a completely transparent phenotype as measured by SMC markers is unfortunate. Using miR expression to explain these results is preliminary and requires much more analysis. In spite of this, SMC marker expression is not always an indicator of the contractile capabilities of SMC cells (personal communication with Brian Wamhoff, Ph.D. on September 6, 2013). Overall, future studies involving CD9 will always require careful consideration of the cell-specific phenotypes elicited by the CD9$\alpha 5 \beta 1-\mathrm{FN}$ interaction. 


\section{LIST OF REFERENCES}

1. Berditchevski, F., Complexes of tetraspanins with integrins: more than meets the eye. J Cell Sci, 2001. 114(Pt 23): p. 4143-51.

2. Hemler, M.E., Tetraspanin functions and associated microdomains. Nat Rev Mol Cell Biol, 2005. 6(10): p. 801-11.

3. Kitadokoro, K., et al., CD81 extracellular domain 3D structure: insight into the tetraspanin superfamily structural motifs. EMBO J, 2001. 20(1-2): p. 12-8.

4. Kitadokoro, K., et al., Crystallization and preliminary crystallographic studies on the large extracellular domain of human CD81, a tetraspanin receptor for hepatitis C virus. Acta Crystallogr D Biol Crystallogr, 2001. 57(Pt 1): p. 156-8.

5. Kersey, J.H., et al., P-24: a human leukemia-associated and lymphohemopoietic progenitor cell surface structure identified with monoclonal antibody. J Exp Med, 1981. 153(3): p. 726-31.

6. Jennings, L.K., et al., Platelet p24/CD9, a member of the tetraspanin family of proteins. Ann N Y Acad Sci, 1994. 714: p. 175-84.

7. Deng, C.T., et al., A monoclonal antibody cross-reactive with human platelets, megakaryocytes, and common acute lymphocytic leukemia cells. Blood, 1983. 61(4): p. 759-64.

8. Jones, N.H., M.J. Borowitz, and R.S. Metzgar, Characterization and distribution of a 24,000-molecular weight antigen defined by a monoclonal antibody (DUALL-1) elicited to common acute lymphoblastic leukemia (cALL) cells. Leuk Res, 1982. 6(4): p. 449-64.

9. Komada, Y., et al., A monoclonal antibody (SJ-9A4) to P24 present on common alls, neuroblastomas and platelets - I. Characterization and development of a unique radioimmunometric assay. Leuk Res, 1983. 7(4): p. 487-98.

10. Bernard, A. and L. Boumsell, The clusters of differentiation (CD) defined by the First International Workshop on Human Leucocyte Differentiation Antigens. Hum Immunol, 1984. 11(1): p. 1-10.

11. Lanza, F., et al., cDNA cloning and expression of platelet $p 24 / C D 9$. Evidence for a new family of multiple membrane-spanning proteins. J Biol Chem, 1991. 266(16): p. 10638-45.

12. Waterhouse, R., C. Ha, and G.S. Dveksler, Murine CD9 is the receptor for pregnancy-specific glycoprotein 17. J Exp Med, 2002. 195(2): p. 277-82. 
13. Snyder, S.K., et al., Pregnancy-specific glycoproteins function as immunomodulators by inducing secretion of IL-10, IL-6 and TGF-betal by human monocytes. Am J Reprod Immunol, 2001. 45(4): p. 205-16.

14. Ha, C.T., et al., Binding of pregnancy-specific glycoprotein 17 to CD9 on macrophages induces secretion of IL-10, IL-6, PGE2, and TGF-beta1. J Leukoc Biol, 2005. 77(6): p. 948-57.

15. Pileri, P., et al., Binding of hepatitis $C$ virus to CD81. Science, 1998. 282(5390): p. 938-41.

16. Higginbottom, A., et al., Identification of amino acid residues in CD81 critical for interaction with hepatitis C virus envelope glycoprotein E2. J Virol, 2000. 74(8): p. 3642-9.

17. Zhang, J., et al., CD81 is required for hepatitis $C$ virus glycoprotein-mediated viral infection. J Virol, 2004. 78(3): p. 1448-55.

18. Hemler, M.E., Specific tetraspanin functions. J Cell Biol, 2001. 155(7): p. 1103-7.

19. Hemler, M.E., Tetraspanin proteins mediate cellular penetration, invasion, and fusion events and define a novel type of membrane microdomain. Annu Rev Cell Dev Biol, 2003. 19: p. 397-422.

20. Stipp, C.S., T.V. Kolesnikova, and M.E. Hemler, Functional domains in tetraspanin proteins. Trends Biochem Sci, 2003. 28(2): p. 106-12.

21. Levy, S. and T. Shoham, Protein-protein interactions in the tetraspanin web. Physiology (Bethesda), 2005. 20: p. 218-24.

22. Bradbury, L.E., et al., The CD19/CD21 signal transducing complex of human B lymphocytes includes the target of antiproliferative antibody-1 and Leu-13 molecules. J Immunol, 1992. 149(9): p. 2841-50.

23. Todd, S.C., et al., CD81 expressed on human thymocytes mediates integrin activation and interleukin 2-dependent proliferation. J Exp Med, 1996. 184(5): p. 2055-60.

24. Bradbury, L.E., V.S. Goldmacher, and T.F. Tedder, The CD19 signal transduction complex of B lymphocytes. Deletion of the CD19 cytoplasmic domain alters signal transduction but not complex formation with TAPA-1 and Leu 13. J Immunol, 1993. 151(6): p. 2915-27.

25. Matsumoto, A.K., et al., Functional dissection of the CD21/CD19/TAPA-1/Leu-13 complex of B lymphocytes. J Exp Med, 1993. 178(4): p. 1407-17.

26. Kolesnikova, T.V., et al., EWI-2 modulates lymphocyte integrin alpha4beta1 functions. Blood, 2004. 103(8): p. 3013-9. 
27. Stipp, C.S., T.V. Kolesnikova, and M.E. Hemler, EWI-2 is a major CD9 and CD81 partner and member of a novel Ig protein subfamily. J Biol Chem, 2001. 276(44): p. 40545-54.

28. Boucheix, C. and E. Rubinstein, Tetraspanins. Cell Mol Life Sci, 2001. 58(9): p. 1189-205.

29. Yang, X., et al., Palmitoylation of tetraspanin proteins: modulation of CD151 lateral interactions, subcellular distribution, and integrin-dependent cell morphology. Mol Biol Cell, 2002. 13(3): p. 767-81.

30. Charrin, S., et al., Differential stability of tetraspanin/tetraspanin interactions: role of palmitoylation. FEBS Lett, 2002. 516(1-3): p. 139-44.

31. Rubinstein, E., et al., $C D 9, C D 63, C D 81$, and $C D 82$ are components of a surface tetraspan network connected to HLA-DR and VLA integrins. Eur J Immunol, 1996. 26(11): p. 2657-65.

32. Berditchevski, F., et al., Expression of the palmitoylation-deficient CD151 weakens the association of alpha 3 beta 1 integrin with the tetraspanin-enriched microdomains and affects integrin-dependent signaling. J Biol Chem, 2002. 277(40): p. 36991-7000.

33. Miranti, C.K. and J.S. Brugge, Sensing the environment: a historical perspective on integrin signal transduction. Nat Cell Biol, 2002. 4(4): p. E83-90.

34. Hynes, R.O., Integrins: bidirectional, allosteric signaling machines. Cell, 2002. 110(6): p. 673-87.

35. Comoglio, P.M., C. Boccaccio, and L. Trusolino, Interactions between growth factor receptors and adhesion molecules: breaking the rules. Curr Opin Cell Biol, 2003. 15(5): p. 565-71.

36. Stipp, C.S. and M.E. Hemler, Transmembrane-4-superfamily proteins CD151 and CD81 associate with alpha 3 beta 1 integrin, and selectively contribute to alpha 3 beta 1-dependent neurite outgrowth. J Cell Sci, 2000. 113 ( Pt 11): p. 1871-82.

37. Shaw, A.R., et al., Ectopic expression of human and feline CD9 in a human B cell line confers beta 1 integrin-dependent motility on fibronectin and laminin substrates and enhanced tyrosine phosphorylation. J Biol Chem, 1995. 270(41): p. 24092-9.

38. Fitter, S., et al., Transmembrane 4 superfamily protein CD151 (PETA-3) associates with beta 1 and alpha IIb beta 3 integrins in haemopoietic cell lines and modulates cell-cell adhesion. Biochem J, 1999. 338 ( Pt 1): p. 61-70. 
39. Berditchevski, F., et al., Analysis of the CD151-alpha3betal integrin and CD151tetraspanin interactions by mutagenesis. J Biol Chem, 2001. 276(44): p. 4116574.

40. Kazarov, A.R., et al., An extracellular site on tetraspanin CD151 determines alpha 3 and alpha 6 integrin-dependent cellular morphology. J Cell Biol, 2002. 158(7): p. 1299-309.

41. Yauch, R.L., et al., Highly stoichiometric, stable, and specific association of integrin alpha3beta1 with CD151 provides a major link to phosphatidylinositol 4kinase, and may regulate cell migration. Mol Biol Cell, 1998. 9(10): p. 2751-65.

42. Serru, V., et al., Selective tetraspan-integrin complexes (CD81/alpha4beta1, CD151/alpha3beta1, CD151/alpha6beta1) under conditions disrupting tetraspan interactions. Biochem J, 1999. 340 ( Pt 1): p. 103-11.

43. Yauch, R.L. and M.E. Hemler, Specific interactions among transmembrane 4 superfamily (TM4SF) proteins and phosphoinositide 4-kinase. Biochem J, 2000. 351 Pt 3: p. 629-37.

44. Yanez-Mo, M., et al., Regulation of endothelial cell motility by complexes of tetraspan molecules CD81/TAPA-1 and CD151/PETA-3 with alpha3 beta1 integrin localized at endothelial lateral junctions. J Cell Biol, 1998. 141(3): p. 791-804.

45. Liu, L., et al., Tetraspanin CD151 promotes cell migration by regulating integrin trafficking. J Biol Chem, 2007. 282(43): p. 31631-42.

46. He, B., et al., Tetraspanin CD82 attenuates cellular morphogenesis through down-regulating integrin alpha6-mediated cell adhesion. J Biol Chem, 2005. 280(5): p. 3346-54.

47. Berditchevski, F. and E. Odintsova, Tetraspanins as regulators of protein trafficking. Traffic, 2007. 8(2): p. 89-96.

48. Yang, X., et al., Palmitoylation supports assembly and function of integrintetraspanin complexes. J Cell Biol, 2004. 167(6): p. 1231-40.

49. Charrin, S., et al., The major CD9 and CD81 molecular partner. Identification and characterization of the complexes. J Biol Chem, 2001. 276(17): p. 14329-37.

50. Gustafson-Wagner, E. and C.S. Stipp, The CD9/CD81 tetraspanin complex and tetraspanin CD151 regulate alpha3betal integrin-dependent tumor cell behaviors by overlapping but distinct mechanisms. PLoS One, 2013. 8(4): p. e61834.

51. Sala-Valdes, M., et al., EWI-2 and EWI-F link the tetraspanin web to the actin cytoskeleton through their direct association with ezrin-radixin-moesin proteins. $\mathrm{J}$ Biol Chem, 2006. 281(28): p. 19665-75. 
52. Kaji, K., et al., The gamete fusion process is defective in eggs of Cd9-deficient mice. Nat Genet, 2000. 24(3): p. 279-82.

53. Le Naour, F., et al., Severely reduced female fertility in CD9-deficient mice. Science, 2000. 287(5451): p. 319-21.

54. Miyado, K., et al., Requirement of CD9 on the egg plasma membrane for fertilization. Science, 2000. 287(5451): p. 321-4.

55. Rubinstein, E., et al., Reduced fertility of female mice lacking CD81. Dev Biol, 2006. 290(2): p. 351-8.

56. Ellerman, D.A., et al., Direct binding of the ligand PSG17 to CD9 requires a CD9 site essential for sperm-egg fusion. Mol Biol Cell, 2003. 14(12): p. 5098-103.

57. Zhu, G.Z., et al., Residues SFQ (173-175) in the large extracellular loop of CD9 are required for gamete fusion. Development, 2002. 129(8): p. 1995-2002.

58. Hasuwa, H., et al., CD9 amino acids critical for upregulation of diphtheria toxin binding. Biochem Biophys Res Commun, 2001. 289(4): p. 782-90.

59. Zijlstra, A., et al., The inhibition of tumor cell intravasation and subsequent metastasis via regulation of in vivo tumor cell motility by the tetraspanin CD151. Cancer Cell, 2008. 13(3): p. 221-34.

60. Kanetaka, K., et al., Possible involvement of tetraspanin CO-029 in hematogenous intrahepatic metastasis of liver cancer cells. J Gastroenterol Hepatol, 2003. 18(11): p. 1309-14.

61. Richardson, M.M., L.K. Jennings, and X.A. Zhang, Tetraspanins and tumor progression. Clin Exp Metastasis, 2011. 28(3): p. 261-70.

62. Hemler, M.E., Targeting of tetraspanin proteins--potential benefits and strategies. Nat Rev Drug Discov, 2008. 7(9): p. 747-58.

63. Zoller, M., Tetraspanins: push and pull in suppressing and promoting metastasis. Nat Rev Cancer, 2009. 9(1): p. 40-55.

64. Lee, D., et al., Prognostic significance of tetraspanin CD151 in newly diagnosed glioblastomas. J Surg Oncol, 2013. 107(6): p. 646-52.

65. Yang, X.H., et al., CD151 accelerates breast cancer by regulating alpha 6 integrin function, signaling, and molecular organization. Cancer Res, 2008. 68(9): p. 3204-13.

66. Hashida, H., et al., Clinical significance of transmembrane 4 superfamily in colon cancer. Br J Cancer, 2003. 89(1): p. 158-67. 
67. Tokuhara, T., et al., Clinical significance of CD151 gene expression in non-small cell lung cancer. Clin Cancer Res, 2001. 7(12): p. 4109-14.

68. Gesierich, S., et al., Colocalization of the tetraspanins, CO-029 and CD151, with integrins in human pancreatic adenocarcinoma: impact on cell motility. Clin Cancer Res, 2005. 11(8): p. 2840-52.

69. Ang, J., et al., CD151 protein expression predicts the clinical outcome of lowgrade primary prostate cancer better than histologic grading: a new prognostic indicator? Cancer Epidemiol Biomarkers Prev, 2004. 13(11 Pt 1): p. 1717-21.

70. Funakoshi, T., et al., Expression of tetraspanins in human lung cancer cells: frequent downregulation of CD9 and its contribution to cell motility in small cell lung cancer. Oncogene, 2003. 22(5): p. 674-87.

71. Nakazawa, Y., et al., Tetraspanin family member CD9 inhibits Aggrus/podoplanin-induced platelet aggregation and suppresses pulmonary metastasis. Blood, 2008. 112(5): p. 1730-9.

72. Copeland, B.T., et al., Knockout of the tetraspanin Cd9 in the TRAMP model of de novo prostate cancer increases spontaneous metastases in an organ-specific manner. Int J Cancer, 2013. 133(8): p. 1803-12.

73. Hwang, J.R., et al., Upregulation of CD9 in ovarian cancer is related to the induction of TNF-alpha gene expression and constitutive NF-kappaB activation. Carcinogenesis, 2012. 33(1): p. 77-83.

74. Kischel, P., et al., Overexpression of CD9 in human breast cancer cells promotes the development of bone metastases. Anticancer Res, 2012. 32(12): p. 5211-20.

75. Iwasaki, T., et al., Deletion of tetraspanin CD9 diminishes lymphangiogenesis in vivo and in vitro. J Biol Chem, 2013. 288(4): p. 2118-31.

76. Hori, H., et al., CD9 expression in gastric cancer and its significance. J Surg Res, 2004. 117(2): p. 208-15.

77. Soyuer, S., et al., Prognostic significance of CD9 expression in locally advanced gastric cancer treated with surgery and adjuvant chemoradiotherapy. Pathol Res Pract, 2010. 206(9): p. 607-10.

78. Wang, J.C., et al., Down-regulation of CD9 expression during prostate carcinoma progression is associated with CD9 mRNA modifications. Clin Cancer Res, 2007. 13(8): p. 2354-61.

79. Nagase, H., R. Visse, and G. Murphy, Structure and function of matrix metalloproteinases and TIMPs. Cardiovasc Res, 2006. 69(3): p. 562-73. 
80. Page-McCaw, A., A.J. Ewald, and Z. Werb, Matrix metalloproteinases and the regulation of tissue remodelling. Nat Rev Mol Cell Biol, 2007. 8(3): p. 221-33.

81. Kessenbrock, K., V. Plaks, and Z. Werb, Matrix metalloproteinases: regulators of the tumor microenvironment. Cell, 2010. 141(1): p. 52-67.

82. Visse, R. and H. Nagase, Matrix metalloproteinases and tissue inhibitors of metalloproteinases: structure, function, and biochemistry. Circ Res, 2003. 92(8): p. 827-39.

83. Gomez, D.E., et al., Tissue inhibitors of metalloproteinases: structure, regulation and biological functions. Eur J Cell Biol, 1997. 74(2): p. 111-22.

84. Zucker, S., J. Cao, and W.T. Chen, Critical appraisal of the use of matrix metalloproteinase inhibitors in cancer treatment. Oncogene, 2000. 19(56): p. 6642-50.

85. Close, D.R., Matrix metalloproteinase inhibitors in rheumatic diseases. Ann Rheum Dis, 2001. 60 Suppl 3: p. iii62-7.

86. Skiles, J.W., N.C. Gonnella, and A.Y. Jeng, The design, structure, and clinical update of small molecular weight matrix metalloproteinase inhibitors. Curr Med Chem, 2004. 11(22): p. 2911-77.

87. Takino, T., et al., Tetraspanin CD63 promotes targeting and lysosomal proteolysis of membrane-type 1 matrix metalloproteinase. Biochem Biophys Res Commun, 2003. 304(1): p. 160-6.

88. Yanez-Mo, M., et al., MT1-MMP collagenolytic activity is regulated through association with tetraspanin CD151 in primary endothelial cells. Blood, 2008. 112(8): p. 3217-26.

89. Jung, K.K., et al., Identification of CD63 as a tissue inhibitor of metalloproteinase-1 interacting cell surface protein. EMBO J, 2006. 25(17): p. 3934-42.

90. Takeda, Y., et al., Double deficiency of tetraspanins CD9 and CD81 alters cell motility and protease production of macrophages and causes chronic obstructive pulmonary disease-like phenotype in mice. J Biol Chem, 2008. 283(38): p. 2608997.

91. Fujita, Y., et al., Tetraspanin CD151 is expressed in osteoarthritic cartilage and is involved in pericellular activation of pro-matrix metalloproteinase 7 in osteoarthritic chondrocytes. Arthritis Rheum, 2006. 54(10): p. 3233-43. 
92. Hong, I.K., et al., Homophilic interactions of Tetraspanin CD151 up-regulate motility and matrix metalloproteinase-9 expression of human melanoma cells through adhesion-dependent c-Jun activation signaling pathways. J Biol Chem, 2006. 281(34): p. 24279-92.

93. Murayama, Y., et al., The tetraspanin CD9 modulates epidermal growth factor receptor signaling in cancer cells. J Cell Physiol, 2008. 216(1): p. 135-43.

94. Chen, S., et al., Functional and biochemical studies of CD9 in fibrosarcoma cell line. Mol Cell Biochem, 2011. 350(1-2): p. 89-99.

95. Zhang, J., et al., CD9 is critical for cutaneous wound healing through JNK signaling. J Invest Dermatol, 2012. 132(1): p. 226-36.

96. Hong, I.K., et al., Tetraspanin CD9 induces MMP-2 expression by activating $p 38$ MAPK, JNK and c-Jun pathways in human melanoma cells. Exp Mol Med, 2005. 37(3): p. 230-9.

97. Saito, Y., et al., Absence of CD9 enhances adhesion-dependent morphologic differentiation, survival, and matrix metalloproteinase-2 production in small cell lung cancer cells. Cancer Res, 2006. 66(19): p. 9557-65.

98. Hanyu, A., et al., Functional in vivo optical imaging of tumor angiogenesis, growth, and metastasis prevented by administration of anti-human VEGF antibody in xenograft model of human fibrosarcoma HT1080 cells. Cancer Sci, 2009. 100(11): p. 2085-92.

99. Zhang, C., et al., Inhibition of the expression on MMP-2, 9 and morphological changes via human fibrosarcoma cell line by 6,6'-bieckol from marine alga Ecklonia cava. BMB Rep, 2010. 43(1): p. 62-8.

100. Baldassarre, M., et al., Filamin A controls matrix metalloproteinase activity and regulates cell invasion in human fibrosarcoma cells. J Cell Sci, 2012. 125(Pt 16): p. 3858-69.

101. Peterfia, B., et al., Syndecan-1 enhances proliferation, migration and metastasis of HT-1080 cells in cooperation with syndecan-2. PLoS One, 2012. 7(6): p. e39474.

102. Jennings, L.K., et al., The activation of human platelets mediated by anti-human platelet p24/CD9 monoclonal antibodies. J Biol Chem, 1990. 265(7): p. 3815-22.

103. Cook, G.A., et al., Identification of CD9 extracellular domains important in regulation of $\mathrm{CHO}$ cell adhesion to fibronectin and fibronectin pericellular matrix assembly. Blood, 2002. 100(13): p. 4502-11.

104. Bassani, S. and L.A. Cingolani, Tetraspanins: Interactions and interplay with integrins. Int J Biochem Cell Biol, 2012. 44(5): p. 703-8. 
105. Tohami, T., et al., Overexpression of tetraspanins affects multiple myeloma cell survival and invasive potential. FASEB J, 2007. 21(3): p. 691-9.

106. Sakuma, T., et al., CD9 antigen interacts with heparin-binding EGF-like growth factor through its heparin-binding domain. J Biochem, 1997. 122(2): p. 474-80.

107. Liu, W., et al., Helicobacter pylori acyl carrier protein: expression, purification, and its interaction with beta-hydroxyacyl-ACP dehydratase. Protein Expr Purif, 2007. 52(1): p. 74-81.

108. Longhurst, C.M., et al., Chinese hamster ovary cell motility to fibronectin is modulated by the second extracellular loop of CD9. Identification of a putative fibronectin binding site. J Biol Chem, 2002. 277(36): p. 32445-52.

109. Cook, G.A., et al., The tetraspanin CD9 influences the adhesion, spreading, and pericellular fibronectin matrix assembly of Chinese hamster ovary cells on human plasma fibronectin. Exp Cell Res, 1999. 251(2): p. 356-71.

110. Rubinstein, E., et al., CD9, but not other tetraspans, associates with the betal integrin precursor. Eur J Immunol, 1997. 27(8): p. 1919-27.

111. Shi, W., et al., The tetraspanin CD9 associates with transmembrane TGF-alpha and regulates $T G F$-alpha-induced EGF receptor activation and cell proliferation. J Cell Biol, 2000. 148(3): p. 591-602.

112. Kim, S., et al., EGF-induced MMP-9 expression is mediated by the JAK3/ERK pathway, but not by the JAK3/STAT-3 pathway in a SKBR3 breast cancer cell line. Cell Signal, 2009. 21(6): p. 892-8.

113. Toda, D., et al., Gefitinib decreases the synthesis of matrix metalloproteinase and the adhesion to extracellular matrix proteins of colon cancer cells. Anticancer Res, 2006. 26(1A): p. 129-34.

114. Cox, G., J.L. Jones, and K.J. O'Byrne, Matrix metalloproteinase 9 and the epidermal growth factor signal pathway in operable non-small cell lung cancer. Clin Cancer Res, 2000. 6(6): p. 2349-55.

115. Qiu, Q., et al., EGF-induced trophoblast secretion of MMP-9 and TIMP-1 involves activation of both PI $3 K$ and MAPK signalling pathways. Reproduction, 2004. 128(3): p. 355-63.

116. Higashihara, M., et al., Purification and partial characterization of CD9 antigen of human platelets. FEBS Lett, 1990. 264(2): p. 270-4.

117. Ovalle, S., et al., The tetraspanin CD9 inhibits the proliferation and tumorigenicity of human colon carcinoma cells. Int J Cancer, 2007. 121(10): p. 2140-52. 
118. Yanez-Mo, M., et al., Tetraspanin-enriched microdomains: a functional unit in cell plasma membranes. Trends Cell Biol, 2009. 19(9): p. 434-46.

119. Furuya, M., et al., Down-regulation of CD9 in human ovarian carcinoma cell might contribute to peritoneal dissemination: morphologic alteration and reduced expression of betal integrin subsets. Cancer Res, 2005. 65(7): p. 2617-25.

120. Sordat, I., et al., Complementary DNA arrays identify CD63 tetraspanin and alpha3 integrin chain as differentially expressed in low and high metastatic human colon carcinoma cells. Lab Invest, 2002. 82(12): p. 1715-24.

121. Lafleur, M.A., D. Xu, and M.E. Hemler, Tetraspanin proteins regulate membrane type-1 matrix metalloproteinase-dependent pericellular proteolysis. Mol Biol Cell, 2009. 20(7): p. 2030-40.

122. Kohno, M., et al., CD151 enhances cell motility and metastasis of cancer cells in the presence of focal adhesion kinase. Int J Cancer, 2002. 97(3): p. 336-43.

123. Zoller, M., Gastrointestinal tumors: metastasis and tetraspanins. Z Gastroenterol, 2006. 44(7): p. 573-86.

124. Testa, J.E., et al., Eukaryotic expression cloning with an antimetastatic monoclonal antibody identifies a tetraspanin (PETA-3/CD151) as an effector of human tumor cell migration and metastasis. Cancer Res, 1999. 59(15): p. 381220.

125. Riikonen, T., et al., Integrin alpha 2 beta 1 is a positive regulator of collagenase (MMP-1) and collagen alpha 1(I) gene expression. J Biol Chem, 1995. 270(22): p. $13548-52$.

126. Pilcher, B.K., et al., The activity of collagenase-1 is required for keratinocyte migration on a type I collagen matrix. J Cell Biol, 1997. 137(6): p. 1445-57.

127. Zvieriev, V., J.C. Wang, and M. Chevrette, Over-expression of CD9 does not affect in vivo tumorigenic or metastatic properties of human prostate cancer cells. Biochem Biophys Res Commun, 2005. 337(2): p. 498-504.

128. Zhu, X., et al., Matrix metalloproteinase-9 silencing by RNA interference promotes the adhesive-invasive switch in HT1080 human fibrosarcoma cells. Clin Lab, 2012. 58(3-4): p. 313-22.

129. Jee, B.K., et al., KAI1/CD82 suppresses tumor invasion by MMP9 inactivation via TIMP1 up-regulation in the H1299 human lung carcinoma cell line. Biochem Biophys Res Commun, 2006. 342(2): p. 655-61. 
130. Okada, Y., et al., Matrix metalloproteinase 9 (92-kDa gelatinase/type IV collagenase) from HT 1080 human fibrosarcoma cells. Purification and activation of the precursor and enzymic properties. J Biol Chem, 1992. 267(30): p. 21712-9.

131. Leco, K.J., et al., Murine tissue inhibitor of metalloproteinases-4 (Timp-4): cDNA isolation and expression in adult mouse tissues. FEBS Lett, 1997. 401(2-3): p. 213-7.

132. Greene, J., et al., Molecular cloning and characterization of human tissue inhibitor of metalloproteinase 4. J Biol Chem, 1996. 271(48): p. 30375-80.

133. Cheng, J.C., et al., Radiation-enhanced hepatocellular carcinoma cell invasion with MMP-9 expression through PI3K/Akt/NF-kappaB signal transduction pathway. Oncogene, 2006. 25(53): p. 7009-18.

134. Cho, S.J., et al., Akt- and MAPK-mediated activation and secretion of MMP-9 into stroma in breast cancer cells upon heregulin treatment. Mol Med Rep, 2008. 1(1): p. 83-8.

135. Barfod, C., et al., Laser-Doppler measurements of concentration and velocity of moving blood cells in rat cerebral circulation. Acta Physiol Scand, 1997. 160(2): p. 123-32.

136. Zhu, X., et al., TGF-betal-induced PI3K/Akt/NF-kappaB/MMP9 signalling pathway is activated in Philadelphia chromosome-positive chronic myeloid leukaemia hemangioblasts. J Biochem, 2011. 149(4): p. 405-14.

137. Duxbury, M.S. and E.E. Whang, RRM2 induces NF-kappaB-dependent MMP-9 activation and enhances cellular invasiveness. Biochem Biophys Res Commun, 2007. 354(1): p. 190-6.

138. Simon, C., et al., The p38 SAPK pathway regulates the expression of the MMP-9 collagenase via AP-1-dependent promoter activation. Exp Cell Res, 2001. 271(2): p. 344-55.

139. Troussard, A.A., et al., The integrin linked kinase (ILK) induces an invasive phenotype via AP-1 transcription factor-dependent upregulation of matrix metalloproteinase 9 (MMP-9). Oncogene, 2000. 19(48): p. 5444-52.

140. Thant, A.A., et al., Fibronectin activates matrix metalloproteinase-9 secretion via the MEK1-MAPK and the PI3K-Akt pathways in ovarian cancer cells. Clin Exp Metastasis, 2000. 18(5): p. 423-8.

141. Cheng, C.Y., et al., PI3-K/Akt/JNK/NF-kappaB is essential for MMP-9 expression and outgrowth in human limbal epithelial cells on intact amniotic membrane. Stem Cell Res, 2012. 9(1): p. 9-23. 
142. Kotha, J., et al., Tetraspanin CD9 regulates beta 1 integrin activation and enhances cell motility to fibronectin via a PI-3 kinase-dependent pathway. Exp Cell Res, 2008. 314(8): p. 1811-22.

143. Kotha, J., et al., Functional relevance of tetraspanin CD9 in vascular smooth muscle cell injury phenotypes: a novel target for the prevention of neointimal hyperplasia. Atherosclerosis, 2009. 203(2): p. 377-86.

144. Lee, C.W., et al., TNF-alpha induces MMP-9 expression via activation of Src/EGFR, PDGFR/PI3K/Akt cascade and promotion of NF-kappaB/p300 binding in human tracheal smooth muscle cells. Am J Physiol Lung Cell Mol Physiol, 2007. 292(3): p. L799-812.

145. Zuo, J.H., et al., Activation of EGFR promotes squamous carcinoma SCC10A cell migration and invasion via inducing EMT-like phenotype change and MMP-9mediated degradation of E-cadherin. J Cell Biochem, 2011. 112(9): p. 2508-17.

146. Kohmo, S., et al., Cell surface tetraspanin CD9 mediates chemoresistance in small cell lung cancer. Cancer Res, 2010. 70(20): p. 8025-35.

147. Nakamoto, T., et al., A novel therapeutic strategy with anti-CD9 antibody in gastric cancers. J Gastroenterol, 2009. 44(9): p. 889-96.

148. Krishnamoorthy, M., et al., Heparin binding epidermal growth factor-like growth factor and PD169316 prevent apoptosis in mouse embryonic stem cells. J Biochem, 2009. 145(2): p. 177-84.

149. Moro, L., et al., Integrins induce activation of EGF receptor: role in MAP kinase induction and adhesion-dependent cell survival. EMBO J, 1998. 17(22): p. 662232 .

150. Kuwada, S.K. and X. Li, Integrin alpha5/betal mediates fibronectin-dependent epithelial cell proliferation through epidermal growth factor receptor activation. Mol Biol Cell, 2000. 11(7): p. 2485-96.

151. Moro, L., et al., Integrin-induced epidermal growth factor (EGF) receptor activation requires $c$-Src and p130Cas and leads to phosphorylation of specific EGF receptor tyrosines. J Biol Chem, 2002. 277(11): p. 9405-14.

152. Hutcheson, I.R., et al., Oestrogen receptor-mediated modulation of the EGFR/MAPK pathway in tamoxifen-resistant MCF-7 cells. Breast Cancer Res Treat, 2003. 81(1): p. 81-93.

153. Liu, Z.M. and H.S. Huang, As2O3-induced c-Src/EGFR/ERK signaling is via Sp1 binding sites to stimulate 21 WAF1/CIP1 expression in human epidermoid carcinoma A431 cells. Cell Signal, 2006. 18(2): p. 244-55. 
154. Genersch, E., et al., Sustained ERK phosphorylation is necessary but not sufficient for MMP-9 regulation in endothelial cells: involvement of Ras-dependent and independent pathways. J Cell Sci, 2000. 113 Pt 23: p. 4319-30.

155. Park, M.J., et al., Protein kinase C-alpha activation by phorbol ester induces secretion of gelatinase B/MMP-9 through ERK 1/2 pathway in capillary endothelial cells. Int J Oncol, 2003. 22(1): p. 137-43.

156. Chen, Y.J., et al., Osteopontin increases migration and MMP-9 up-regulation via alphavbeta3 integrin, FAK, ERK, and NF-kappaB-dependent pathway in human chondrosarcoma cells. J Cell Physiol, 2009. 221(1): p. 98-108.

157. Sil, H., T. Sen, and A. Chatterjee, Fibronectin-integrin (alpha5beta1) modulates migration and invasion of murine melanoma cell line B16F10 by involving MMP9. Oncol Res, 2011. 19(7): p. 335-48.

158. Owens, G.K., M.S. Kumar, and B.R. Wamhoff, Molecular regulation of vascular smooth muscle cell differentiation in development and disease. Physiol Rev, 2004. 84(3): p. 767-801.

159. Moiseeva, E.P., Adhesion receptors of vascular smooth muscle cells and their functions. Cardiovasc Res, 2001. 52(3): p. 372-86.

160. Zhang, F., et al., Tetraspanins and vascular functions. Cardiovasc Res, 2009. 83(1): p. 7-15.

161. Zhang, X.A., A.L. Bontrager, and M.E. Hemler, Transmembrane-4 superfamily proteins associate with activated protein kinase C (PKC) and link PKC to specific beta(1) integrins. J Biol Chem, 2001. 276(27): p. 25005-13.

162. Powner, D., et al., Tetraspanin CD9 in cell migration. Biochem Soc Trans, 2011. 39(2): p. 563-7.

163. Scherberich, A., et al., Tetraspanin CD9 is associated with very late-acting integrins in human vascular smooth muscle cells and modulates collagen matrix reorganization. Arterioscler Thromb Vasc Biol, 1998. 18(11): p. 1691-7.

164. Scherberich, A., et al., FAK-mediated inhibition of vascular smooth muscle cell migration by the tetraspanin CD9. Thromb Haemost, 2002. 87(6): p. 1043-50.

165. Rensen, S.S., P.A. Doevendans, and G.J. van Eys, Regulation and characteristics of vascular smooth muscle cell phenotypic diversity. Neth Heart J, 2007. 15(3): p. $100-8$.

166. Bishop, A.L. and A. Hall, Rho GTPases and their effector proteins. Biochem J, 2000. 348 Pt 2: p. 241-55. 
167. Zhang, W., Y. Huang, and S.J. Gunst, The small GTPase RhoA regulates the contraction of smooth muscle tissues by catalyzing the assembly of cytoskeletal signaling complexes at membrane adhesion sites. J Biol Chem, 2012. 287(41): p. 33996-4008.

168. Flatau, G., et al., Toxin-induced activation of the $G$ protein $p 21$ Rho by deamidation of glutamine. Nature, 1997. 387(6634): p. 729-33.

169. Benink, H.A. and W.M. Bement, Concentric zones of active RhoA and Cdc42 around single cell wounds. J Cell Biol, 2005. 168(3): p. 429-39.

170. Seasholtz, T.M., et al., Rho and Rho kinase mediate thrombin-stimulated vascular smooth muscle cell DNA synthesis and migration. Circ Res, 1999. 84(10): p. $1186-93$.

171. Pille, J.Y., et al., Anti-RhoA and anti-RhoC siRNAs inhibit the proliferation and invasiveness of MDA-MB-231 breast cancer cells in vitro and in vivo. Mol Ther, 2005. 11(2): p. 267-74.

172. Chen, C.N., et al., Synergistic roles of platelet-derived growth factor-BB and interleukin-1beta in phenotypic modulation of human aortic smooth muscle cells. Proc Natl Acad Sci U S A, 2006. 103(8): p. 2665-70.

173. Orr, A.W., et al., Molecular mechanisms of collagen isotype-specific modulation of smooth muscle cell phenotype. Arterioscler Thromb Vasc Biol, 2009. 29(2): p. $225-31$.

174. Tang, Y., et al., Notch and transforming growth factor-beta (TGFbeta) signaling pathways cooperatively regulate vascular smooth muscle cell differentiation. $\mathrm{J}$ Biol Chem, 2010. 285(23): p. 17556-63.

175. Bi, D., et al., Contractile properties of the cultured vascular smooth muscle cells: the crucial role played by RhoA in the regulation of contractility. Circ Res, 2005. 96(8): p. 890-7.

176. Shields, M.A., et al., Interplay between betal-integrin and Rho signaling regulates differential scattering and motility of pancreatic cancer cells by snail and Slug proteins. J Biol Chem, 2012. 287(9): p. 6218-29.

177. Costa, P., et al., Integrin-Specific Control of Focal Adhesion Kinase and RhoA Regulates Membrane Protrusion and Invasion. PLoS One, 2013. 8(9): p. e74659.

178. Delaguillaumie, A., et al., Rho GTPases link cytoskeletal rearrangements and activation processes induced via the tetraspanin CD82 in T lymphocytes. J Cell Sci, 2002. 115(Pt 2): p. 433-43. 
179. Johnson, J.L., et al., Tetraspanin CD151 regulates RhoA activation and the dynamic stability of carcinoma cell-cell contacts. J Cell Sci, 2009. 122(Pt 13): p. 2263-73.

180. Novitskaya, V., et al., Integrin alpha3beta1-CD151 complex regulates dimerization of ErbB2 via RhoA. Oncogene, 2013.

181. Hong, I.K., et al., Tetraspanin CD151 stimulates adhesion-dependent activation of Ras, Rac, and Cdc42 by facilitating molecular association between betal integrins and small GTPases. J Biol Chem, 2012. 287(38): p. 32027-39.

182. Gu, J., et al., Laminin-10/11 and fibronectin differentially regulate integrindependent Rho and Rac activation via p130(Cas)-CrkII-DOCK180 pathway. J Biol Chem, 2001. 276(29): p. 27090-7.

183. Ren, X.D., W.B. Kiosses, and M.A. Schwartz, Regulation of the small GTPbinding protein Rho by cell adhesion and the cytoskeleton. EMBO J, 1999. 18(3): p. 578-85.

184. Pickering, J.G., et al., alpha5betal integrin expression and luminal edge fibronectin matrix assembly by smooth muscle cells after arterial injury. Am J Pathol, 2000. 156(2): p. 453-65.

185. Sawada, N., et al., Inhibition of rho-associated kinase results in suppression of neointimal formation of balloon-injured arteries. Circulation, 2000. 101(17): p. 2030-3.

186. Eto, Y., et al., Gene transfer of dominant negative Rho kinase suppresses neointimal formation after balloon injury in pigs. Am J Physiol Heart Circ Physiol, 2000. 278(6): p. H1744-50.

187. Uehata, M., et al., Calcium sensitization of smooth muscle mediated by a Rhoassociated protein kinase in hypertension. Nature, 1997. 389(6654): p. 990-4.

188. Huang, C.L., et al., MRP-1/CD9 gene transduction regulates the actin cytoskeleton through the downregulation of WAVE2. Oncogene, 2006. 25(49): p. 6480-8.

189. Davis, B.N., et al., Induction of microRNA-221 by platelet-derived growth factor signaling is critical for modulation of vascular smooth muscle phenotype. J Biol Chem, 2009. 284(6): p. 3728-38.

190. Liu, X., et al., A necessary role of miR-221 and miR-222 in vascular smooth muscle cell proliferation and neointimal hyperplasia. Circ Res, 2009. 104(4): p. 476-87. 
191. Jiang, Y., H. Yin, and X.L. Zheng, MicroRNA-1 inhibits myocardin-induced contractility of human vascular smooth muscle cells. J Cell Physiol, 2010. 225(2): p. 506-11.

192. Long, X., et al., Smooth muscle calponin: an unconventional CArG-dependent gene that antagonizes neointimal formation. Arterioscler Thromb Vasc Biol, 2011. 31(10): p. 2172-80.

193. Hedin, U., et al., Diverse effects of fibronectin and laminin on phenotypic properties of cultured arterial smooth muscle cells. J Cell Biol, 1988. 107(1): p. 307-19.

194. Hedin, U., et al., Role of tyrosine kinases in extracellular matrix-mediated modulation of arterial smooth muscle cell phenotype. Arterioscler Thromb Vasc Biol, 1997. 17(10): p. 1977-84.

195. Hedin, U., et al., A substrate of the cell-attachment sequence of fibronectin (ArgGly-Asp-Ser) is sufficient to promote transition of arterial smooth muscle cells from a contractile to a synthetic phenotype. Dev Biol, 1989. 133(2): p. 489-501.

196. Palmer, T.D., et al., Integrin-free tetraspanin CD151 can inhibit tumor cell motility upon clustering and is a clinical indicator of prostate cancer progression. Cancer Res, 2013.

197. Ahsan, A., et al., Role of cell cycle in epidermal growth factor receptor inhibitormediated radiosensitization. Cancer Res, 2009. 69(12): p. 5108-14.

198. Haglund, K., et al., Multiple monoubiquitination of RTKs is sufficient for their endocytosis and degradation. Nat Cell Biol, 2003. 5(5): p. 461-6.

199. Hirakawa, M., et al., Sequential activation of RhoA and FAK/paxillin leads to ATP release and actin reorganization in human endothelium. J Physiol, 2004. 558(Pt 2): p. 479-88.

200. Pirone, D.M., et al., An inhibitory role for FAK in regulating proliferation: a link between limited adhesion and RhoA-ROCK signaling. J Cell Biol, 2006. 174(2): p. 277-88.

201. Li, H., et al., Simulation of crosstalk between small GTPase RhoA and EGFRERK signaling pathway via MEKK1. Bioinformatics, 2009. 25(3): p. 358-64.

202. Mateus, A.R., et al., EGFR regulates RhoA-GTP dependent cell motility in Ecadherin mutant cells. Hum Mol Genet, 2007. 16(13): p. 1639-47.

203. Turner, N.A., et al., Simvastatin inhibits MMP-9 secretion from human saphenous vein smooth muscle cells by inhibiting the RhoA/ROCK pathway and reducing MMP-9 mRNA levels. FASEB J, 2005. 19(7): p. 804-6. 
204. Abecassis, I., et al., RhoA induces MMP-9 expression at CD44 lamellipodial focal complexes and promotes HMEC-1 cell invasion. Exp Cell Res, 2003. 291(2): p. 363-76.

205. Danen, E.H., et al., The fibronectin-binding integrins alpha5betal and alphavbeta3 differentially modulate RhoA-GTP loading, organization of cell matrix adhesions, and fibronectin fibrillogenesis. J Cell Biol, 2002. 159(6): p. 1071-86.

206. Yu, Y.M. and H.C. Lin, Curcumin prevents human aortic smooth muscle cells migration by inhibiting of MMP-9 expression. Nutr Metab Cardiovasc Dis, 2010. 20(2): p. 125-32.

207. Knipp, B.S., et al., Increased MMP-9 expression and activity by aortic smooth muscle cells after nitric oxide synthase inhibition is associated with increased nuclear factor-kappaB and activator protein-1 activity. J Surg Res, 2004. 116(1): p. $70-80$.

208. Cho, A., J. Graves, and M.A. Reidy, Mitogen-activated protein kinases mediate matrix metalloproteinase-9 expression in vascular smooth muscle cells. Arterioscler Thromb Vasc Biol, 2000. 20(12): p. 2527-32.

209. Bill, H.M., et al., Epidermal growth factor receptor-dependent regulation of integrin-mediated signaling and cell cycle entry in epithelial cells. Mol Cell Biol, 2004. 24(19): p. 8586-99.

210. Morodomi, T., et al., Purification and characterization of matrix metalloproteinase 9 from U937 monocytic leukaemia and HT1080 fibrosarcoma cells. Biochem J, 1992. 285 ( Pt 2): p. 603-11.

211. Ettinger, S.J. and E.C. Feldman, Textbook of veterinary internal medicine: diseases of the dog and cat. 4th ed. 1995, Philadelphia: W.B. Saunders.

212. Higashiyama, M., et al., Reduced motility related protein-1 (MRP-1/CD9) gene expression as a factor of poor prognosis in non-small cell lung cancer. Cancer Res, 1995. 55(24): p. 6040-4.

213. Adachi, M., et al., Novel staging protocol for non-small-cell lung cancers according to MRP-1/CD9 and KAII/CD82 gene expression. J Clin Oncol, 1998. 16(4): p. 1397-406. 
APPENDIX A. QRT-PCR PRIMERS

Table A-1. List of primers and probes used for tetraspanin and integrin qRTPCR analysis.

\begin{tabular}{|c|c|c|c|}
\hline Gene & Direction & Primers & $\begin{array}{c}\text { Taqman } \\
\text { probe }\end{array}$ \\
\hline CD9 EC1 & $\begin{array}{l}\text { Forward } \\
\text { Reverse }\end{array}$ & $\begin{array}{l}\text { GAGGCACCAAGTGCATCAA } \\
\text { AGCCATAGTCCAATGGCAAG }\end{array}$ & 56 \\
\hline CD9 EC2 & $\begin{array}{l}\text { Forward } \\
\text { Reverse }\end{array}$ & $\begin{array}{l}\text { GGCGTGGAACAGTTTATCTCA } \\
\text { GATGGCATCAGGACAGGACT }\end{array}$ & 43 \\
\hline CD63 & $\begin{array}{l}\text { Forward } \\
\text { Reverse }\end{array}$ & $\begin{array}{l}\text { TGAAATGTGTGAAGTTCTTGCTC } \\
\text { CAATCAGTCCCACTGCACA }\end{array}$ & 18 \\
\hline CD81 & $\begin{array}{l}\text { Forward } \\
\text { Reverse }\end{array}$ & $\begin{array}{l}\text { TCGTCTTCAATTTCGTCTTCTG } \\
\text { CTCCCAGCTCCAGATACAGG }\end{array}$ & 19 \\
\hline CD151 & $\begin{array}{l}\text { Forward } \\
\text { Reverse }\end{array}$ & $\begin{array}{l}\text { GGAGCTTCTGTCCACCTGTC } \\
\text { TCGTTGAACTCACCCATCCT }\end{array}$ & 82 \\
\hline$\alpha 2$ & $\begin{array}{l}\text { Forward } \\
\text { Reverse }\end{array}$ & $\begin{array}{l}\text { TCGTGCACAGTTTTGAAGATG } \\
\text { TGGAACACTTCCTGTTGTTACC }\end{array}$ & 7 \\
\hline$\alpha 4$ & $\begin{array}{l}\text { Forward } \\
\text { Reverse }\end{array}$ & $\begin{array}{l}\text { GATGAAAATGAGCCTGAAACG } \\
\text { GCCATACTATTGCCAGTGTTGA }\end{array}$ & 22 \\
\hline$\alpha 5$ & $\begin{array}{l}\text { Forward } \\
\text { Reverse }\end{array}$ & $\begin{array}{l}\text { ACCCTGCCGCTCAGATTT } \\
\text { AAAACCACACGGCCAGTC }\end{array}$ & 18 \\
\hline$\alpha 6$ & $\begin{array}{l}\text { Forward } \\
\text { Reverse }\end{array}$ & $\begin{array}{l}\text { TGGCCTCTTCATTTGGCTAT } \\
\text { AAAATACTGTGGGGCTCCAAT }\end{array}$ & 77 \\
\hline$\beta 1$ & $\begin{array}{l}\text { Forward } \\
\text { Reverse }\end{array}$ & $\begin{array}{l}\text { TTCGATGCCATCATGCAA } \\
\text { ACACCAGCAGCCGTGTAAC }\end{array}$ & 19 \\
\hline
\end{tabular}


Table A-2. List of primers and probes used for MMP and TIMP qRT-PCR analysis.

\begin{tabular}{|c|c|c|c|}
\hline Gene & Direction & Primers & $\begin{array}{c}\text { Taqman } \\
\text { Probe }\end{array}$ \\
\hline MMP-1 & $\begin{array}{l}\text { Forward } \\
\text { Reverse }\end{array}$ & $\begin{array}{l}\text { GCTAACCTTTGATGCTATAACTACGA } \\
\text { TTTGTGCGCATGTAGAATCTG }\end{array}$ & 7 \\
\hline MMP-2 & $\begin{array}{l}\text { Forward } \\
\text { Reverse }\end{array}$ & $\begin{array}{l}\text { ATAACCTGGATGCCGTCGT } \\
\text { AGGCACCCTTGAAGAAGTAGC }\end{array}$ & 70 \\
\hline MMP-3 & $\begin{array}{l}\text { Forward } \\
\text { Reverse }\end{array}$ & $\begin{array}{l}\text { GCAAGGACCTCGTTTTCATT } \\
\text { CTCTTGGGTATCCAGCTCGT }\end{array}$ & 6 \\
\hline MMP-7 & $\begin{array}{l}\text { Forward } \\
\text { Reverse }\end{array}$ & $\begin{array}{l}\text { TGGACGGATGGTAGCAGTCT } \\
\text { TCTCCATTTCCATAGGTTGGAT }\end{array}$ & 6 \\
\hline MMP-8 & $\begin{array}{l}\text { Forward } \\
\text { Reverse }\end{array}$ & $\begin{array}{l}\text { GGGAACGCACTAACTTGACC } \\
\text { TTCAAAGGCATCCTTGATAGC }\end{array}$ & 30 \\
\hline MMP-9 & $\begin{array}{l}\text { Forward } \\
\text { Reverse }\end{array}$ & $\begin{array}{l}\text { GAACCAATCTCACCGACAGG } \\
\text { GCCACCCGAGTGTAACCATA }\end{array}$ & 6 \\
\hline MMP-14 & $\begin{array}{l}\text { Forward } \\
\text { Reverse }\end{array}$ & $\begin{array}{l}\text { CTGTCAGGAATGAGGATCTGAA } \\
\text { AGGGGTCACTGGAATGCTC }\end{array}$ & 37 \\
\hline MMP-16 & $\begin{array}{l}\text { Forward } \\
\text { Reverse }\end{array}$ & $\begin{array}{l}\text { AGGGCATCCAGAAGATATATGG } \\
\text { GGCACTGTCGGTAGAGGTCTT }\end{array}$ & 39 \\
\hline TIMP1 & $\begin{array}{l}\text { Forward } \\
\text { Reverse }\end{array}$ & $\begin{array}{l}\text { GGGCTTCACCAAGACCTACA } \\
\text { TGCAGGGGATGGATAAACAG }\end{array}$ & 76 \\
\hline TIMP2 & $\begin{array}{l}\text { Forward } \\
\text { Reverse }\end{array}$ & $\begin{array}{l}\text { GAAGAGCTTGAACCAACAGGT } \\
\text { CGGGGAGGAGATGTAGCAC }\end{array}$ & 43 \\
\hline TIMP3 & $\begin{array}{l}\text { Forward } \\
\text { Reverse }\end{array}$ & $\begin{array}{l}\text { TGCAACTCCGACATCGTG } \\
\text { AAGGGCCCCTCCTTTACC }\end{array}$ & 60 \\
\hline
\end{tabular}


Table A-3. List of primers and probes used for EGFR and HAOSMC qRT-PCR analysis.

\begin{tabular}{|c|c|c|c|}
\hline Gene & Direction & Primers & $\begin{array}{c}\text { Taqman } \\
\text { Probe }\end{array}$ \\
\hline EGFR & $\begin{array}{l}\text { Forward } \\
\text { Reverse }\end{array}$ & $\begin{array}{l}\text { CATGTCGATGGACTTCCAGA } \\
\text { GGGACAGCTTGGATCACACT }\end{array}$ & 44 \\
\hline $\begin{array}{l}\mathrm{SM} \alpha- \\
\text { actin }\end{array}$ & $\begin{array}{l}\text { Forward } \\
\text { Reverse }\end{array}$ & $\begin{array}{l}\text { CTGTTCCAGCCATCCTTCAT } \\
\text { TCATGATGCTGTTGTAGGTGGT }\end{array}$ & 58 \\
\hline SM22 $\alpha$ & $\begin{array}{l}\text { Forward } \\
\text { Reverse }\end{array}$ & $\begin{array}{l}\text { CAGTGTGGCCCTGATGTG } \\
\text { CACCAGCTTGCTCAGAATCA }\end{array}$ & 41 \\
\hline Calponin & $\begin{array}{l}\text { Forward } \\
\text { Reverse }\end{array}$ & $\begin{array}{l}\text { CCAACCATACACAGGTGCAG } \\
\text { TCACCTTGTTTCCTTTCGTCTT }\end{array}$ & 79 \\
\hline RhoA & $\begin{array}{l}\text { Forward } \\
\text { Reverse }\end{array}$ & $\begin{array}{l}\text { GGGAGCTAGCCAAGATGAAG } \\
\text { GTACCCAAAAGCGCCAATC }\end{array}$ & 13 \\
\hline
\end{tabular}




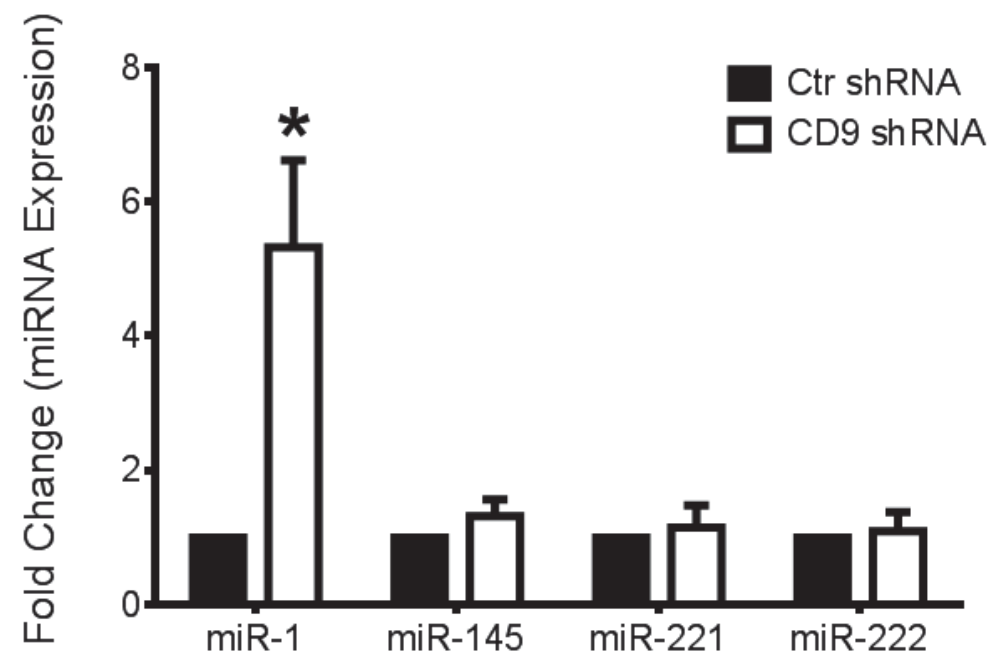

Figure B-1. Expression of microRNAs between Ctr and CD9 shRNA HAOSMC. MicroRNA (miRNA) was harvested from Ctr and CD9 shRNA HAOSMC and screened for four miRNAs of interest.
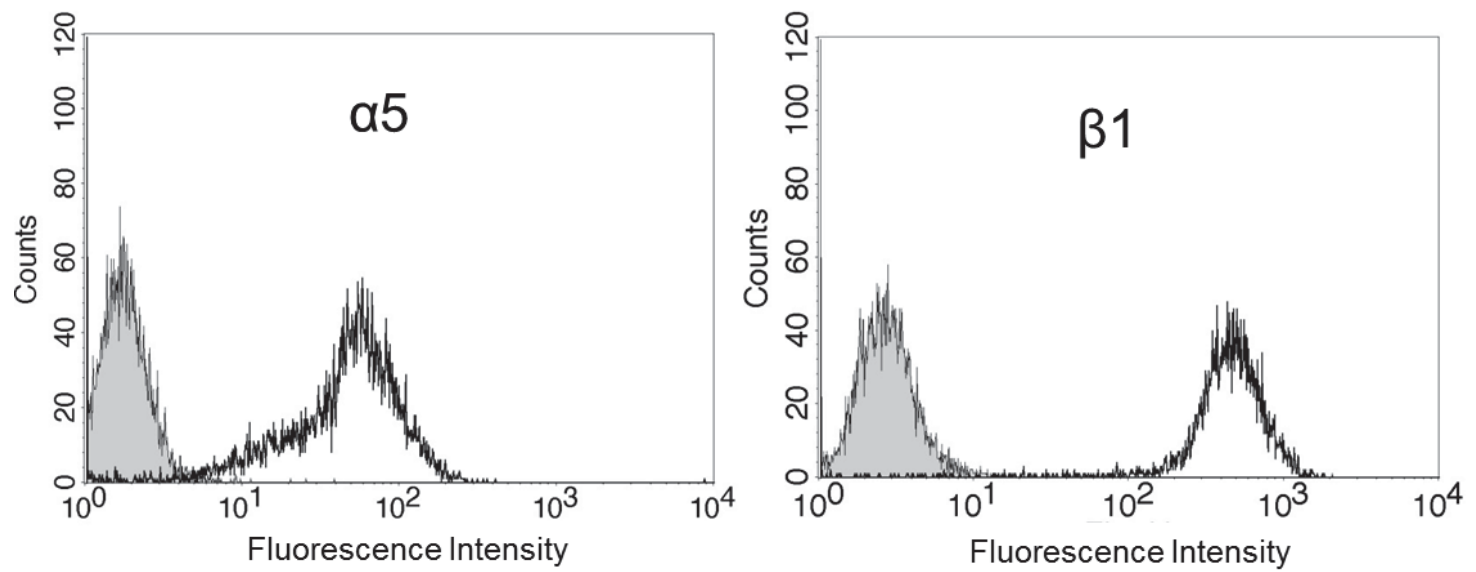

Figure B-2. The expression of integrin $\alpha 5$ and $\beta 1$ subunits on the cell surface of naïve HAOSMC.

The cell surface expression of $\alpha 5$ and $\beta 1$ integrin subunits was measured on nonpermeabilized, naïve HAOSMC. The shaded histograms in each panel represent nonspecific IgG antibody binding. The unshaded histograms indicate the integrin labeled in each panel. 


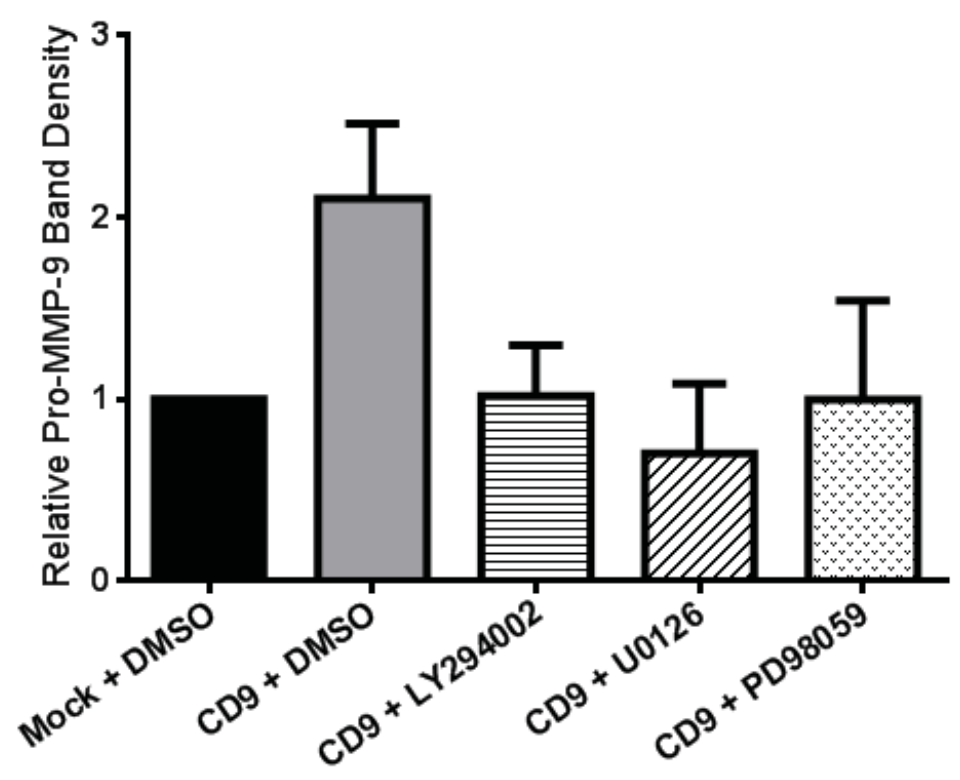

Figure B-3. Inhibition of pro-MMP-9 gelatinolytic activity by LY294002, U0126, and PD98059.

Mock and CD9 HT1080 cells were plated on fibronectin in the presence of equal volumes of DMSO or the above inhibitors at a final concentration of $5 \mu \mathrm{M}$. After 24 hours, the media was harvested, cleared, and subjected to gelatin zymographic analysis.

Densitiometry was performed using ImageJ software and band density values were normalized to Mock+DMSO $(n=3)$. 


\section{VITA}

Michael James Herr, II was born in Memphis, TN in 1986 exactly when tetraspanins were beginning to be discovered. He lived in Memphis, TN his entire life, but loved to travel all over the nation particularly to large metropolitan cities.

Immediately after graduating from Christian Brothers University in 2008 he began his journey in the College of Graduate Health Sciences at the University of Tennessee Health Science Center. This venture originated as a sluggish ascent through a more comprehensive repeat of his Biology major and a baptism by fire approach to basic science techniques. After joining Dr. Lisa Jennings' laboratory and being directed by Dr. Jayaprakash Kotha on how to pour the perfect polyacrylamide gels he began his dissertation study. Wading through the confusing field of tetraspanins was the most challenging and prosperous learning experience of his academic career. This experience culminated in the composition of this dissertation and his marriage to the woman who got him through it all, Ashley Renee Elliott, in November, 2013. 